


\section{EXPERIENCIAS DE INNOVACIÓN EDUCATIVA}

- TOMO 1 -

GRANCOLOMBIANO

INSTITUCIÓN UNIVERSITARIA 


\title{
EXPERIENCIAS DE INNOVACIÓN EDUCATIVA
}

\author{
Autores \\ Luis Martín Trujillo Flórez \\ Ronald Mauricio Martínez Contreras \\ Hernando Espitia López \\ Juan Carlos Rojas Paredes \\ Yolanda Rocío Vargas Leguizamón \\ Germán Andrés Castro Cabal
}

Laboratorio de Innovación Pedagógica de Educación Virtual - LIPEV.

Dirección Académica de Educación Virtual

Vicerrectoría Académica.

Institución Universitaria Politécnico Grancolombiano

2017 


\section{POLI \\ POLITÉCNICO \\ GRANCOLOMBIANO \\ INSTITUCIÓN UNIVERSITARIA}

(c) Politécnico Grancolombiano

Experiencias de Innovación educativa

Primera Edición: Abril de 2018

ISBN: 978-958-8721-77-4

E-ISBN: 978-958-8721-79-8

Ebook: 978-958-8721-78-1

\section{Publicaciones Politécnico Grancolombiano}

Calle 57 \# 3-00 Este

Tel: 7455555, ext. 1171

E-mail: editorial@poligran.edu.co Bogotá, Colombia.

\section{Autores}

Luis Martín Trujillo Flórez

Ronald Mauricio Martínez Contreras

Hernando Espitia López

Juan Carlos Rojas Paredes

Yolanda Rocío Vargas Leguizamón

Germán Andrés Castro Cabal

\section{Lider de Publicaciones}

Eduardo Norman Acevedo

\section{Analista de Producción Editorial}

Paulo Mora Noguera

Ilustraciones

Mónica Nayibet Carrero Becerra

Diseño y Diagramación

Mónica Nayibet Carrero Becerra

Leonardo Stiglich Campos

\section{Corrección de Estilo}

Ana Ximena Oliveros

\section{Impresión}

Xpress Estudio Gráfico y Digital S.A.

\section{Impreso en Colombia}

Printed in Colombia
Trujillo Flórez, Luis Martín

Experiencias de innovación educativa / Luis Martín Trujillo Flórez; Ronald Mauricio Martínez Contreras; Hernando Espitia López; Juan Carlos Rojas Paredes; Yolanda Rocío Vargas Leguizamón; Germán Andrés Castro Cabal; Laboratorio de innovación educativa de educación virtual ; líder de publicaciones, Eduardo Norman Acevedo; analista de producción editorial, Paulo Mora Noguera; - Bogotá D.C.: Publicaciones Politécnico Grancolombiano., 2018.

170 p. : il.; $17 \times 24 \mathrm{~cm}$.

Incluye referencias bibliográficas.

ISBN: 978-958-8721-77-4

E-ISBN: 978-958-8721-79-8

Ebook: 978-958-8721-78-1

1. Innovación educativa 2. Software educativo 3. Simuladores 4. Modelos de simulación 5. Métodos de aprendizaje I. Norman Acevedo, Eduardo II. Mora Noguera, Paulo III. Laboratorio de innovación educativa de educación virtual IV. Institución Universitaria Politécnico Grancolombiano V. Tít.

SCDD 378.17 T866 Vo.1

Co-BolUP

Sistema Nacional de Bibliotecas - SISNAB Institución Universitaria Politécnico Grancolombiano

La Editorial Politécnico Grancolombiano pertenece a la Asociación de Editoriales Universitarias de Colombia ASEUC.

El contenido de esta publicación se puede citar o reproducir con propósitos académicos siempre y cuando se de la fuente o procedencia. Las opiniones expresadas son responsabilidad exclusiva de los autores.

\section{¿Cómo citar este libro?}

Trujillo et al. (2018), Experiencias de Innovación educativa, Bogotá: Editorial Politécnico Grancolombiano. 


\section{TABLA DE CONTENIDO}

\section{- Presentación de los autores}

- Introducción: La importancia de un Laboratorio de Innovación Pedagógica en Educación Virtual para la Institución Universitaria Politécnico Grancolombiano. Luis Martin Trujillo Flórez.

- Capítulo 1: Simulador de Diagnostico Empresarial. Ronald Mauricio Martínez Contreras y Luis Martín Trujillo Flórez.

- Capítulo 2: Simulador de análisis prospectivo. Ronald Mauricio Martínez Contreras y Luis Martín Trujillo Flórez.

- Capítulo 3: Simulador de gestión financiera para Administración Financiera. Hernando Espitia López y Luis Martín Trujillo Flórez.

- Capítulo 4: Simulador de inversión en Renta Variable para el Mercado de Capitales. Juan Carlos Rojas Paredes y Luis Martín Trujillo Flórez.

- Capítulo 5: Simulador de evaluación financiera de proyectos. Yolanda Rocío Vargas Leguizamón y Luis Martín Trujillo Flórez.

- Capítulo 6: Juego Gerencial basado en Balanced Scorecard. Germán Andrés Castro Cabal y Luis Martín Trujillo Flórez. 


\section{PRESENTACIÓN}

La Institución Universitaria Politécnico Grancolombiano pendiente de los múltiples cambios que está viviendo la educación y de los avances vertiginosos que tienen los ambientes virtuales ha decidido implementar un Laboratorio de innovación pedagógica e Investigación de Educación Virtual, el cual tiene como propósito gestionar con los docentes de la institución el desarrollo de proyectos de innovación centrada en estrategias de aprendizaje tales como: simuladores, juegos educativos o juegos serios, aplicaciones, realidad aumentada, realidad virtual, entre otros. El Laboratorio apoya todas aquellas iniciativas que conduzcan a la construcción de diversos ambientes educativos mediados por tecnología que les permitan a los estudiantes fortalecer la adquisición de competencias en los diferentes programas académicos.

Este proyecto se inicia en el 2017, es transversal a todas las facultades del Politécnico Grancolombiano y tiene como misión crear, gestionar, orientar, acompañar y diseñar con las entidades académicas cada uno de los proyectos considerados como innovadores, para ello las Facultades a través de los Departamentos Académicos proponen los diferentes proyectos a implementar, se hace la selección de estos y el Laboratorio orienta la planeación y construcción de cada uno de ellos.

Un área de innovación educativa debe tener un fuerte componente de investigación, por eso, además de implementar cada uno de los proyectos, estos se acompañan de un desarrollo investigativo que se trabaja en dos partes. La primera parte está compuesta por las memorias de las experiencias académicas que nos cuentan qué se hizo y cómo fue todo el proceso de construcción de cada proyecto de innovación. Este es el documento que usted lee en este momento y que nosotros presentamos con todo el cariño y esfuerzo con que realizamos nuestros proyectos. Aquí resumimos el arduo trabajo que se realizó durante todo el año que abarca desde la planeación, diseño, diagramación, redacción de guiones, diseño gráfico, animación, programación, y que continúa con las pruebas pilotos e implementación en las aulas con los estudiantes. 
El segundo componente investigativo consta de un artículo de investigación con la coautoría y direccionamiento del Observatorio de Educación Virtual del Politécnico Grancolombiano que junto con el Laboratorio de innovación pedagógica y los autores de manera conjunta redactan los documentos para publicar en revistas de investigación de vanguardia mundial. El Observatorio acompaña a los autores en proyectos posteriores de investigación asociados al proyecto que se construyó en el Laboratorio. Probablemente algunos proyectos por su potencial o porque son muy amplios requieren de una segunda fase en su desarrollo, en tal caso el Laboratorio tiene como primicia que todo proyecto que se inicie debe finalizarse, así que posteriormente se hace la segunda fase, si se requiere, porque un principio fundamental de la innovación es que sea una realidad tangible.

Hoy en día el aprendizaje mediado con tecnología requiere de ambientes más inmersivos (alta interacción del usuario) que permitan evidenciar la adquisición de competencias por parte de los estudiantes. Por ello desde la década de los 80 's se empezó a hablar de simuladores (herramientas de software que emulan procesos reales) con los cuales los estudiantes se enfrentaran en ambientes simulados a situaciones de su quehacer profesional, esto le permite a un egresado prepararse mejor para el mundo laboral y ser capaz de dar respuesta a diversas situaciones.

Por otro lado, desde hace varias décadas en el mundo empresarial se está trabajando lo que se llamamos business games o juego de negocios, también en la parte comportamental se implementaron los serious games o juegos serios para emular ambientes cotidianos donde se quiere saber la respuesta del individuo. Estos juegos han sido trabajados en la educación durante mucho tiempo, sólo que ahora los podemos llevar con mayor facilidad a los ambientes digitales y ampliar su uso educativo.

Aquí se presentan seis experiencias iniciales que se desarrollaron durante el año 2017, cinco simuladores y un juego gerencial.

La primera de ellas es un software para el Diagnóstico empresarial que fortalece la calidad de los productos de consultoría entregados por los estudiantes de Administración de Empresas; a partir de la metodología de diagnóstico propuesta por Fred Davis se realiza un desarrollo de software que permite al estudiante aplicar el método a cualquier tipo de empresa.

El segundo proyecto es un Simulador de análisis prospectivo, para este diseño se hizo una revisión conceptual y metodológica del proceso de análisis 
prospectivo, al final se desarrolló una herramienta tecnológica que permite la identificación de escenarios futuros a partir del análisis de las tendencias clave de índole interno y externo que puedan afectar a una organización en un horizonte temporal de diez años.

\section{El tercer proyecto es un Simulador de gestión financiera para Administración}

Financiera centrado en el análisis de dicha área que conduzca a la acertada toma de decisiones. Es una herramienta pensada para los futuros financistas que se enfrentan a contextos reales. El objetivo es que los estudiantes puedan analizar diversas empresas del sector real, confrontando sus conocimientos con su entorno laboral.

El cuarto proyecto que se presenta es un Simulador de inversión en Renta Variable para el Mercado de Capitales. Aunque esta experiencia ya existe en el mercado, la innovación está en que la herramienta se adapta a las necesidades académicas y les permite a los estudiantes una experiencia de aprendizaje más estructurada que incluye competencias en la interpretación, diagnóstico y toma de decisiones de inversión en el mercado de renta variable.

La quinta experiencia de aprendizaje es el Simulador de evaluación financiera de proyectos, es el software que realiza la simulación de evaluación de un proyecto de inversión que le permite a los estudiantes construir un aprendizaje significativo al ser capaces de validar la viabilidad de un proyecto de inversión para una empresa.

El sexto y último proyecto es un Juego Gerencial que se enmarca en la categoría de juego serio. Consiste en un video juego interactivo que enfrenta al estudiante a decisiones gerenciales basándose en la metodología Balanced Scorecard. Según las decisiones que tome cada participante serán asignados puntajes acumulativos que afectan los indicadores de la compañía. Aquí el estudiante es un Chiefs Executive Officer (CEO) que se enfrenta a las decisiones gerenciales que marcan el futuro de la compañía.

En este libro encontrará todo el proceso, desde una perspectiva educativa, cómo se diseñó y estructuró la estrategia pedagógica para que desarrollara las diferentes competencias, y cómo combinó los saberes propios de cada uno de los módulos a los que se vincula. La mayoría de los proyectos son productos completamente nuevos en el ámbito educativo con las patentes para la Institución.

Es para los autores es un gusto presentar este documento de las experiencias pedagógicas que se están implementando actualmente en cada uno de los 
módulos o cursos virtuales a los que pertenecen, esperamos que sean un aporte significativo para nuestros estudiantes y en general para el ámbito académico.

\section{Atentamente,}

Los autores. 


\title{
La importancia de un Laboratorio de Innovación Pedagógica para la Institución Universitaria Politécnico Grancolombiano
}

\begin{abstract}
Autor
Luis Martín Trujillo Flórez. Ingeniero electricista de la Universidad Nacional de Colombia. Máster en Edición Universitaria Universidad de Salamanca. Maestría en Ambientes Virtuales de Aprendizaje Universidad de Panamá. Especialista en virtualidad Centro de Altos Estudios de Argentina. Coordinador del Laboratorio de innovación pedagógica Politécnico Grancolombiano.Correspondencia:mtrujilo@ poligran.edu.co
\end{abstract}

\section{Resumen}

Los programas académicos virtuales cada día requieren estrategias educativas más inmersivas que permitan evidenciar la adquisición de competencias por parte de los estudiantes. Para facilitar dichos procesos se creó un Laboratorio de innovación pedagógica que a través de una metodología denominada ADDIEI (Análisis, Diseño, Desarrollo, Implementación, Evaluación, e Investigación), creada a partir de la combinación de varios métodos para elaborar ambientes y herramientas virtuales facilita el diseño, producción y elaboración de diversos proyectos de innovación educativa mediados por TIC. La creación de un Laboratorio de innovación pedagógica ha permitido el desarrollo de tales proyectos educativos de manera fácil y sostenible, con la gran ventaja que los productos resultantes se elaboran de acuerdo con las necesidades de los programas académicos y pueden implementarse en cualquier institución educativa. 


\section{Palabras claves}

Simuladores, Juego serio, Software educativo, IDI (Investigación + Desarrollo + Innovación).

\section{Introducción}

El proyecto nace desde la necesidad que manifiesta la academia en la verificación de la adquisición de las competencias por parte de los estudiantes, lo cual es complejo de evidenciar sobre todo en ambientes mediados con tecnología. Por esta razón, se pensó en simuladores, visto como herramientas que permiten recrear escenarios de práctica cercanos a los que encuentra el estudiante en su quehacer profesional. También se pretende que a través de metodologías activas los estudiantes con su "hacer" pongan en evidencia su "saber" y lo incorporen a su "ser", es decir, que desde la parte académica se pueda evidenciar la apropiación en las tres dimensiones de la competencia por parte de los estudiantes.

En el año de 2017 la Dirección Académica de Educación Virtual buscó mejorar el proceso de consecución y la adquisición de competencias para los programas virtuales de la Institución Universitaria Politécnico Grancolombiano propuso la creación de un proyecto denominado "simuladores" con el fin de crear diversos softwares de simulación que ayuden a los diferentes programas en la parte teórico-práctica o práctica. Los simuladores son herramientas valiosas para evidenciar la adquisición de las competencias porque le permiten al estudiante darle a la información sus propios significados, de esa manera relaciona los conocimientos nuevos adquiridos en la representación con los previos adquiridos en los módulos.

Sin embargo, cuando al llegar a la ejecución del proyecto encontramos desde los programas y los tutores propuestas de proyectos tan variados como: simuladores, ambientes virtuales de aprendizaje (AVA), storytelling educativos, aplicaciones educativas, juegos serios, realidad aumentada, realidad virtual y ambientes personales de aprendizaje (PLE), que también facilitan y permiten evidenciar la adquisición de competencias por parte del estudiante. Esto condujo a la Dirección Académica de Virtual a la reorientación hacia un proyecto más ambicioso que se denominó Laboratorio de innovación pedagógica, para que no limitase su alcance únicamente a los simuladores, sino que permitiera la planeación, diseño, desarrollo, montaje y publicación a los estudiantes de diversas estrategias educativas mediadas por tecnologías propicias para ambientes virtuales. Para que sean innovadoras deben ser 0 
novedosas o diferentes, que ayuden a mejorar el proceso de aprendizaje de los estudiantes y propendan por la calidad educativa.

Cada proyecto se origina en las necesidades de los programas académicos, el laboratorio es el mediador para la realización de lo que se propone desde el área académica, con dicha necesidad se diseña la propuesta de aprendizaje, con la propuesta se elige la herramienta más efectiva, esto quiere decir que puede existir una propuesta pedagógica para todo un programa que desarrolle en los diferentes módulos distintas estrategias que desencadenen en diferentes proyectos, también se puede elaborar una herramienta para un módulo preciso, depende de lo que requiera el programa.

La conformación del Laboratorio de innovación pedagógica se estructuró con un equipo interdisciplinario, la Dirección Académica de Educación Virtual es la encargada de la Coordinación del Laboratorio de Innovación quien realiza el direccionamiento académico de los proyectos que va desde el asesoramiento pedagógico, el diseño estructural, la construcción de guiones, la elaboración de los documentos investigativos hasta el diseño pedagógico y comunicativo de cada proyecto que se verá reflejado en los guiones para el diseño gráfico y la programación, de igual manera, provee el equipo de diseño gráfico que construyen las interfaces y diseñan toda la parte gráfica de los proyectos. El Área de tecnología y su Jefatura de Innovación y desarrollo de tecnología avala los proyectos para el desarrollo y programación, desde allí se nombran a los ingenieros y programadores para volver los proyectos una realidad, todo el desarrollo de software se hace desde la misma área. El Departamento de Investigación facilita el equipo editorial para la publicación de las experiencias y el acompañamiento para la publicación de los artículos científicos, además, provee el Observatorio de Educación Virtual que acompaña y direcciona toda la construcción de los artículos de divulgación científica que se producen en el Laboratorio. Las facultades por medio de sus departamentos académicos solicitan los diferentes proyectos de acuerdo con las necesidades de cada programa y las estrategias propuestas por los directores académicos de los diversos programas, además, nombran a los autores para cada uno de los proyectos. Todo es un proceso interdisciplinario con el fin de propender por la excelencia académica. El laboratorio está adscrito a la Vicerrectoría Académica de la institución.

El Laboratorio de innovación pedagógica en conjunto con los Departamentos Académicos hace el diseño pedagógico de la estrategia. El diseño funcional, 
los mapas y los diagramas conceptuales de funcionamiento son realizados con el autor del proyecto. Este primer proceso deber ser avalado pedagógica y tecnológicamente para proseguir a la redacción de los guiones, con ellos se realizan las pruebas de funcionamiento, se procede al diseño gráfico de las interfaces, el desarrollo de software, las verificaciones y pruebas de uso. La estrategia es puesta en marcha con los estudiantes. Cada proyecto es documentado en un libro de experiencias y en la redacción de artículos científicos convirtiéndose en un proceso de innovación e investigación.

\section{Marco teórico}

\section{Problemática que atiende}

Como ya se mencionó el problema central para la construcción del Laboratorio es facilitar la adquisición de las competencias por parte de los estudiantes a través de estrategias de aprendizaje que desencadenan el desarrollo de herramientas que facilitan la implementación de esta en los estudiantes.

Para que cada proyecto de innovación cumpla con el propósito que plantea el laboratorio debe satisfacer los siguientes parámetros de acuerdo con Guzmán (2008)

- El proyecto permite al estudiante realizar su proceso de aprendizaje por sí mismo, a su ritmo y en sus tiempos (aprendizaje autónomo)

- El proyecto es claro, comprensible y significativo.

- El proyecto permite el desarrollo de procesos individuales y colectivos

- El proyecto permite poner en práctica las competencias

Por consiguiente, la problemática para el montaje del Laboratorio de innovación pedagógica fue crear una metodología de trabajo que permitiera abordar cualquier tipo de proyecto de innovación educativa. Es decir, un proceso con el cual se pudiera hacer un simulador tanto como una aplicación o cualquier ambiente virtual de aprendizaje. 


\section{Metodología de trabajo en el Laboratorio de innovación pedagógica}

Un proyecto de innovación educativa sin importar complejidad se estructura bajo cuatro niveles o arquitecturas:

La arquitectura pedagógica. Contiene las estrategias educativas para desarrollar o evidenciar las competencias, para los primeros proyectos, que se presentan en este primer tomo de experiencias, se trabajó con tres estrategias pedagógicas fundamentales: el aprendizaje problémico, el trabajo por proyectos y la metodología de casos. La arquitectura pedagógica es la más relevante, aquí se adopta el papel de pedagogo y se definen las estrategias de aprendizaje, diseña las diferentes guías y actividades metodológicas. Se toma el papel de estudiante y se mira que tan efectivo es la herramienta en el desarrollo del aprendizaje. El autor y el pedagogo del laboratorio de innovación son los diseñadores de esta arquitectura.

La arquitectura estructural o de nivel lógico. Nos indica la organización de las actividades (qué va a hacer el estudiante) qué va a encontrar durante su recorrido, no es sola la lógica sino la secuencia pedagógica que debe realizar durante el proceso. La arquitectura estructural es el esqueleto del proyecto, si bien, el programador realiza en lenguaje de programación toda esta arquitectura, el autor debe elaborar el mapa conceptual y las rutas de aprendizaje que conforman el proyecto. Esta arquitectura es diseñada entre el autor y el pedagogo del laboratorio de innovación y llega a los programadores a través de los guiones.

La arquitectura navegacional o del usuario. Se compone de las formas y herramientas de acceso a la información o navegabilidad (cómo lo va a ver y cómo va a recorrer el simulador). Esta arquitectura se basa en el diseño de las interfaces y trabaja de manera enfática la percepción del estudiante puesto que no solo debe encontrar una herramienta que le sea útil sino que lo motive en su proceso de aprendizaje. En la arquitectura navegacional debemos revisar que un proyecto se construye por escenarios, entonces analiza cómo debe ser ese escenario desde lo pedagógico, desde lo visual y desde la navegación (de dónde viene, a dónde va). Esta arquitectura es trazada entre el autor y el pedagogo del laboratorio de innovación y llega a los diseñadores gráficos a través de los guiones. 
La arquitectura funcional. Representa la morfología de los nodos, es la del diseño y programación como plantillas, botones de navegación, barras, jerarquías gráficas, tipologías, etc. No es únicamente cómo debe verse el proyecto, es algo más complejo, es cómo facilitar la interactividad de los usuarios y cómo va a mostrarse la información de tal forma que cumpla con el propósito comunicativo y pedagógico. Esta arquitectura es trabajada en conjunto entre el pedagogo del laboratorio de innovación, el diseñador gráfico y el programador, es probable que esta fase requiera ajustes en los guiones porque depende de lo que en programación y diseño se pueda llevar a cabo.

La figura 1. Reúne las cuatro arquitecturas que tiene un simulador y los roles de trabajo que asume cada miembro del equipo de producción.

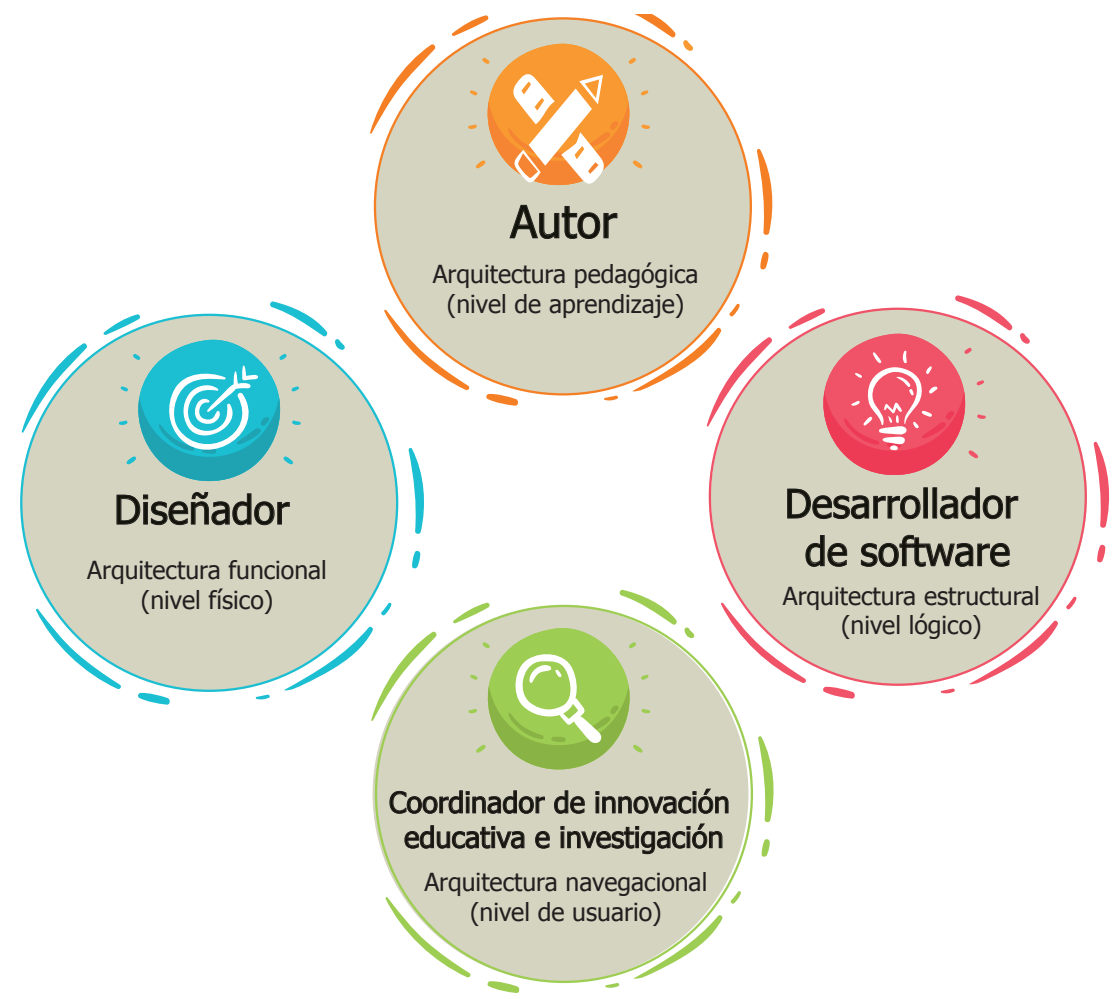

Figura 1. Arquitecturas de un simulador.

Fuente: creación propia.

Es importante aclarar que los proyectos realizados en el Laboratorio de Innovación no están pensados para teorizar y explicar una serie de contenidos, esto se hace en las aulas virtuales y sus diversos materiales. La base de estos 
proyectos es la práctica, el propósito es que el estudiante dé cuenta en la práctica de la teoría que ya adquirió. En otras palabras, los proyectos del Laboratorio buscan trabajar la aplicación de un conocimiento y la prueba de unas competencias adquiridas, o la adquisición de ciertas habilidades. Por tal razón, las explicaciones conceptuales son para determinados puntos y se trabajan como elementos de microelearning. Todos los proyectos están estructurados para que el estudiante de acuerdo con su actuar reciba retroalimentación del tutor según los resultados, decisiones y conclusiones.

Para resolver la complejidad de desarrollar diversos tipos de proyectos, cada uno con sus particularidades, se estructuró una metodología construida con el Modelo de Proceso Interdisciplinario para Desarrollo de Software Educativo de Simulación (MoPIS) y el Modelo de simulación basados en agentes (MABS) propuesto por Brito J. (2006). Con estos dos modelos, se tomó inicialmente uno con las siglas ADDIIE según Saavedra (2013) que consiste en Análisis (análisis), Design (diseño), Development (desarrollo), Implementation (Implementación), Innovation (innovación) y Evaluation (evaluación). Para el Laboratorio no aplicaban todos los pasos ni coincidían las siglas, por eso fue modificado a un modelo propio que se denomina ADDIER que significa cada una de las etapas que tiene el proceso: 1. Análisis, 2. Diseño, 3. Desarrollo, 4. Implementación, 5. Evaluación, 6. Investigación. Mirar figura 2

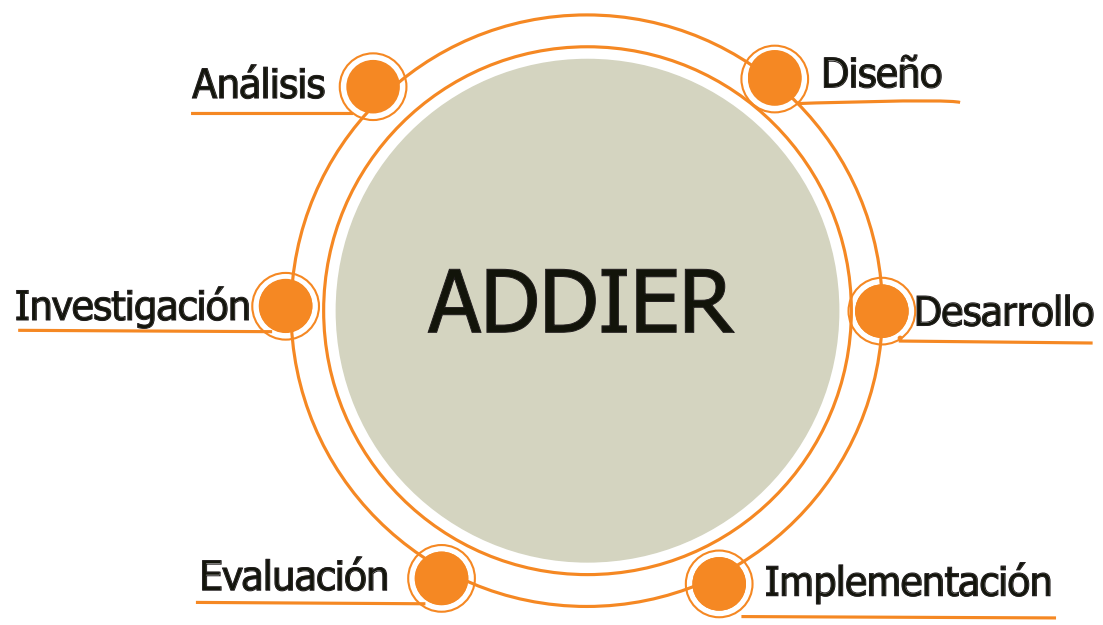

Figura 2. Modelo ADDIER.

Fuente: creación propia. 
Para cada una de las etapas se precisa la construcción de un modelo de trabajo, que debe tener las siguientes características: cubrir todo el universo, es decir, que reproduzca procesos de la realidad. En lo posible, que no utilice un lenguaje complejo, sino por el contrario, que cualquier persona pueda leerlo y comprenderlo. Recordemos que este proceso pasa por un equipo interdisciplinario que no maneja el tema y debe llegar a un estudiante que tiene nociones y que cada día evoluciona su aprendizaje.

Etapa 1. Análisis y captura de requerimientos: En esta fase se establecen los servicios, alcances y competencias del proyecto. Es fundamental delimitar el entorno de trabajo del proyecto para posteriormente enlistar los requerimientos que debe tener. Esta etapa termina con la viabilidad pedagógica y tecnológica del proyecto.

Desde la programación Londoño (2005 P.12) indica: "El objetivo es identificar y caracterizar el comportamiento del sistema. Aquí se identifican todos los roles que un usuario puede interpretar al utilizar el sistema y qué acciones o tareas puede realizar con él. Aquí se construyen los diagramas de interacción, los actores y el proceso".

Etapa 2. Diseño: En esta etapa se trabajan de forma interdisciplinaria y de manera independiente los tres ejes: el pedagógico, el comunicacional y el informático. Es importante aclarar que una parte significativa del diseño se adelanta durante la etapa anterior. Esta etapa finaliza con la redacción de los guiones.

Etapa 3: Desarrollo: esta etapa se centra en el desarrollo del software, aquí se toman los guiones y se diseñan gráficamente todas las piezas y requerimientos que posteriormente se combinan con programación hasta obtener la versión Beta de la herramienta. El final de este proceso es la construcción de las guías metodológicas para los estudiantes.

Etapa 4. Implementación: esta etapa empieza con la validación de la herramienta por parte del tutor y finaliza con la implementación en el aula virtual. Aquí se trabajan los tutoriales para el manejo de las herramientas.

Etapa 5. Evaluación: esta etapa evalúa toda la experiencia e incluye la evaluación por parte de los estudiantes y su percepción tanto de la estrategia de aprendizaje como de la herramienta. 
Etapa 6. Investigación: Esta etapa se realiza cuando el autor entrega los guiones y termina los documentos de acompañamiento para el estudiante, es decir, mientras el área de diseño convierte la maqueta en un diseño definitivo, y se elabora el código de programación. El autor inicia la construcción del documento de investigación, básicamente, en esta etapa, debe elaborar la experiencia académica. La segunda fase investigativa se hace con el simulador terminado, entonces se prueba la herramienta y la estrategia con los estudiantes.

\section{Estrategia de aprendizaje}

Los proyectos del Laboratorio de Innovación se trabajan con métodos activos de aprendizaje, se denominan activos cuando en el proceso predomina la participación del estudiante, su autonomía le permite desarrollar la capacidad de descubrimiento y autorregulación. Algunas metodologías activas son: Métodos explicativos-ilustrativos, (concepto- práctica), Métodos reproductivos (se reproducen escenarios reales para ser simulados), Métodos problémicos (se plantea un problema que el estudiante resuelve ayudado por la simulación).

Martínez (2007 P. 17 y 18.) habla de los medios pedagógicos que pueden trabajarse a través de la simulación y que son aplicables en los proyectos que se van a realizar en el Laboratorio de Innovación:

"Medios de experimentación académica: con ellos los estudiantes pueden realizar trabajos experimentales.

Medios de entrenamiento o ejercitación: sirven para imitar situaciones de aprendizaje utilizando parámetros reales.

Medios de programación de la enseñanza: se caracterizan porque el simulador se confecciona dosificando la información y estableciendo la retroalimentación a cada paso. Es ideal para el auto estudio y el trabajo independiente.

Medios de control del aprendizaje: se emplean para determinar en qué medida los educandos han asimilado los conocimientos. Pueden ser de uso individual o colectivo."

Para los primeros proyectos, que se presentan en este primer tomo de experiencias, trabajamos con tres estrategias pedagógicas fundamentales: el aprendizaje problémico, el trabajo por proyectos y la metodología de casos. 
El aprendizaje problémico le permite al estudiante dimensionar hasta dónde conoce o desconoce un tema. Buscando mantener la motivación de los estudiantes se planeó que fueran situaciones que enfrentan en la vida real o en su quehacer profesional, este diseño de situaciones se realizó con los autores que son profesionales tutores y tienen una amplia experiencia en el campo profesional. Es claro que no sólo se trata de darle un problema al estudiante, es retarlo en su aprendizaje y en la acción de sus procesos mentales. La resolución de un problema requiere del dominio de conocimientos previos, de planteamientos de solución, de la observación del comportamiento de las variables y la supervisión de los avances, así como de la búsqueda de soluciones y el enfoque por la que considere más adecuada. Por esa misma razón el primer proceso en los proyectos antes de esbozar las herramientas fue diseñar y construir las situaciones problémicas. En este punto surgió una dificultad adicional porque con frecuencia las situaciones fueron muy específicas y resultó complejo llevarlas a un modelo para la simulación, para este proceso se pensó en la aplicación de metodologías de solución para que el estudiante a través del simulador aplicara una metodología que pudiese darle solución a diversas situaciones problémicas, esto permitió manejar las variables en rangos en lugar de valores fijos, de esa manera, cambiaron las situaciones problémicas para cada estudiante y el proceso se hizo más personalizado y significativo.

En segunda instancia, la metodología por proyectos, en la cual se relacionan diversos saberes con actividades variadas para la implementación de un proyecto que satisfaga una necesidad o resuelva un problema determinado. En este caso los escenarios se construyen pensando en un producto final o proyecto que debe entregar el estudiante. La herramienta le ayuda a desarrollar cada una de las etapas en la construcción del proyecto, lo que cambia son las condiciones iniciales generando que aplique la metodología de solución pero que cada proyecto conserve sus diferencias.

La metodología de casos, en algunos aspectos es similar a la resolución de problemas, sino que aquí se delimita a un contexto determinado y toma en cuenta variables reales de casos que han sucedido en organizaciones o empresas. Con esta metodología se pretende acercarse al máximo a un contexto real, por tal razón hay un avatar que actúa como el jefe en la empresa y los estudiantes son un equipo de personas contratadas por la organización, por lo tanto, proponen, trabajan, e interactúan, y son responsables de sus compromisos para resolver el caso. 
Con las estrategias pedagógicas se concluyó que los simuladores y los juegos serios son muy apropiados para la efectividad de estas en ambientes virtuales porque facilitan la adquisición de las competencias pues el estudiante logra: ejemplificar modelos, sacar conclusiones de datos, hacer deducciones, inferencias lógicas, considerar soluciones alternas, formular hipótesis y comprobarlas a través de la evaluación de los resultados. En las tres estrategias el estudiante, o el equipo de estudiantes, debe argumentar las decisiones tomadas, así como justificar lo que incluyen o eliminan del proyecto, o en su propio caso.

El laboratorio de innovación pedagógica amplió el espectro a otras estrategias y herramientas, sin embargo, se hablará a continuación de los simuladores y los juegos serios porque son los proyectos que actualmente están en desarrollo e implementación.

Los simuladores. Son herramientas de software que emulan procesos reales en los cuales los estudiantes se enfrentan a situaciones de su quehacer profesional en ambientes seguros. Según Blasco López (2000) el estudiante en un simulador aprende combinando los rasgos de un juego: competición, cooperación, reglas, participantes o roles. Sumándole las características de la simulación: un modelo dinámico de la realidad. Por tanto, la simulación tiene las características propias del juego, pero la situación sobre la que se juega representa un modelo de la vida real. La mayoría de los proyectos son empresariales, entonces es viable recrear situaciones que vive el estudiante en un ambiente laboral y le resulta significativo porque debe confrontar sus conocimientos a situaciones que vivirá en su quehacer diario. Tal confrontación permite evidenciar la adquisición de la competencia.

Los juegos serios. Sirven para emular ambientes cotidianos donde se desea conocer la respuesta del individuo ante una situación determinada, el estudiante interviene en las variables y cambia el resultado, aunque las simulaciones también lo permiten, pero se diferencia en que el juego serio nos permite analizarlo con mayor profundidad desde lo comportamental. El juego como elemento para facilitar el aprendizaje se considera como un conjunto de actividades agradables, cortas, divertidas, con reglas que permiten el fortalecimiento de los aprendizajes y le permiten al estudiante interiorizar los conocimientos hasta volverlos significativos. Según Torres (2002) el juego sirve para enlazar los contenidos conceptuales, procedimentales y actitudinales con la acción del estudiante en un ambiente de motivación permanente. 
Tanto para la simulación como para el juego serio se produce un escenario (emulación de la realidad) con unas condiciones determinadas. Dependiendo de la didáctica del tutor se puede optar por: brindarle al estudiante la información sobre el problema y que sea este quien lo plantee; sugerir la metodología a utilizar para que el estudiante realice la búsqueda y selección de la información; en ocasiones, dependiendo de la finalidad educativa, se le brinda al estudiante una serie de datos para que realice los análisis. Otros tutores prefieren que el estudiante haga el muestreo, recolecte la información y con ella simule los cálculos y presente sus resultados. En otros casos, los tutores pretenden que la simulación arroje los resultados y el estudiante sea quien desarrolle los análisis. Otra estrategia, es realizar un proyecto de ejecución y solicitar al estudiante que ejecute los parámetros y saque las conclusiones, en este caso el informe es de resultados y conclusiones como funciona en muchos laboratorios reales.

\section{La experiencia de aprendizaje}

Comúnmente cuando una institución requiere un simulador consulta la oferta existente en el mercado y de acuerdo con los hallazgos adapta su proceso de formación en el aula, esta estrategia limita el aprendizaje de acuerdo con lo que pueda ofrecer la herramienta y en cuanto a lo que puede hacer el tutor con sus estudiantes. En el laboratorio de innovación pedagógica se arranca de las necesidades educativas de cada programa, con estas se diseña una estrategia de aprendizaje, se propone la herramienta (simulador, juego, aplicación, o AVA), es decir, las herramientas se hacen con rutas pedagógicas incorporadas según las necesidades de formación. Las herramientas son hechas por y para la academia y ayudan al fortalecimiento y desarrollo de unas competencias específicas, algo difícil de encontrar en un software comercial así sea educativo.

Otra ventaja, es que son herramientas pensadas para un estudiante que desarrolla su proceso de aprendizaje, la mayoría de las herramientas como son de aplicación profesional no se detienen en las complicaciones que pueda tener el alumno. Sin embargo, la innovación más fuerte que presenta el Laboratorio es la creación de la metodología ADDIEl para la elaboración y desarrollo de herramientas virtuales de manera escalable y económicamente sostenible. Cada simulador o video juego se realiza bajo cuatro arquitecturas de manera que al tenerlas en cuenta la metodología es óptima para elaborar un simulador, un videojuego, una app, o cualquier tipo de ambiente virtual para el aprendizaje (AVA) que quiera desarrollarse. 
Este método invierte de cierta manera la forma de trabajar en un área IDI (Investigación Desarrollo e Innovación) normal, porque se parte de la necesidad de formación, se diseña la estrategia educativa, se plantea la herramienta para dicha estrategia, se diseña simultáneamente la estrategia pedagógica y la herramienta, se elaboran los guiones, se diseñan las interfaces, se redactan las guías e instructivos, se desarrolla el software, se evalúa la herramienta, se prueba con los estudiantes, se genera el proyecto de investigación. Es decir, se investiga a partir de la innovación, aunque se puede partir de la investigación para llegar a la innovación, no es un proceso excluyente, es simplemente otra forma de trabajar.

\section{Proceso de implementación del Laboratorio de innovación pedagógica}

El laboratorio inició como parte de la producción de contenidos, sin embargo, las experiencias iniciales demostraron que era necesario un equipo interdisciplinario que dedicara el tiempo por completo a dicha tarea. Con el área de contenidos fueron adelantados proyectos iniciales como la "caja de herramientas" que consiste en agrupar diferentes herramientas web educativas para la gestión del estudiante y la facilidad del trabajo académico. De allí nació, el proyecto "Punto de Partida" un emulador de la navegación en el aula virtual para los estudiantes que cursan el primer semestre. En este caso, la estrategia de innovación se volcó a preguntar a la academia por sus necesidades y como resultado se obtuvieron una gran cantidad de ideas de los académicos que llevó a crear un área denominada inicialmente "Simuladores" que se transformó en el Laboratorio de innovación pedagógica.

Actualmente se adelantan los siguientes proyectos:

- Simulador de Análisis Financiero: recrea un trabajador de una empresa en finanzas y se divide en tres simuladores: simulador de mercado de valores, simulador de evaluación financiera de proyectos, y análisis financiero para las inversiones.

- Simulador de Salud e Higiene Laboral: sirve para el análisis de riesgos biológicos, químicos, seguridad, biomecánicos, naturales y físicos, que puede experimentar un trabajador en diversas empresas (oficina, pozo petrolero, manufacturera, laboratorio químico y de servicios generales). El simulador lleva al estudiante desde la identificación del riesgo hasta la proposición de controles que mitiguen el mismo. 
- Simulador de prospectiva: le permite al estudiante definir los probables escenarios que puede afrontar una empresa para que a partir genere sus estrategias gerenciales.

- Simulador de diagnóstico empresarial: permite evaluar la situación de la empresa y establecer sus estrategias administrativas.

- Juego de toma de decisiones gerenciales: el estudiante es el CEO de la compañía y acorde a sus decisiones basadas en la metodología Balanced Scorecard afecta los indicadores de la organización.

Los siguientes son los proyectos que iniciará el Laboratorio una vez culmine los que adelanta actualmente. Como respuesta a la convocatoria llegaron 25 propuestas de las cuales, por capacidad del equipo de trabajo, fueron aprobadas solo once que se presentan a continuación:

Tabla 1. Proyectos que se van a realizar en el Laboratorio de innovación pedagógica.

\begin{tabular}{|l|l|l|}
\hline $\begin{array}{l}\text { Nombre del } \\
\text { proyecto }\end{array}$ & Descripción del proyecto & $\begin{array}{l}\text { Tipo de } \\
\text { proyecto }\end{array}$ \\
\hline $\begin{array}{l}\text { Juego } \\
\text { administrativo } \\
\text { y gerencial }\end{array}$ & $\begin{array}{l}\text { Es un juego de toma de decisiones que busca } \\
\text { generar el mayor valor para la compañía a } \\
\text { través de diferentes decisiones de mercadeo, } \\
\text { finanzas, producción, talento humano, } \\
\text { contratación de personal. Se trabaja para } \\
\text { tres tipos de empresas: Inicial, Manufactura } \\
\text { y Servicios. Son cuatro jugadas cada una } \\
\text { corresponde a un trimestre, el jugador simula } \\
\text { el trabajo de un año y con la simulación de } \\
\text { acuerdo con las decisiones que tome genera } \\
\text { nuevos resultados financieros e indicadores } \\
\text { empresariales. }\end{array}$ & \\
empresarial \\
\hline Simulador de \\
costos & $\begin{array}{l}\text { Es un software que se divide en dos partes, } \\
\text { la primera para trabajar los costos de } \\
\text { producción, estado de resultados y balance } \\
\text { general. La segunda parte se enfoca en los } \\
\text { asientos contables de acuerdo con el régimen } \\
\text { empresarial. }\end{array}$ & \\
\hline
\end{tabular}




\begin{tabular}{|c|c|c|}
\hline $\begin{array}{l}\text { Simulador } \\
\text { en Finanzas } \\
\text { corporativas }\end{array}$ & $\begin{array}{l}\text { El simulador deberá proyectar los estados } \\
\text { financieros y el flujo de caja apoyado en los } \\
\text { datos históricos y en las perspectivas del } \\
\text { sector según las condiciones entregadas. }\end{array}$ & Simulador \\
\hline $\begin{array}{l}\text { Diseño y } \\
\text { elaboración de } \\
\text { proyectos de } \\
\text { política social }\end{array}$ & $\begin{array}{l}\text { Se simula una oficina de planeación de un } \\
\text { ente territorial allí el estudiante asume el } \\
\text { rol de coordinador de proyectos y recibe } \\
\text { un requerimiento por parte del director de } \\
\text { planeación, por lo tanto, debe diseñar y } \\
\text { presentar el proyecto piloto de intervención } \\
\text { pública, ligado al cumplimiento de alguno } \\
\text { de los Objetivos de Desarrollo Sostenible } \\
\text { con restricciones de presupuestario, políticas, } \\
\text { jurídicas y técnicas. }\end{array}$ & Simulador \\
\hline $\begin{array}{l}\text { Software de } \\
\text { habilidades } \\
\text { gerenciales }\end{array}$ & $\begin{array}{l}\text { Es un software que ayuda a detectar y } \\
\text { diagnosticar las competencias y habilidades } \\
\text { gerenciales en las personas. Con esas } \\
\text { habilidades se genera un proceso adaptativo } \\
\text { para ayudarle a mejorar sus capacidades a } \\
\text { través de diversos contenidos de multimedia. }\end{array}$ & Software \\
\hline $\begin{array}{l}\text { Simulador del } \\
\text { departamento } \\
\text { editorial de una } \\
\text { revista }\end{array}$ & $\begin{array}{l}\text { Este es un simulador de una editorial de } \\
\text { una revista donde se le solicita al estudiante } \\
\text { un artículo con ciertas características para } \\
\text { publicar, de esta manera el periodista debe } \\
\text { hacer la producción editorial. La idea es que } \\
\text { con el simulador quede publicada la revista. }\end{array}$ & Simulador \\
\hline $\begin{array}{l}\text { Diplomado } \\
\text { con AVA para } \\
\text { la producción } \\
\text { de artículos de } \\
\text { investigación o } \\
\text { científicos }\end{array}$ & $\begin{array}{l}\text { Es un Diplomado que aborda los siguientes } \\
\text { puntos para los docentes de la institución } \\
\text { que quieren iniciar sus procesos de } \\
\text { investigación. Funciona de forma blended } \\
\text { con un ambiente virtual con la parte } \\
\text { teórica y con sesiones presenciales } \\
\text { prácticas. El objetivo es que el docente } \\
\text { tenga competencias en búsqueda de } \\
\text { información en base de datos, conocimiento } \\
\text { de posibles revistas para publicar, } \\
\text { elaboración de artículos, lenguaje científico, } \\
\text { construcción borrador del artículo, citación y } \\
\text { referenciación, construcción del artículo final, } \\
\text { gestión para la publicación. }\end{array}$ & Diplomado \\
\hline
\end{tabular}




\begin{tabular}{|c|c|c|}
\hline $\begin{array}{l}\text { Ambiente } \\
\text { Virtual de } \\
\text { Aprendizaje } \\
\text { para el } \\
\text { desarrollo de } \\
\text { competencias } \\
\text { de } \\
\text { razonamiento } \\
\text { cuantitativo. }\end{array}$ & $\begin{array}{l}\text { Se propone una situación cotidiana, en } \\
\text { la que se haga uso de distintas formas de } \\
\text { representación, sobre las que se generarán } \\
\text { problemas con distintos niveles de dificultad } \\
\text { y que conlleven a la toma de decisiones } \\
\text { para encontrar una solución. Tendrá con } \\
\text { una biblioteca disponible para que puedan } \\
\text { consultar aspectos de contenido que sean } \\
\text { soporte para dar solución al problema } \\
\text { elegido. El estudiante debe avanzar en los } \\
\text { tres niveles, de manera secuencial. Cada nivel } \\
\text { contiene estándares básicos, que se requieren } \\
\text { para avanzar al siguiente nivel. }\end{array}$ & AVA \\
\hline $\begin{array}{l}\text { Diseño de } \\
\text { medios } \\
\text { didácticos para } \\
\text { el aprendizaje } \\
\text { activo en } \\
\text { matemáticas }\end{array}$ & $\begin{array}{l}\text { Es un libro interactivo multimedia organizado } \\
\text { en unidades y secciones. En cada sección } \\
\text { el estudiante encuentra una situación } \\
\text { problémica que debe resolver. Cada situación } \\
\text { está simulada de tal manera que el estudiante } \\
\text { entienda qué es lo que quiere responder, el } \\
\text { estudiante puede interactuar con la situación, } \\
\text { cambiar valores y ver cómo esto repercute en } \\
\text { la solución del problema. }\end{array}$ & $\begin{array}{l}\text { Libro } \\
\text { interactivo }\end{array}$ \\
\hline $\begin{array}{l}\text { Desarrollo } \\
\text { html para los } \\
\text { simuladores de } \\
\text { física }\end{array}$ & $\begin{array}{l}\text { Se va a hacer el desarrollo en html para los } \\
\text { simuladores de física para el fácil acceso de } \\
\text { los estudiantes. Ya existen los simuladores } \\
\text { de física en otro idioma de programación y } \\
\text { se pasarán a html para facilitar el acceso y } \\
\text { trabajo de estos. }\end{array}$ & Simulador \\
\hline $\begin{array}{l}\text { Simulador de } \\
\text { ingeniería } \\
\text { industrial }\end{array}$ & $\begin{array}{l}\text { La estrategia de aprendizaje se basaría en la } \\
\text { simulación de casos prácticos (semejantes } \\
\text { a los vividos en un entorno real), sobre los } \\
\text { cuales el estudiante debe realizar análisis, } \\
\text { tomar decisiones, evaluar los resultados y } \\
\text { presentar informes. El simulador recibirá } \\
\text { una información definida por el estudiante, } \\
\text { tomará decisiones basadas en el azar } \\
\text { y finalmente presentará los resultados } \\
\text { esperados (por la implementación de } \\
\text { las decisiones tomadas por el estudiante, } \\
\text { después de realizar corridas en un periodo de } \\
\text { tiempo). }\end{array}$ & $\begin{array}{l}\text { Laboratorio } \\
\text { virtual }\end{array}$ \\
\hline
\end{tabular}

Fuente: Creación propia. 


\section{Conclusiones}

Todos los proyectos pueden aplicarse en diferentes espacios académicos, en programas de modalidad virtual, distancia o presencial. Muchos no tienen similares en el mercado, sin embargo, su potencial de uso es alto porque son hechos a partir de las necesidades de formación de los diferentes programas.

Hace unos años era inviable, desde diferentes perspectivas, que una institución educativa desarrollara un Laboratorio como el que se presenta, hoy en día el desarrollo de software se puede tercerizar igual que el diseño gráfico; el aporte más valioso es la cantidad de propuestas de innovación educativa dadas por el equipo docente y académico.

Un laboratorio de innovación pedagógica, además de los proyectos, la mejora en la calidad educativa, el apoyo a la investigación de la institución tiene una ganancia muy significativa para la percepción e impacto en los estudiantes de sus programas académicos porque mejora sus procesos de aprendizaje.

\section{Referencias}

Blasco López, M. (2000). Aprendizaje y Marketing: investigación experimental del juego de simulación como método de aprendizaje. (Tesis Doctoral) Universidad Complutense de Madrid.

Brito Julio (2006). Gestión del Proceso de Desarrollo de Simuladores Virtuales Educativos un enfoque transdisciplinario. Instituto Universitario Aeronáutico: Córdoba. En: http://sedici.unlp.edu.ar/bitstream/handle/10915/19191/ Documento_completo.pdf?sequence $=1$

González J. (2014) Nuevas tendencias en innovación educativa superior. Madrid: Editorial ACCI.

Guzmán M. (2008). Producción de materiales educativos. Institución Universitaria Politécnico Grancolombiano, Bogotá.

Londoño F. (2005) Metodología De Desarrollo De Producciones Educativas Hipermediales Personalizantes. Universidad Católica De Manizales, Colombia. En: http://www.colombiaaprende.edu.co/html/mediateca/1607/articles-75593_ 
archivo.pdf

Martínez M. (2007) Propuesta Metodológica para el diseño de Multimedia Educativas del Programa Nacional de Formación de Medicina Integral Comunitaria en la República Bolivariana de Venezuela. Escuela de Salud Pública. Cuba.

Saavedra A. (2013) Diseño De Un Software Educativo Para El Aprendizaje De Funciones Matemáticas En La Institución Educativa De Rozo-Palmira. Universidad Nacional de Colombia. Tesis de Maestría.

Torres C. M. (2002) El juego como estrategia de aprendizaje. En: www.saber.ula.ve/ bitstream/123456789/17543/2/carmen_torres.pdf 


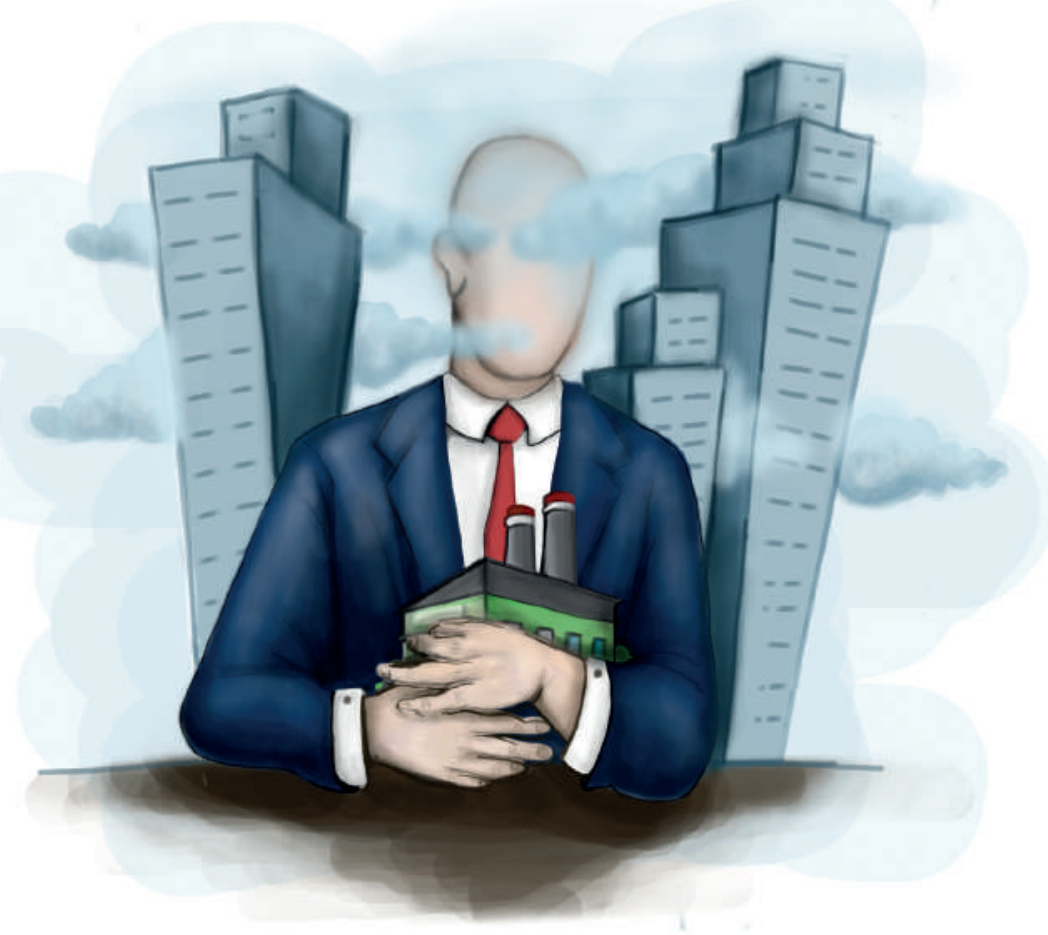

- Capítulo 1 -

\section{Simulador de Diagnostico Empresarial}

\section{Autores}

Ronald Mauricio Martínez Contreras. Administrador de empresas del Politécnico Grancolombiano y Magister en Administración Financiera de la universidad Sergio Arboleda, con más de 10 años de experiencia en cargos directivos y ejecutivos en 
empresas del sector real, financiero y de servicios, vinculado al sector educativo desde hace más de cuatro años y en la actualidad es el director del departamento académico de administración del Politécnico Grancolombiano.

Correspondencia: romartin@poligran.edu.co

Luis Martín Trujillo Flórez. Ingeniero electricista de la Universidad Nacional de Colombia. Máster en Edición Universitaria Universidad de Salamanca. Maestría en Ambientes Virtuales de Aprendizaje Universidad de Panamá. Especialista en virtualidad Centro de Altos Estudios de Argentina. Coordinador del Laboratorio de innovación pedagógica Politécnico Grancolombiano.

Correspondencia:mtrujilo@poligran.edu.co

\section{Diseñador de interfaces del simulador}

Mónica Carrero Becerra. Diseñadora gráfica e ilustradora del Politécnico Grancolombiano. Tecnóloga en multimedia del Servicio Nacional de Aprendizaje. Actualmente se desempeña como diseñadora del Laboratorio de innovación pedagógica del Politécnico Grancolombiano.

Correspondencia:mncarrero@poligran.edu.co

\section{Resumen}

Debido a la relación existente entre los estudiantes de administración de empresas del Politécnico Grancolombiano con el sector empresarial a través del módulo de diagnóstico empresarial, surge la necesidad de desarrollar un software que fortalezca la calidad de los productos de consultoría entregados al finalizar el curso. El propósito de esta experiencia de aprendizaje es brindarle al estudiante una herramienta que les permita profundizar en sus procesos de análisis teniendo como base conceptual la metodología de diagnóstico propuesta por Fred Davis (1995). Tras una revisión hecha a lo largo del proyecto de las tecnologías existentes para el desarrollo del análisis estratégico de las compañías fue posible identificar que en el mercado no existe un software con las características desarrolladas por el equipo de trabajo, y se hizo una revisión de las bases académicas que le dan sustento al diagnóstico empresarial en los 
tiempos modernos de tal modo, que el usuario del simulador cuente con un software de vanguardia desde el punto de vista académico y tecnológico.

\section{Palabras claves}

Diagnóstico empresarial, análisis estratégico, simuladores, software educativo, estrategias de aprendizaje basadas en simulación, cinco fuerzas de Porter, PESTEL, DOFA, Matriz Space

\section{Introducción}

El análisis estratégico se remonta a las épocas de Sun Tsu quien vivió hacia el año 500 antes de cristo y planteó una serie de estrategias para obtener la victoria en el campo militar, sus planteamientos fueron publicados en el libro El Arte de la Guerra en 1958, y hoy en día es utilizado en distintos ámbitos como los negocios, la política y los deportes. Sin embargo, no es sino hasta después de mediados del siglo XX con autores como Ansoff, Druker y Minstberg que realmente se comienza a hablar de estrategia empresarial. Sobre la base de los aportes realizados por estos autores se ha desarrollado posteriormente matrices y metodologías enfocadas en el análisis estratégico y el diagnóstico empresarial.

Sin embargo, el mercado no provee softwares especializados en la aplicación de estas herramientas a nivel pedagógico, por tal motivo surge la necesidad de hacer un desarrollo en esta dirección en el cual los estudiantes a partir de un análisis externo que explora las oportunidades y amenazas para la empresa compuesto por el análisis PESTEL (1967) y el análisis de las cinco fuerzas de PORTER (1979). Posteriormente un análisis interno que explora las fortalezas y debilidades de la empresa, los estudiantes pueden aplicar una metodología de análisis que les permite construir un análisis DOFA (1964) de manera correcta, identificar el cuadrante estratégico más adecuado para la empresa analizada e identificar la estrategia idónea a implementar por la compañía. En otras palabras, ir del diagnóstico a las posibles soluciones, la cual está pensada como el diseño de un plan estratégico a partir del diagnóstico realizado. 


\section{Marco Teórico}

\section{Problemática que atiende}

El módulo de Diagnostico Empresarial por décadas ha sido el elemento diferenciador y el sello de los estudiantes de administración de empresas del Politécnico Grancolombiano, decenas de microempresarios se han beneficiado de las asesorías recibidas por los estudiantes del programa, quienes evalúan la empresa y entregan a la misma todo un plan estratégico para ser implementado gracias al diagnóstico que realizan durante el desarrollo del módulo. Esta práctica educativa ha sido muy agradecida desde la empresa con la institución porque encuentran en la academia un apoyo a sus necesidades, para la institución representa un componente importante de su proyección social.

De igual manera, en esta práctica se ha detectado que gran parte del trabajo de los estudiantes se dedica a la operatividad en la construcción de las matrices dejando en segundo lugar de importancia el análisis estratégico, que es el objetivo primordial del ejercicio académico. Por tal motivo, el propósito de esta experiencia es desarrollar un software que facilite el proceso operativo de introducción de variables, que a su vez integre todas las matrices en un solo lugar, permitiéndole al estudiante una mayor eficiencia y coherencia en los resultados encontrados en la aplicación de su proceso de diagnóstico empresarial.

El problema fundamental al que se enfrenta el estudiante en el proceso de diagnóstico empresarial es la identificación de la estrategia más adecuada para ser implementada por una compañía, por tal razón, el proceso de diagnóstico inicia con el análisis de factores internos y externos los cuales se clasifican en un principio en fortalezas, oportunidades, debilidades y amenazas. El estudiante debe dar una valoración de acuerdo con su relevancia estratégica que encuentra para la organización de acuerdo con la información e investigación realizada para la misma. De esta primera y fundamental etapa se desprende un análisis de matrices que tienen una secuencia lógica comenzando por las matrices EFI y EFE, para luego alimentar la matriz de perfil competitivo, la matriz DOFA y la matriz SPACE, finalmente debe encontrar la estrategia idónea para la compañía en la matriz cuantitativa de planeación estratégica. A partir de la definición de la estrategia el estudiante parte de los insumos entregados por el software para hacer un análisis cuantitativo y cualitativo necesario para la implementación de la estrategia en la compañía. 
A nivel del desarrollo de la programación el proyecto del simulador de diagnóstico empresarial se sustenta en la aplicación de la metodología de análisis estratégico propuesta por Fred Davis (2003) en su libro La Administración Estratégica. De acuerdo con las indagaciones del equipo de investigadores de este proyecto no se encontró un software con tales características.

Los dos elementos que se trabajan con el simulador son la incorporación de todo el proceso de análisis estratégico en un solo software y una plataforma amigable con el usuario que le permite tener claridad de los resultados encontrados en todas las etapas del diagnóstico empresarial.

\section{Antecedentes}

Antes de empezar el diseño de la herramienta para el diagnóstico empresarial se hizo un análisis de las herramientas existentes en el mercado. La mayoría está enfocada en el diagnóstico financiero de una organización para el análisis de la situación económico-financiera, como Managerial Analyzer. el cual presenta un organigrama para que el usuario a partir del ingreso de los datos pueda obtener los resultados de su situación.

Existen otras herramientas que sirven para la construcción de un plan de negocio empresarial, muchas de ellas son basadas en Excel, y más que un aplicativo son plantillas para facilitar los cálculos que permiten calcular la viabilidad y rentabilidad de la inversión o diagnosticas la situación del negocio y su rentabilidad.

El Centro de Promoción Agropecuaria Campesina (CEPAC), cuenta con una herramienta que permite realizar un diagnóstico a una pequeña o mediana empresa (PyME) en cinco áreas: Finanzas, Administración, Dirección, Mercadeo y Producción, y Medio Ambiente; a través de un cuestionario el usuario ingresa las respuestas y hace un diagnóstico inicial. A manera de introducción es una herramienta útil, sin embargo, no cumple con el objetivo pedagógico que es la realización de matrices estratégicas que permitan un análisis minucioso de la organización a nivel interno y externo. Para ampliar la información sobre esta herramienta sugerimos consultar: http://simmype.cepac.org.bo/index.php?option=com_ frontpage\&/temid=1

Otra herramienta es ISOTools que ayuda a la elaboración del diagnóstico en las organizaciones desde su sistema de gestión, el software tiene una función 
de autodiagnóstico que le permite a las empresas identificar sus debilidades y diseñar correctivos oportunos. Como ya se mencionó en este documento, la herramienta diseñada en la experiencia le permite al estudiante realizar las siguientes matrices: EFI y EFE, de perfil competitivo, DOFA, SPACE, y la matriz cuantitativa de planeación estratégica, entre otras. Lo que proporciona un análisis de las debilidades, las oportunidades, fortalezas y amenazas, es decir, hacer un estudio en múltiples direcciones. Para ampliar la información sobre esta herramienta consultar: $h$ ttps://www.isotools.org/soluciones/evaluacion-y-resultados/ diagnostico

Son pocas las herramientas que existen para el diagnóstico empresarial, y con todas las dimensiones que se quieren lograr desde el propósito educativo no existe una similar.

\section{Estrategia de Aprendizaje}

Para el desarrollo del software se tuvieron en cuenta las diferentes herramientas de diagnóstico empresarial integradas bajo la metodología propuesta por Fred Davis (2003) con la cual se busca fortalecer la capacidad de análisis de los estudiantes del pregrado de Administración de Empresas del Politécnico Grancolombiano y mejorar los procesos de consultoría que se hacen desde el aula de clases en el módulo de Diagnostico Empresarial.

Actualmente el módulo o asignatura trabaja la metodología del aprendizaje basada en proyectos, una estrategia que requiere de un problema real y los estudiantes de manera colaborativa deben generarle soluciones, además de una integración total del proyecto con el currículo del módulo de forma que su desarrollo o de la asignatura se supedita a la resolución de la problemática. (Fondo Social Europeo, 2012). Los estudiantes presentan una situación que genera el conflicto cognitivo que consiste en crear un plan estratégico para la empresa que elijan, la única condición es que se trate de una empresa real y que puedan obtener la información necesaria para el proyecto; por tal razón, los estudiantes deben lograr que la empresa les permita realizar el diagnóstico. Para ello la institución cuenta con unas cláusulas de confidencialidad que firma con la compañía. El módulo tiene la doble función de proveerle asesoría de alto nivel con estudiantes de último semestre.

La Estrategia de Aprendizaje para el módulo de Diagnóstico Empresarial cumple los pasos que establecen Bottoms \& Webb (1988) para el aprendizaje 
por proyectos. 1) Una situación o problema, realizar la estrategia empresarial para una organización a partir de un diagnóstico de esta. 2) Descripción y propósito del proyecto, para esto se entrega una guía metodológica que le da al estudiante las orientaciones necesarias para el desarrollo del proyecto, con la implementación de la herramienta se cambió la guía, pero el propósito pedagógico se mantuvo. En dicha guía se encuentran los pasos 3) Especificaciones de desempeño: lista de criterios que el proyecto debe cumplir y 4) Reglas o instrucciones para desarrollarlo. Cómo parte de la entrega los estudiantes deben especificar los roles de los integrantes del grupo y deben consignar la información de los expertos o miembros de la empresa que le ayudaron en el proyecto, este es el paso 5 . El paso 6) Evaluación, se evalúa el desempeño y el producto final que desarrollan los estudiantes, por eso tiene unas entregas parciales y una entrega del producto final que es evaluado junto con la aprobación de la empresa a la que se le hizo el diagnóstico. Los estudiantes como entrega final realizan el plan estratégico para la empresa.

Cuando la empresa entrega la información los estudiantes deben hacer un levantamiento de esta, hacen el análisis inicial que entregan al tutor, quien retroalimenta para uno más preciso pues es el insumo para la información que se consigna en el software. Aprobada la información por el tutor los estudiantes inician la construcción de las matrices estratégicas. En esta parte del proceso se encuentra otra dificultad que justifica la creación de la herramienta ya que la mayoría de los estudiantes se centran en la parte operativa para la construcción de las matrices y dejan a un lado el análisis, que es lo más importante. Para evitar esto, se creó un Excel que facilita el proceso, con este aplicativo se han obtenido buenos resultados, sin embargo, se busca una estrategia más retadora, tanto para el equipo de tutores como para los estudiantes ya que el propósito de aprendizaje fundamental de la herramienta es facilitar el proceso de análisis del estudiante que conduzca a un mejoramiento en la calidad de sus proyectos de investigación.

Por su parte, la herramienta permite que los requerimientos establecidos dentro del proyecto de Diagnóstico Empresarial sean trabajados de forma práctica, es decir, el estudiante evidencia sus aprendizajes en un contexto real con una empresa verdadera lo que fortalece su compromiso y sus aprendizajes se tornan más significativos. Este proceso no solo lo perciben los estudiantes sino los empresarios que encuentran un servicio de asesoría del cual todos se benefician.

Los proyectos basados en escenarios reales, por sencillos que sean, permiten 
a los estudiantes profundizar en el conocimiento de un tema determinado, evidenciar lo visto en la teoría. Además, lo llevan a desarrollar habilidades y actitudes propias Carreras, Yuste y Sánchez, (2007) que ayudan a la interiorización del conocimiento y a generar estrategias gerenciales adecuadas para la solución de problemas.

Es importante aclarar que el software ayuda únicamente a la realización del diagnóstico y de la matriz cuantitativa de planeación estratégica que le ayuda al equipo de estudiantes a construir toda la estrategia que van a entregar a la compañía y al tutor.

\section{Modelo para la simulación}

De acuerdo con Mintzberg (1997) estrategia es el patrón o plan que integra las principales metas y políticas de una organización y, a la vez, establece la secuencia coherente de las acciones a realizar. Sin embargo, ¿cómo es posible para una organización encontrar la estrategia más adecuada para alcanzar su visión?

En este contexto Drucker (1954) determinó que el principio para que una organización llegara a una situación deseada hoy llamada la visión, radica en el análisis de su situación actual. Para dicho análisis en una empresa se debe tener en cuenta tanto factores externos como internos que mediante su estudio ayudan a identificar la posición competitiva de la misma.

Dentro de los factores externos a estudiar, Fahey y Narayanan (1986) complementan su modelo de análisis del entorno con las variables ambientales y legales dando origen al análisis PESTEL, mediante el cual se analizan todos los factores del macroentorno y su impacto en la gestión corporativa.

En otra línea del análisis externo, Porter (1980) desarrolló el análisis de las cinco fuerzas como una metodología para analizar el microentorno de la compañía. Bajo este procedimiento se determina que existen cinco fuerzas que afectan el ambiente competitivo en el que se desenvuelve y que son fundamentales para entender el comportamiento de un sector en particular. Los aspectos por evaluar en el análisis de Porter son: 
- Poder de negociación de los compradores

- Poder de negociación de los proveedores

- Amenaza de nuevos competidores entrantes

- Amenaza de productos sustitutos

- Rivalidad entre competidores

Sin embargo, el análisis externo solamente representa una parte del diagnóstico, ya que también se deben identificar las fortalezas y las debilidades de cada una de áreas funcionales de la organización, esto se conoce como el análisis interno de la compañía. Para dicho propósito se ha establecido que independientemente de su estructura organizacional todas las empresas deben responder a las necesidades de seis áreas funcionales que son:

- Administración

- Finanzas

- Mercadeo

- Producción

- Talento Humano

- Tecnología

Las dos primeras matrices de diagnóstico que son la EFE y la EFI se construyen a partir de estos dos análisis. La matriz EFE permite identificar la posición de la compañía para enfrentar los factores del entorno, si el resultado de la matriz está por encima del valor 2,5 significa que la compañía se encuentra en una posición competitiva favorable frente al entorno, de lo contrario, las amenazas que enfrente la compañía son mayores a sus oportunidades. Por su parte, la matriz EFI permite identificar la posición interna de la compañía para el éxito de la estrategia; un resultado en esta matriz por encima del valor 2,5 indica que la compañía tiene una posición interna fuerte y que son mayores sus fortalezas que sus debilidades al momento de implementar la estrategia.

Por otro lado, también es importante identificar la posición estratégica de la compañía con respecto a sus competidores, este análisis se realiza por medio 
de la matriz de perfil competitivo que permite clasificar cada factor crítico de éxito presente en el sector para cada empresa es analizada a la siguiente escala:

- Gran fortaleza-4

- Fortaleza menor-3

- Debilidad menor-2

- Gran debilidad-1

Esta escala se multiplica por el peso dado a cada factor crítico de éxito, de tal manera que, el sumatorio total de ponderaciones arroja un puntaje total para cada compañía analizada. De acuerdo con este análisis la compañía con el mayor puntaje se considera la más fuerte del mercado competitivamente.

Otero y Gache (2006) ubican el nacimiento del análisis DOFA en la década de los sesenta, gracias a un equipo de la universidad de Stanford liderado por Albert Humphrey, varias décadas antes que otras herramientas de análisis descritas en este documento, sin embargo, gracias al desarrollo de matrices de análisis interno y externo esta metodología se reinventa y toma un papel central en el análisis estratégico. El análisis DOFA parte de la identificación de las fortalezas, debilidades, oportunidades y amenazas para que a partir un conocimiento profundo de la situación interna de la compañía y de su entorno se identifiquen las estrategias más idóneas a partir de cuatro cuadrantes estratégicos que son:

Estrategias del cuadrante FO: buscan utilizar las fortalezas de la compañía para aprovechar las oportunidades que ofrece el entorno; estas estrategias son de enfoque agresivo.

Estrategias del cuadrante FA: buscan utilizar las fortalezas de la empresa, para hacer frente a las amenazas del entorno, son consideradas estrategias de índole competitivo.

Estrategias del cuadrante DO: se enfocan en aprovechar las oportunidades del entorno para eliminar las debilidades de la compañía, son consideradas estrategias de carácter defensiva.

Estrategias del cuadrante DA: se enfocan en buscar caminos dirigidos a minimizar las debilidades para hacerle frente a un entorno hostil, este es el escenario menos deseado por una empresa. Las estrategias de este cuadrante son consideradas conservadoras. 
Posteriormente Rowe, Mason y Dickel (1982) desarrollaron la matriz de posición estratégica y evaluación de la acción, también llamada matriz SPACE que le permite al analista identificar el cuadrante estratégico dentro del cual se debe ubicar la empresa.

Para llegar a este cuadrante la matriz clasifica los factores internos y externos en cuatro cuadrantes de la siguiente manera:

Fuerza financiera: En este cuadrante se ubican los factores internos que están relacionados con las fortalezas y debilidades financieras de la compañía. Estos factores son calificados con una escala de 1 a 6 , donde un factor considerado como gran debilidad financiera se califica con 1 y uno considerado como gran fortaleza financiera se califica con 6 .

Ventaja Competitiva: En este cuadrante se evalúan los factores internos previamente identificados distintos a la fortaleza financiera, es decir que se tienen en cuenta factores internos de tipo administrativo, tecnológico, de mercadeo, de talento humano y de producción, estos se califican de -1 a - 6 siendo -1 una gran fortaleza de la compañía y - 6 una gran debilidad.

Estabilidad del Ambiente: En este cuadrante se ubican los factores externos evaluados en el análisis PESTEL, estos se califican de -1 a - 6, donde un factor calificado con -1 se considera una gran oportunidad y un factor calificado con - 6 representa una gran amenaza para la compañía.

Fuerza de la Industria: En este cuadrante se evalúan los factores externos provenientes del análisis de las Cinco Fuerzas de Porter en una escala de 1 a 6 . En la cual, los factores considerados como una gran amenaza se califican con un puntaje de 1 y los factores considerados como una gran oportunidad se califican con un puntaje de 6 .

Del resultado de esta evaluación de factores se obtiene la representación gráfica de la matriz, que ubica a la compañía en un cuadrante estratégico que guarda relación directa con los cuadrantes de la matriz DOFA. Los cuadrantes que componen el Grafico SPACE son los siguientes:

Cuadrante agresivo: Este es el cuadrante óptimo en el cual debería estar ubicada una compañía, corresponde a las estrategias FO de la matriz DOFA, donde se encuentran las estrategias que utilizan las fortalezas de la compañía para aprovechar las oportunidades del entorno. Sin 
embargo, para que una empresa se ubique en este cuadrante primero debe tener una clara ventaja competitiva y la capacidad financiera para poder desarrollar la estrategia.

Cuadrante Competitivo: Este cuadrante se relaciona con las estrategias FA de la matriz DOFA, es decir que la empresa debe utilizas sus fortalezas para hacer frente a las amenazas del entorno. En este cuadrante la empresa cuenta con la fortaleza financiera requerida para implementar la estrategia, sin embargo, debe desarrollar una ventaja competitiva con la cual hacerles frente a sus rivales en el mercado.

Cuadrante Conservador: En este cuadrante se ubican las estrategias DO de la matriz DOFA, las estrategias a desarrollar incorporan el aprovechamiento de las oportunidades del entorno para mitigar las debilidades de la empresa. En este cuadrante la compañía cuenta con ventajas competitivas pero su estrategia es limitada debido a su debilidad financiera.

Cuadrante Defensivo: Este cuadrante representa la situación más compleja a la que se enfrenta una compañía y corresponde a las estrategias DA de la matriz DOFA, las estrategias de este cuadrante están enfocadas en procurar transformar las debilidades en fortalezas para hacer frente a las amenazas del entorno. En esta situación la empresa se enfrenta a un entorno hostil con una debilidad financiera evidente y con pocas o nulas ventajas competitivas, dependiendo de la complejidad de la situación la liquidación o venta de la compañía son estrategias válidas.

Finalmente, bajo la metodología de Fred Davis la última etapa para la selección de la estrategia adecuada para la compañía la constituye la Matriz Cuantitativa de Planeación Estratégica. En esta se hace una valoración de las estrategias pertenecientes al cuadrante seleccionado de acuerdo con los resultados de la matriz SPACE. Cada estrategia identificada se evalúa a la luz de las fortalezas y debilidades previamente identificadas en las matrices EFI y EFE, de tal manera, que la estrategia con mayor puntuación es la estrategia que debe ser implementada por la compañía, y así concluir el proceso de Diagnostico Empresarial.

A partir de la identificación de la estrategia la compañía debe proceder a evaluar la viabilidad financiera de la misma y desarrollar la planeación estratégica necesaria para una adecuada implementación. Este plan estratégico se entrega al tutor y si es aprobado a la empresa. 
El proceso de simulación inicia con la identificación de los factores críticos de éxito tanto de carácter externo, como interno. En primer lugar, el estudiante evalúa los factores externos y en segundo lugar los internos. Simultáneamente, en la identificación de factores externos primero se realiza la evaluación del macroentorno mediante el análisis PESTEL y posteriormente la del microentorno mediante el análisis de las cinco fuerzas de Porter.

Al momento de realizar el análisis PESTEL el estudiante debe identificar quince factores y clasificarlos de acuerdo a los componentes del análisis (Político, Económico, Social, Tecnológico, Ecológico y Legal); adicionalmente, debe ser descrito y justificado detalladamente, así como clasificarlos en función del análisis DOFA como Oportunidad o Amenaza para asignarles el nivel de impacto que tienen para la organización en una escala de cero a tres, en la que cero equivale a un impacto nulo y tres a un impacto alto. Finalmente, el estudiante determina el orden de importancia de las variables clasificándolas en un ranking del uno al quince.

El proceso de análisis del microentorno con las Cinco Fuerzas de Porter se desarrolla bajo el mismo esquema del paso anterior (PESTEL) pero los componentes deben clasificarse según los siguientes factores:

- Poder de negociación de clientes

- Poder de negociación de proveedores

- Amenaza de nuevos competidores entrantes

- Amenaza de nuevos productos sustitutos

- Rivalidad entre competidores

El siguiente paso en la simulación es la construcción del ranking externo el cual se realiza teniendo en cuenta los diez principales factores críticos de éxito del análisis del macroentorno (PESTEL) y los diez principales factores clave de éxito del análisis del microentorno (PORTER). De este total de veinte factores el estudiante debe hacer una escala que identifique el orden de importancia de los factores externos.

La siguiente etapa en la simulación, es el análisis de factores internos; en este punto el estudiante identifica los treinta factores críticos de éxito que desde la óptica interna tienen el mayor impacto en el desarrollo de la estrategia de la compañía. Estos factores se clasifican de acuerdo con las áreas básicas de 
cualquier organización donde se identifican las áreas de finanzas, producción, mercadeo, talento humano, administración y tecnología. Además, para cada factor crítico de éxito el estudiante debe hacer una descripción detallada, clasificarlo de acuerdo con el análisis DOFA como debilidad o fortaleza y determinar cuál es su magnitud de impacto en una escala de cero a tres, donde, cero implica un impacto nulo y tres es un impacto alto.

Una vez se supera esta etapa de identificación y clasificación, el proceso de simulación pasa a la realización del ranking interno. Para esto, el simulador le muestra al estudiante los factores críticos de éxito con la mayor magnitud de impacto, así el podrá ubicarlos de acuerdo con su orden de importancia, de tal modo que obtenga como resultado el ranking interno con los veinte factores críticos de éxito más relevantes para la compañía.

Es importante que se realicen los rankings internos y externos porque facilitan el proceso de construcción de las matrices de análisis estratégico necesarias para el Diagnóstico Empresarial.

La primera matriz que el estudiante elabora en el proceso de simulación es la de evaluación de factores internos (MEFI). Para este proceso el simulador le muestra al estudiante una tabla con los veinte principales Factores Críticos de Éxito del Análisis Interno. Estos se separan en fortalezas y debilidades, y se ordenan de acuerdo con la importancia dada en el ranking. En primer lugar, el estudiante analiza las fortalezas y continúa con las debilidades. Adicionalmente, la matriz contiene otras tres columnas con los datos Peso, Calificación y Puntuación para que el estudiante disponga de esta información.

En la columna Peso el estudiante ingresa el peso que ocupa cada factor crítico de éxito con un valor que pude ir desde 0,01 hasta 0,99. Con la limitante de que la sumatoria de los pesos para Fortalezas y Debilidades debe ser igual a $1(100 \%)$

La columna Calificación tiene dos subcolumnas que son Tipo y Número. En la primera el estudiante clasifica los factores críticos de éxito de la siguiente manera: las fortalezas se identifican como Fortaleza Mayor (4) o Fortaleza Menor (3) y las debilidades se identifican como Debilidad Menor (2) o Debilidad Mayor (1).

Finalmente, en la columna Puntuación el simulador le muestra al estudiante para cada factor crítico de éxito el resultado de multiplicar la columna Peso con la subcolumna Número. El resultado de sumar y totalizar esta puntuación 
corresponde a la posición interna de la compañía; cabe recordar que una puntuación por encima de 2,5 significa que la posición interna de la compañía es fuerte, de lo contrario se dice que la compañía tiene una posición interna débil.

La segunda matriz que se desarrolla en el proceso de simulación es la Matriz Cuantitativa de factores Externos (MEFE). Para este proceso el simulador le muestra al estudiante una tabla con los veinte Factores Críticos de Éxito identificados en el ranking externo. Estos se separan en oportunidades y amenazas y se ordenan de acuerdo con la posición que ocupan en el ranking externo. En primer lugar, el estudiante analiza las oportunidades y en segundo lugar analiza las amenazas. Adicionalmente, de la misma manera que ocurre en la MEFI, el estudiante tiene a su disposición tres columnas más con la información del Peso, Calificación y Puntuación.

En la columna Peso el estudiante ingresa el peso que ocupa cada factor crítico de éxito con un valor que pude ir desde 0,01 hasta 0,99. Con la condición de que la sumatoria de los pesos para Fortalezas y Debilidades debe ser igual a $1(100 \%)$

La columna Calificación tiene dos subcolumnas tituladas Tipo y Número. En la subcolumna Tipo el estudiante clasifica los factores críticos de éxito como Respuesta Superior (4), Respuesta superior a la Media (3), Respuesta Media (2), Respuesta Mala (1).

Finalmente, en la columna Puntuación el simulador le muestra al estudiante para cada factor crítico de éxito el resultado de multiplicar la columna Peso con la subcolumna Número. Esta puntuación se suma y se totaliza con el propósito de identificar la posición externa de la compañía; cabe recordar que una puntuación superior a 2,5 significa que le empresa tiene una posición competitiva fuerte para aprovechar las condiciones del entorno, lo contrario deja ver que la compañía tiene una posición competitiva débil.

El proceso de simulación continúa con el desarrollo de la Matriz de Perfil Competitivo (MPC). El sistema trae a la matriz el nombre de la empresa analizada y por su parte el estudiante ingresa el nombre de las tres empresas consideradas como las principales competidoras. Adicionalmente, el sistema trae los factores críticos de éxito y su peso de la MEFE, que han sido alimentados previamente en el sistema, para ser evaluados para la empresa y para los tres competidores según la siguiente escala de calificación: 
- Gran fortaleza (4)

- Fortaleza Menor (3)

- Debilidad Menor (2)

- Gran Debilidad (1)

Finalmente, el sistema muestra un puntaje para cada factor crítico de éxito que surge como resultado de multiplicar su Peso por la subcolumna Número perteneciente a la columna Calificación. La sumatoria del puntaje de todos los factores críticos de éxito para cada empresa da como resultado un valor numérico con el cual se identifica la posición competitiva de las empresas analizadas dentro de la rama de negocio analizada.

La siguiente etapa de la simulación corresponde al análisis DOFA, para este proceso el simulador trae los dieciséis factores externos más importantes conforme al ranking externo y los dieciséis factores internos más importantes de acuerdo al interno, estos se clasifican en el cuadrante respectivo de acuerdo a su correspondencia con fortalezas, oportunidades, debilidades o amenazas. A partir de estos factores críticos de éxito el estudiante propone las estrategias para los cuadrantes FO, FA, DO y DA.

Posteriormente se inicia el proceso de depuración de la estrategia, el cual se desarrolla con la matriz SPACE. El simulador muestra una matriz dividida en cuatro cuadrantes dos a la derecha correspondientes a la posición estratégica interna y dos a la izquierda correspondientes a la posición estratégica externa, también corresponden a la fuerza financiera y ventaja competitiva. En cambio, los dos de la derecha corresponden a estabilidad del ambiente y a fuerza de la industria. Los factores de la posición estratégica interna corresponden a los dieciséis primeros del ranking interno y los factores de la posición estratégica externa son los dieciséis primeros del ranking externo.

En el cuadrante de Fuerza Financiera el simulador ubica los factores internos identificados como pertenecientes al área financiera. El estudiante debe calificar cada factor de uno a seis donde uno representa una gran debilidad y seis una gran fortaleza.

En el cuadrante de Ventaja Competitiva el simulador incluye los factores internos distintos a los pertenecientes al área financiera; estos se califican de: -1 a -6, donde - 1 representa una gran fortaleza y -6 una gran debilidad. 
En los cuadrantes de la posición estratégica externa en primer lugar se encuentra la Estabilidad del Ambiente, en este cuadrante el simulador trae los factores pertenecientes al análisis PESTEL y el estudiante debe calificarlos de: -1 a -6 , donde -1 implica una oportunidad importante y -6 una gran amenaza.

Para culminar la matriz SPACE es necesario que el estudiante evalúe el último cuadrante correspondiente a la Fuerza de la Industria. En este, el simulador trae los factores pertenecientes al análisis de las cinco fuerzas de Porter, y el estudiante debe calificar cada factor de 1 a 6 , donde 1 representa una gran amenaza y 6 representa una gran oportunidad.

A partir del análisis realizado por el estudiante se obtienen los insumos para que el simulador construya el grafico de la matriz SPACE. A partir del gráfico se identifica el cuadrante estratégico en el que se ubica la compañía. Que como ya se describió, está directamente relacionado con los cuadrantes estratégicos de la matriz DOFA. Los cuadrantes del gráfico SPACE son los siguientes:

- $\operatorname{Agresivo(FO)}$

- Competitivo (FA)

- Conservador (DO)

- Defensivo (DA)

En este punto, el simulador no solamente identifica el cuadrante estratégico de la compañía, sino que muestra al estudiante las estrategias que corresponden a lo desarrollado previamente en el análisis DOFA.

La etapa final del proceso de simulación consiste en identificar la estrategia óptima para la compañía la cual realiza el estudiante con la ayuda de la matriz cuantitativa de planeación estratégica. El simulador trae todos los factores críticos de éxito con sus respectivos pesos de las matrices EFI y EFE para que el estudiante pueda evaluar cada estrategia perteneciente al cuadrante estratégico identificado en el análisis SPACE. En el proceso de calificación el estudiante clasifica cada una de la siguiente forma:

- No atractiva (1)

- Poco atractiva (2)

- Razonablemente atractiva (3)

- Muy atractiva (4) 
A partir de la clasificación anterior el simulador calcula una puntuación para cada estrategia a partir de la sumatoria de las puntuaciones individuales de cada factor clave de éxito. Esta puntuación se obtiene a partir de la multiplicación del peso del factor con el número correspondiente a la calificación asignada. Finalmente, el estudiante selecciona la estrategia que obtiene la mayor puntuación para ser implementada por la compañía.

\section{Desarrollo de la experiencia de aprendizaje}

En primera instancia se realizó la estrategia de aprendizaje basada por proyectos, para ello fue construida una guía metodológica para que fuera posible la realización del diagnóstico empresarial por parte del estudiante. Posteriormente, para mejorar el módulo se realizó un aplicativo en Excel que permite la elaboración de las matrices estratégicas, este es el inicio del simulador.

Se planteó entonces la construcción de una estrategia de aprendizaje que continuara con la misma estrategia de formación por proyectos como fue estructurado el módulo, con la incorporación de la herramienta de simulación, para ello se tomaron del sílabo del módulo de Diagnóstico Empresarial las competencias a desarrollar en la simulación como punto de partida para la creación de la ficha pedagógica y técnica de la herramienta. Se extrajo del aplicativo en Excel la lógica de funcionamiento para el simulador y se implementó dentro del mapa conceptual, luego se elaboró el mapa de tareas que contiene las acciones y respuestas de cada una de las entidades que intervienen en el proceso pedagógico de simulación (estudiante, tutor, herramienta, material complementario y del aula). El propósito es que la herramienta esté vinculada con lo que sucede en el módulo.

Se inició la redacción de la escaleta, la cual ofrece las indicaciones para el diseño de las interfaces y del contenido gráfico de cada escenario virtual. Con los escenarios se inició la redacción de los guiones, los cuales como paso final fueron probados para pasar al diseño gráfico y a la programación.

Se creó un personaje de ayuda que es transversal a todos los proyectos de simulación del área administrativa denominado Mila. Ver figura 1. 


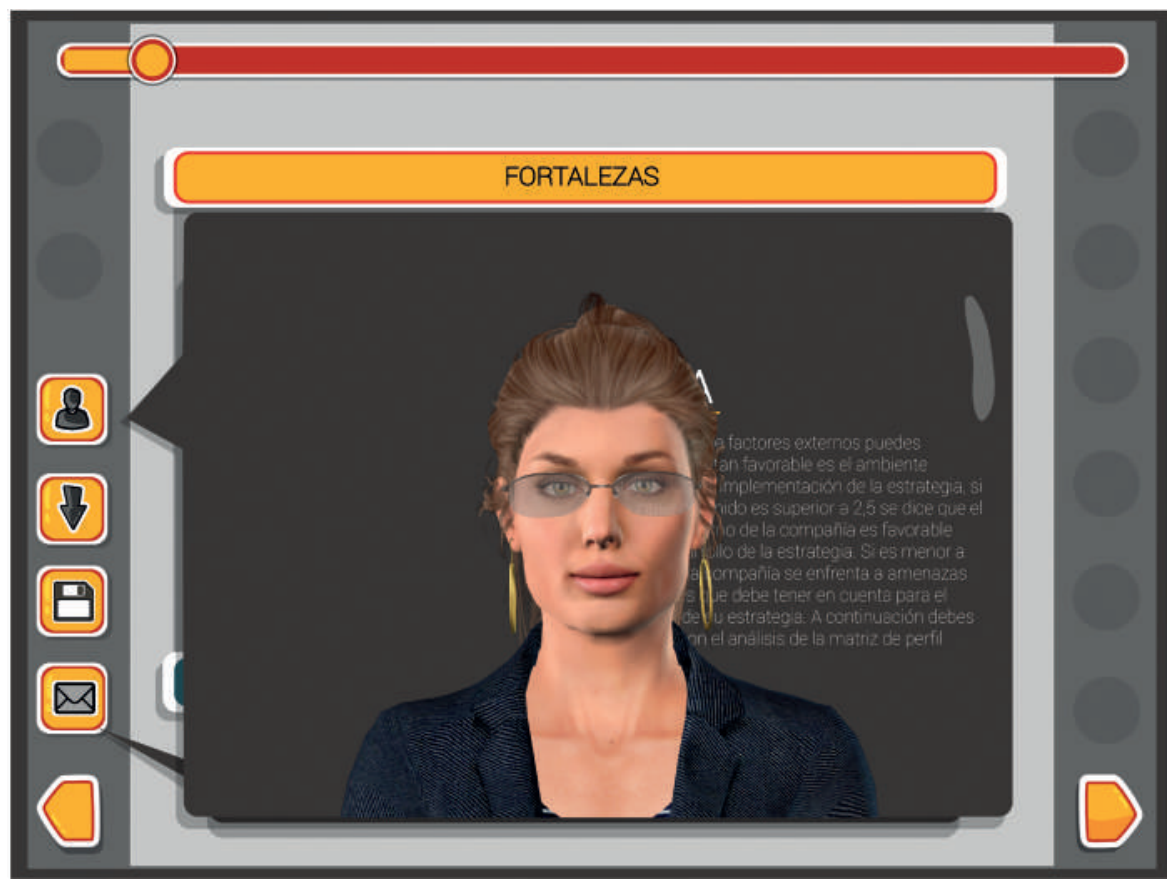

Figura 1. Personaje de interacción Mila.

Fuente: Politécnico Grancolombiano.

Para facilitar la navegación y que sea una herramienta intuitiva se introdujo un menú en la parte superior que direcciona a las matrices de análisis estratégico. Cada botón corresponde a una matriz que activa a medida que el estudiante va adelanta el proceso de simulación, esto porque múltiples resultados que ingresa el estudiante dependen de lo que el simulador le arroja o le trae de matrices anteriores.

A la izquierda, de forma vertical, se implementó otro menú con botones que son transversales a toda la simulación y sirven para descargar informes en Excel, guardar un parcial de la información, avatar de ayuda por si requiere alguna explicación acerca del funcionamiento o informar sobre lo que debe hacer en el escenario. En la figura 2 se pueden apreciar los dos menús. 


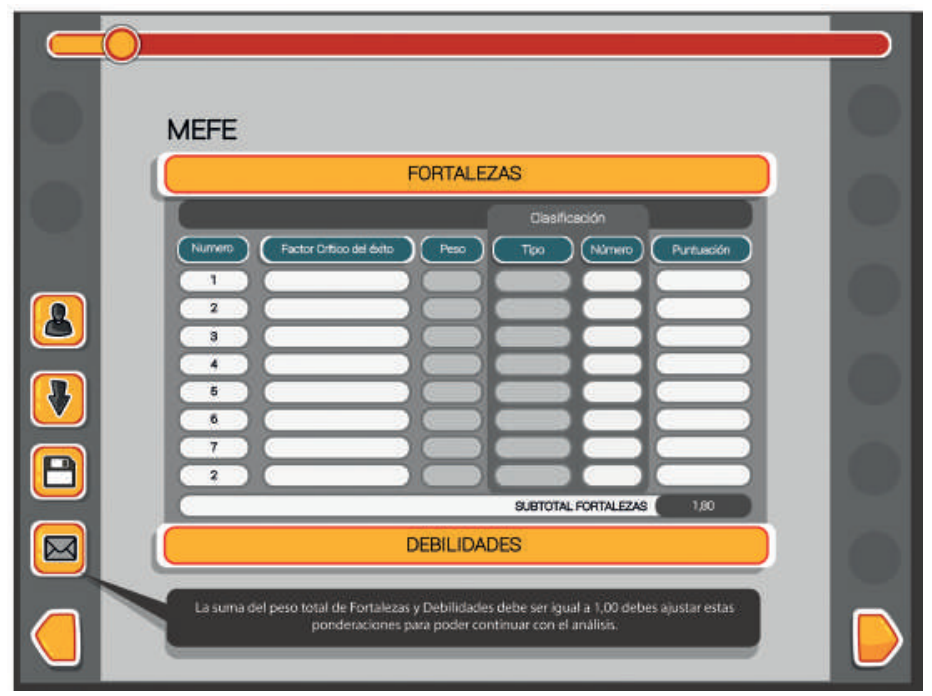

Figura 2. Menú horizontal de las matrices y menú a la izquierda de funcionalidad.

Fuente: Politécnico Grancolombiano.

Para cada matriz se diseñó una interface de acuerdo con las acciones que hace el estudiante dentro de ella, el estudiante consigna la información y la ve conforme a lo que se programó en la parte de desarrollo. Cada matriz la puede descargar en Excel o guardar con información parcial para salir y continuar trabajando cuando realice su próximo ingreso. Ver figura 3.

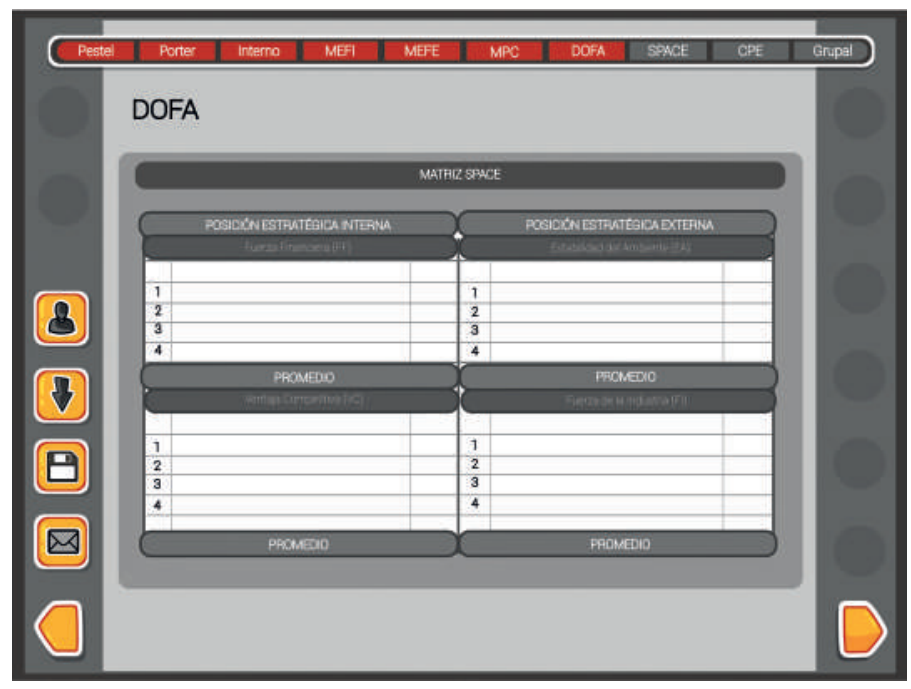

Figura 3. Interface para cada matriz.

Fuente: Politécnico Grancolombiano. 
El diseño de cada escenario corresponde a las especificaciones y necesidades académicas y solo se modificó en cuanto a la usabilidad en los casos en que el autor lo haya solicitado. Todas las herramientas de simulación de la institución tienen una etapa de verificación en su funcionamiento y diseño durante la realización del mismo por parte del tutor y de los asesores pedagógicos. Sin dicha verificación ninguna versión beta de los simuladores se publica a los estudiantes porque un mal funcionamiento de la herramienta puede causar el efecto contrario del que se espera. En la figura 4 se puede ver cómo se diseñó el escenario con los elementos que solicitó el autor en el guion.

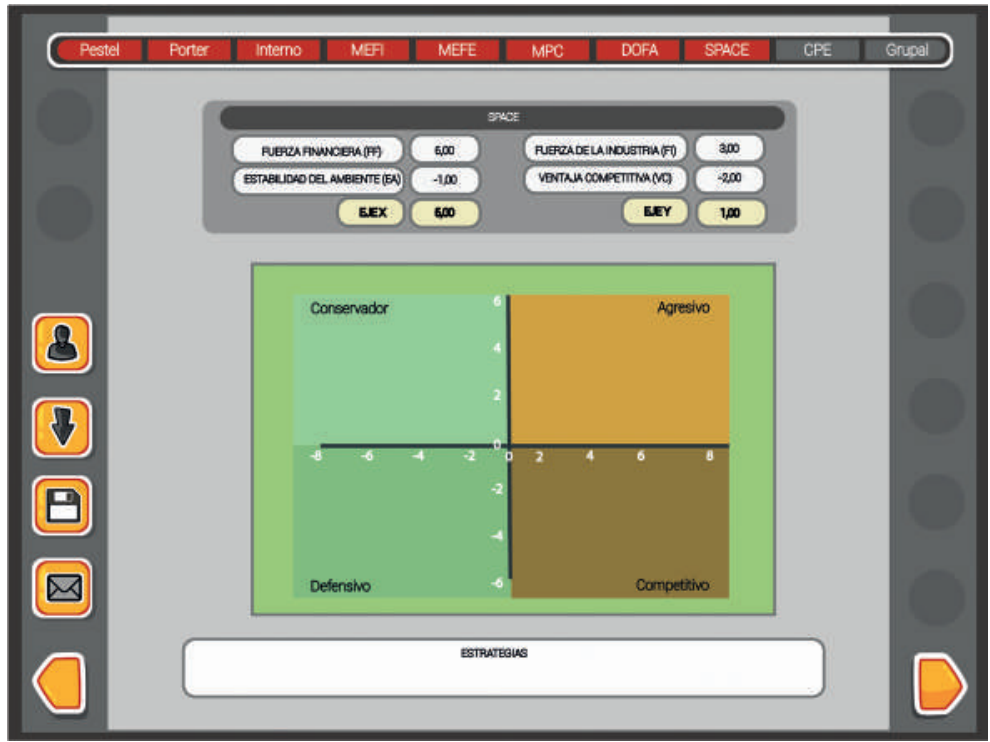

Figura 4. Interface de acuerdo con los requerimientos académicos.

Fuente: Politécnico Grancolombiano.

\section{Resultados obtenidos}

A partir de la identificación de la estrategia, el estudiante debe continuar con el proceso de planeación estratégica por fuera del simulador. Dentro de la estrategia pedagógica el estudiante debe cuantificar el impacto de la implementación de la estrategia desde el punto de vista financiero, del mismo modo, debe determinar los objetivos, metas e indicadores para que el empresario pueda medir la evolución de la estrategia propuesta.

Uno de los resultados más importantes es que desarrolló una herramienta que hace un diagnóstico de la compañía desde diversas perspectivas y le 
permite al estudiante evidenciar según la información que tiene las principales debilidades, oportunidades, fortalezas y amenazas que enfrenta la empresa. Asimismo, permite establecer diversas estrategias que puede implementar en su plan para la empresa.

\section{Conclusiones}

La herramienta que se creó una herramienta permite al estudiante centrarse en el análisis para elaborar un diagnóstico más profundo de una organización a través de un análisis matricial.

La estrategia pedagógica para el módulo está pensada para que el estudiante dé una solución integral y estratégica a lo que enfrenta una empresa en su realidad, lo que contribuye no solo a un mejoramiento de la responsabilidad social de la institución, sino que permite crear alianzas y consultorías con las empresas donde se benefician las organizaciones y la institución.

La implementación de la herramienta en las aulas virtuales y presenciales da origen a otros procesos de investigación para evidenciar la utilidad del software en la adquisición de las competencias y en el mejoramiento del proceso de aprendizaje por parte de los estudiantes.

\section{Bibliografía o referencias}

Bottoms, G., \& Webb, L.D. (1998). Connecting the curriculum to "real life." Breaking Ranks: Making it happen. Reston, VA: National Association of Secondary School Principals. (ERIC Document Reproduction Service No. ED434413)

Carreras C., Yuste M. y Sánchez J. (2007). La importancia del trabajo experimental en física: un ejemplo para distintos niveles de enseñanza, Rev. Cubana de Física 24, 80-83

Davis, F. R. (2003). Conceptos de administración estratégica. Pearson Educación, México.

Drucker, P. F. (1954). The practice of management: A study of the most important function in America society. Harper \& Brothers.

Fahey, L., \& Narayanan, V. K. (1986). Macroenvironmental analysis for strategic management. St. Paul, MN: West Publishing Company, p. 58. 
Fondo Social Europeo. (2012). Competencias para la inserción laboral - Guía para el profesorado. Unión Europea - Ministerio de Educación, Cultura y Deporte de España, p. 21. Disponible en: http://www.sepe.es/LegislativaWeb/verFichero. do?fichero $=09017$ edb800f8507

Mintzberg, H., Quinn, J. B., \& Voyer, J. (1997). El proceso estratégico: conceptos, contextos y casos. Pearson Educación.

Porter, M. (1980). Las 5 fuerzas de Porter. Cambridge: Harvard Business School.

Otero, D; Gache, F L; (2006). Evoluciones dinámicas en el diagrama FODA. Revista Científica "Visión de Futuro", 6. Recuperado de http://www.redalyc.org/articulo. oa?id=357935465001

Rowe A., Mason R. y Dickel K. (1982) "Strategic Management and Business policy: A Methodological Approach". Addison-Wesley, New York.

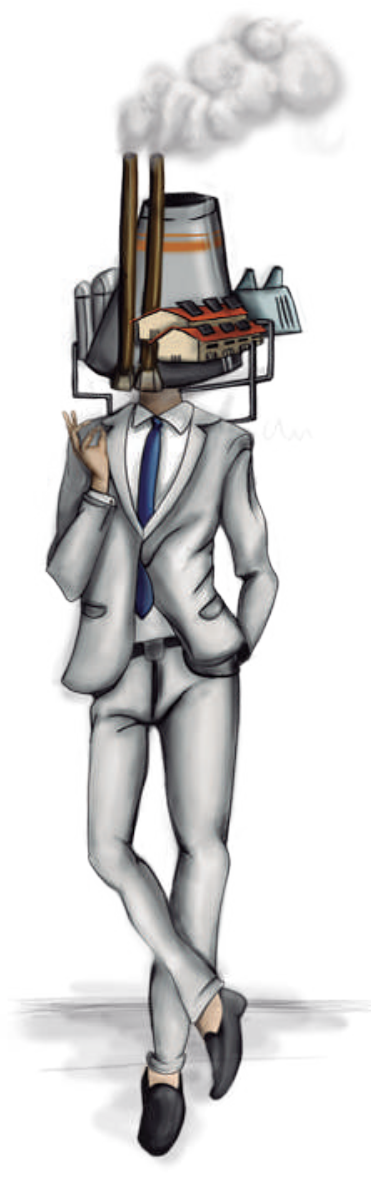




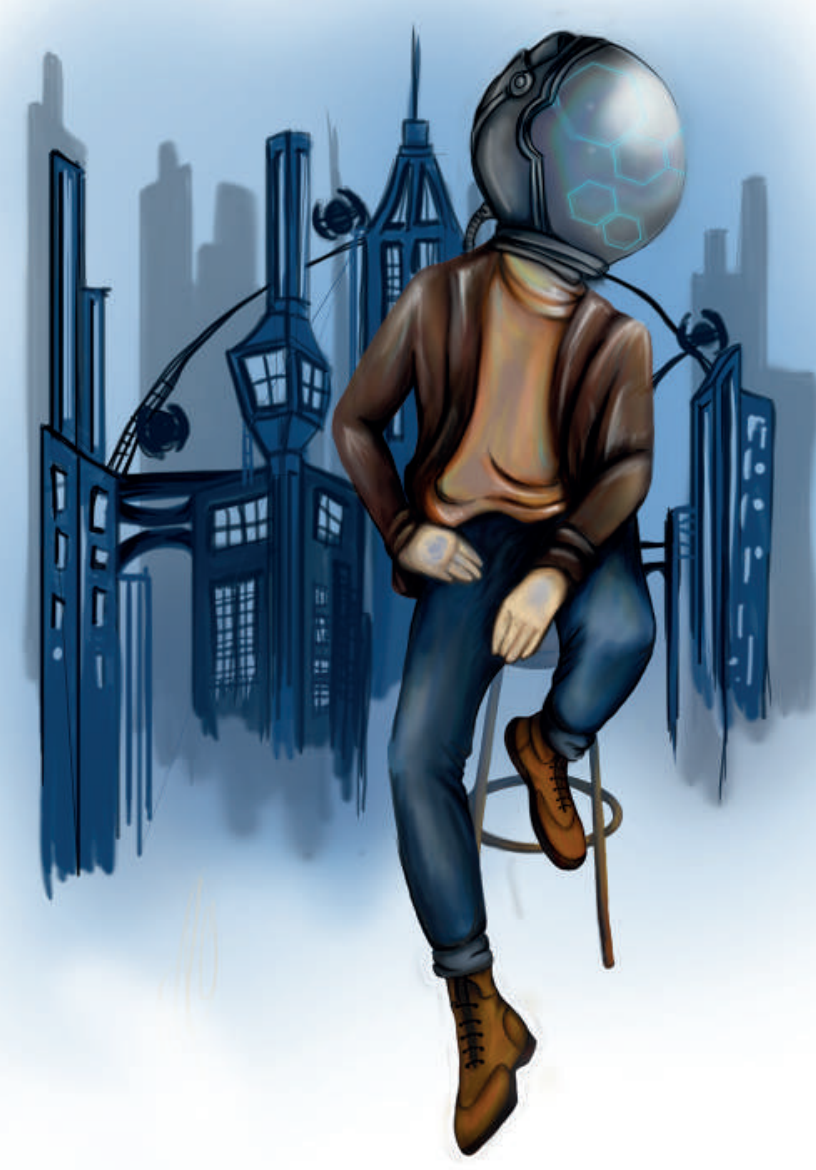

- Capítulo 2 -

\section{Simulador de análisis prospectivo}

\section{Autores}

Ronald Mauricio Martínez Contreras. Administrador de empresas egresado del Politécnico Grancolombiano y Magister en Administración Financiera de la universidad Sergio Arboleda, con más de 10 años de experiencia en cargos directivos y ejecutivos en empresas del sector real, financiero y de servicios, 
vinculado al sector educativo desde hace más de cuatro años y en la actualidad es Director del Departamento Académico de Administración del Politécnico Grancolombiano.

Correspondencia: romartin@poligran.edu.co

Luis Martín Trujillo Flórez. Ingeniero electricista egresado de la Universidad Nacional de Colombia. Máster en Edición Universitaria Universidad de Salamanca. Maestría en Ambientes Virtuales de Aprendizaje Universidad de Panamá. Especialista en virtualidad Centro de Altos Estudios de Argentina. Coordinador del Laboratorio de innovación pedagógica Politécnico Grancolombiano.

Correspondencia:mtrujilo@poligran.edu.co

\section{Diseñador de interfaces del simulador}

Mónica Carrero Becerra. Diseñadora gráfica e ilustradora del Politécnico Grancolombiano. Tecnóloga en multimedia del Servicio Nacional de Aprendizaje. Actualmente se desempeña como diseñadora del Laboratorio de innovación pedagógica del Politécnico Grancolombiano.

Correspondencia:mncarrero@poligran.edu.co

\section{Resumen}

Ante la necesidad de contar con un software de prospectiva que integrara diferentes técnicas y herramientas de análisis y a su vez, tuviera un alto componente pedagógico, se desarrolló el proyecto denominado "Simulador de Análisis Prospectivo". Con este propósito se hizo una revisión conceptual y metodológica del proceso de análisis prospectivo con el fin de desarrollar la herramienta tecnología más idónea para la identificación de escenarios futuros partiendo del análisis de las tendencias clave de índole interno y externo que pueden afectar a una organización en un horizonte temporal de diez años. Gracias a este proceso investigativo se desarrolló una herramienta tecnológica que facilita el proceso de aprendizaje de los estudiantes con una metodología teórico-práctica y que traerá beneficios académicos en dos frentes, en primer 
lugar, mejorará la calidad de los proyectos de investigación de los estudiantes $y$, en segundo lugar, fortalecerá la relación con el sector externo debido al mejoramiento de la calidad en el análisis prospectivo realizado por los estudiantes.

\section{Palabras claves}

Análisis Estructural, DOFA, Escenarios, Futuribles, Hipótesis, Mic-Mac, PESTEL, Prospectiva.

\section{Introducción}

El análisis prospectivo es uno de los conceptos administrativos que más debate ha generado en las últimas décadas debido a que la posibilidad de idear escenarios futuros para algunos expertos todavía se acerca más al campo de la adivinación que al de la administración. Sin embargo, los cambios abruptos en los mercados que provocaron los cambios en las dinámicas empresariales, además de las crisis financieras de nuestro siglo, le han dado mayor relevancia a la creación de escenarios futuros que conduzcan a una planeación estratégica. De hecho, recientemente nació un concepto nuevo denominado Riesgo Estratégico en el que se enmarca la planeación estratégica y la prospectiva empresarial (Ryan, 2017), bajo esta óptica la planeación por escenarios se vuelve una necesidad de todas las empresas porque les permite anticiparse a los riesgos potenciales que puedan enfrentar en el corto, mediano y largo plazo.

El propósito del análisis prospectivo es la identificación de diferentes escenarios posibles a partir del análisis de las tendencias clave que pueden afectar el desempeño futuro de una organización. Este análisis y depuración de variables se hace mediante diferentes técnicas y herramientas que ayudan a que el resultado sea el más acertado posible. En este mismo contexto diversos autores, a lo largo de la historia, han desarrollado variadas herramientas como el método Delphi, las matrices de análisis estructural, el método de escenarios y los arboles de competencias que han dotado al análisis prospectivo bases metodológicas que sustentan su aplicabilidad en la gestión empresarial.

A partir de tales herramientas y ante la necesidad de fortalecer en los estudiantes la capacidad de realizar un adecuado análisis estratégico surge la oportunidad 
de desarrollar una estrategia de aprendizaje que le permita al aprendiz integrar diferentes técnicas de análisis prospectivo, de tal manera que utilizando un método organizado pueda analizar y depurar los datos hasta llegar a los escenarios futuros más probables a los que se puede enfrentar una compañía en un horizonte de diez años. De esta manera, disminuir considerablemente la incertidumbre asociada a los sucesos futuros y realizar una planeación más estructurada.

El inicio del proceso se inició con la creación de un método para el análisis prospectivo que reúne varias técnicas combinadas con aportes del autor, dicho método fue implementado en un archivo de Excel que los estudiantes pueden trabajar. Sin embargo, para lograr una experiencia más amplia de aprendizaje, se desarrolló un simulador que integra el método elaborado (incluye un análisis de probabilidades que no está en el Excel) con una estrategia pedagógica que involucra la simulación al módulo o asignatura de Pensamiento Estratégico y Prospectiva.

Desde lo académico, el simulador le permite al estudiante hacer un diagnóstico de los escenarios futuros para cualquier empresa real, a través de un proceso metódico que lo lleva a la selección de las tendencias clave hasta llegar a la construcción de los escenarios más probables y finalmente a la selección del escenario meta.

En el desarrollo del simulador se integraron en un sistema dos funciones inexistentes en el mercado; la primera, integrar en un sólo software diversas técnicas de análisis prospectivo; la segunda, está enfocada en brindar una solución pedagógica amigable para los estudiantes de los programas de pregrado y posgrado de Administración de Empresas del Politécnico Grancolombiano.

\section{Marco teórico}

\section{Problemática que atiende}

En el aprendizaje de la prospectiva existe una dificultad que se evidencia en el desarrollo de los proyectos de aula y se vuelve la pregunta inicial para este proyecto: ¿Cómo evidenciar en un contexto real los conceptos de prospectiva que estudia el aprendiz? 
Esa es una de las mayores dificultades que se encontró en el desempeño de los estudiantes. Gran parte de lo que ve el estudiante se queda en conceptos y definiciones, poco se logra en la construcción de escenarios. De allí, surge la necesidad de crear una estrategia de aprendizaje que permita al estudiante aplicar lo visto en la teoría del módulo o asignatura a una empresa real y lo lleve a establecer un escenario - meta que le permita diseñar su estrategia gerencial.

En el módulo o asignatura de Pensamiento Estratégico y Prospectiva (en donde se aplica esta experiencia) el proyecto de aula consiste en tomar una organización y realizar un análisis prospectivo de la misma, con dicho análisis se tiene el insumo para elaborar la planeación estratégica de la empresa con miras a ser aplicada en el futuro y que le produzca mejores resultados. Con este proyecto de aula se evidencian algunas dificultades por parte de los educandos, el primero de ellos es la adecuada definición de variables que conduzcan a un correcto análisis, para ello el tutor los orienta con el fin de que ellos puedan depurar sus variables y hacer un análisis más cercano a la realidad empresarial. La segunda dificultad es que los estudiantes en su gran mayoría no saben aplicar los métodos de análisis dedicándose más a la parte procedimental que a la parte de diagnóstico, definición de variables y análisis que es lo más importante, por consiguiente, pierden mucho tiempo en la aplicación de los métodos y al no obtener unas hipótesis adecuadas los escenarios no llegan a ser del todo consistentes, por ende, la planeación estratégica con el escenario meta no logra lo que se espera.

A partir de esta dificultad nace la primera problemática a la que se enfrentó el proyecto, integrar un método de análisis prospectivo que iniciara con la identificación de las variables, su definición, su nivel de impacto, hasta llegar a la selección del escenario meta. Para esto fueron consultadas e integradas varias metodologías ya existentes, lo cual derivó en la construcción de un método con aportes propios del autor.

El método inicia con la definición de las variables que pueden afectar en el futuro a la empresa a nivel interno y externo, también se tiene en cuenta la evaluación del posible impacto en la compañía. En cada análisis se depuran las variables hasta cuantificar posibles probabilidades de ocurrencia, asimismo se analiza la dependencia que tienen con otras variables y cómo estas afectan a la compañía directa e indirectamente. De esa manera, la construcción de escenarios se vuelve un juego que depura las rutas de mayor probabilidad para construir desde allí los escenarios más factibles. Al final del proceso se 
encuentran los diez escenarios con una alta probabilidad de ocurrencia para que el estudiante elija el escenario meta y desde allí construya su estrategia gerencial. Es decir, el proceso involucra lo que un gerente debe hacer cuando aplica la prospectiva a su organización. Luego le apuesta a un escenario meta donde enfoca su estrategia gerencial que es la parte final de la experiencia de aprendizaje.

Con este método de análisis se procedió a crear un aplicativo en Excel que integra las técnicas y el estudiante ingresa la información permitiéndole superar la dificultad procedimental, de esta manera, puede centrarse más en el análisis prospectivo. El aplicativo acompaña al estudiante hasta la creación de las diferentes hipótesis que afectarán los escenarios.

A partir del aplicativo en Excel se procedió a desarrollar el simulador que incluye la evaluación de las hipótesis de acuerdo con su probabilidad de ocurrencia, dentro de la programación se tuvo la gran dificultad de hacer un algoritmo que analizara las rutas de mayor probabilidad y fuera construyendo los escenarios más probables. Para superar este obstáculo se recurrió a la programación de grafos y árboles de decisiones, al final el software le entrega al estudiante los diez escenarios más probables.

Para este aspecto se estudiaron otras experiencias similares y se encontró que el simulador desarrollado en este proyecto supera las iniciativas anteriores, como las desarrolladas por el Ministerio de Relaciones Exteriores de Francia junto con France Telecom y otras empresas asociadas quienes han creado herramientas gratuitas de análisis prospectivo.

Los dos elementos que se trabajan con el simulador son la incorporación de todo el proceso de análisis prospectivo en un solo software y una plataforma amigable con el usuario que le permita tener claridad de los resultados encontrados en todas las etapas del análisis prospectivo. Además, el simulador permite que los contenidos temáticos del módulo relacionado sean trabajados de forma práctica, de tal manera que los temas pueden ser contrastados con la realidad empresarial. Tal vez la característica más importante que tiene el simulador es que puede ser aplicado a cualquier tipo de empresa y en cualquier etapa de su ciclo de vida. 


\section{Estrategia de aprendizaje}

El aprendizaje de la prospectiva en la era del conocimiento cada día adquiere mayor relevancia, hoy en día el análisis de lo que puede suceder en el futuro no solo activa la imaginación sino la creatividad a través de la generación de ideas e hipótesis que permitan adelantarse a lo que pueda suceder, también permite desarrollar la capacidad de innovar al implementar en la estrategia gerencial procesos y proyectos que no se han realizado, es tener la capacidad de afrontar nuevos retos. Ya no se trate de dejar el futuro al azar sino analizar las probabilidades de acuerdo con los comportamientos, la información de lo que ocurre en el entorno, las dinámicas económicas y sociales que permitan a futuro tomar las decisiones más acertadas que permitan hacer de la incertidumbre una oportunidad.

Según Quiroga (2008) "La gestión del conocimiento y el uso de herramientas que faciliten el diseño y construcción del futuro de las empresas, disminuyen los riesgos organizacionales". Significa que las decisiones empresariales tomadas en ambientes de incertidumbre conllevan a altos riesgos debido a la competencia global. Es por lo que la creación de escenarios que permitan la adecuada toma de decisiones por parte de los actores directamente relacionados disminuye estos riesgos en forma considerable, percibiéndose la importancia y necesidad que la empresa posea herramientas de gestión como la prospectiva empresarial, que permite diseñar y construir el futuro con el menor riesgo posible y con el mayor grado de probabilidad de ocurrencia, aún en ambientes de incertidumbre (Quiroga, 2008).

La disminución de la incertidumbre fue el punto de partida para la estrategia pedagógica que después dio origen al simulador. La incertidumbre disminuye si identificamos las mayores probabilidades de ocurrencia de un fenómeno. Por tal razón, tanto el simulador como la experiencia de aprendizaje se fundamentan en los principios básicos de la prospectiva que son:

- No existe un solo camino para el negocio.

- El pasado no explica el futuro.

- Se requiere una gestión de los negocios activa y creativa.

Por lo tanto, atendiendo el primer principio, el proceso de simulación se basa en que el estudiante seleccione las posibles variables y las clasifique de acuerdo con los factores externos e internos que puedan tener incidencias futuras en la organización. 
Para el segundo principio, a partir de las tendencias claves del negocio se plantean hipótesis de las cuales se crean los escenarios futuros.

Para el tercer principio, la propuesta es que el estudiante, a partir de su experiencia de simulación y con su escenario meta, construya la estrategia gerencial completa para implementar en la compañía.

Teniendo estos tres principios empezamos a trabajar en una estrategia pedagógica que nos permitiera evidenciar un análisis prospectivo en una empresa real. Como primera medida se implementó en el módulo o asignatura un proyecto de aula donde los equipos de estudiantes seleccionaban una empresa y aplicaban algunos métodos de análisis como el Delphi, el análisis PESTEL, el método MIC-MAC, entre otros. En la mayoría de casos el estudiante se complicaba más en la aplicación de los métodos que en procurar construir una información de calidad que permitiera un mejor diagnóstico de la empresa, pues la mayor dificultad radicaba en una correcta definición de las variables que afectan la empresa y de las hipótesis para la creación de escenarios.

Pensamos, entonces, en una estrategia que hiciera que los estudiantes se preocuparán más por el análisis que por la aplicación de un método específico. Esa es una de las ventajas del simulador, que permite al estudiante concentrarse en un análisis más profundo de la empresa que en seguir los pasos adecuados para aplicar el método. Para ello se creó un aplicativo en Excel que se aplicó en los estudiantes con buenos resultados. De dicho aplicativo nace la idea de convertirlo en un simulador, pues se pretende un aprendizaje más significativo para el estudiante, y no sólo se enfrenta al análisis, sino que existe un gerente que emula un escenario empresarial y le hace solicitudes al estudiante, pasando de la mera aplicación del método que ofrece el Excel a una experiencia de un ambiente virtual de aprendizaje.

La parte teórica es trabajada con los materiales del módulo de Pensamiento Estratégico y Prospectiva. (Lecturas fundamentales, objetos virtuales de aprendizaje, teleconferencias, encuentros sincrónicos, etc.). El área de la aplicación o la práctica se compone de dos partes, la primera, es el análisis prospectivo de la empresa que se trabaja en el simulador, el cual da como resultado la elección del escenario meta. La segunda, es tomar ese escenario meta y de manera colaborativa deben construir la planeación estratégica de la empresa. 
Para ello, se recurre a la aplicación de métodos activos de aprendizaje, donde la primicia es aprender haciendo, en este caso en particular, el propósito es que el estudiante aplique de forma práctica en un contexto real lo que ve de manera teórica.

La base pedagógica de la experiencia es el aprendizaje vivencial cuyo fundamento consiste en que los estudiantes aprenden mejor cuando participan activamente en experiencias abiertas de aprendizaje que cuando lo hacen de manera pasiva, en actividades estructuradas como sucedía en el módulo. Por lo tanto, el Aprendizaje Vivencial permite que el estudiante aplique lo aprendido en situaciones reales. De esa manera, el estudiante se enfrenta a problemas, plantea por sí mismo diferentes hipótesis de solución, prueba las soluciones e interactúa con sus compañeros en un contexto determinado (Moore, 2013).

La metodología que se deriva del aprendizaje vivencial y se aplica a los estudiantes es el aprendizaje basado en proyectos donde los estudiantes deben generar un producto, presentación, o ejecución de la solución (Larmer, 2015). Los estudiantes inician con la selección de una empresa del sector real, después establecen las variables que van a analizar, realizan el análisis prospectivo para obtener el escenario meta y de manera colaborativa desarrollan la planeación estratégica que es el producto con el que finaliza la experiencia.

El Aprendizaje Vivencial es un enfoque holístico integrador del aprendizaje, que combina la experiencia, la cognición y el comportamiento (Akella, 2010). El simulador sirve para que los estudiantes obtengan el análisis prospectivo, pero no pueden llegar a este si no tienen claro el comportamiento y los conceptos para concluir en dicho análisis. Con el fin de integrar la experiencia y comprometer a cada estudiante se plantea una simulación individual, la cual se hace con la empresa que seleccionó el equipo y posteriormente cada miembro del equipo propone sus variables y simula por separado. Superada esta etapa, se realiza una reunión de equipo para consolidar la información y hacer una simulación grupal. A medida que hacen las simulaciones envían los resultados al tutor para obtener la retroalimentación, si es correcta el tutor da su aprobación para que continúen, si deben hacer cambios deben retomar y realizar los ajustes. Cuando los estudiantes terminan y obtienen los diez escenarios, de manera conjunta deben seleccionar un escenario meta. A partir de ese escenario meta los estudiantes deben construir de manera colaborativa la estrategia empresarial y el proceso cognitivo se fortalece porque evidencia la aplicación de la teoría en una empresa real. 
La figura 1. Muestra las etapas de la estrategia pedagógica para la simulación.

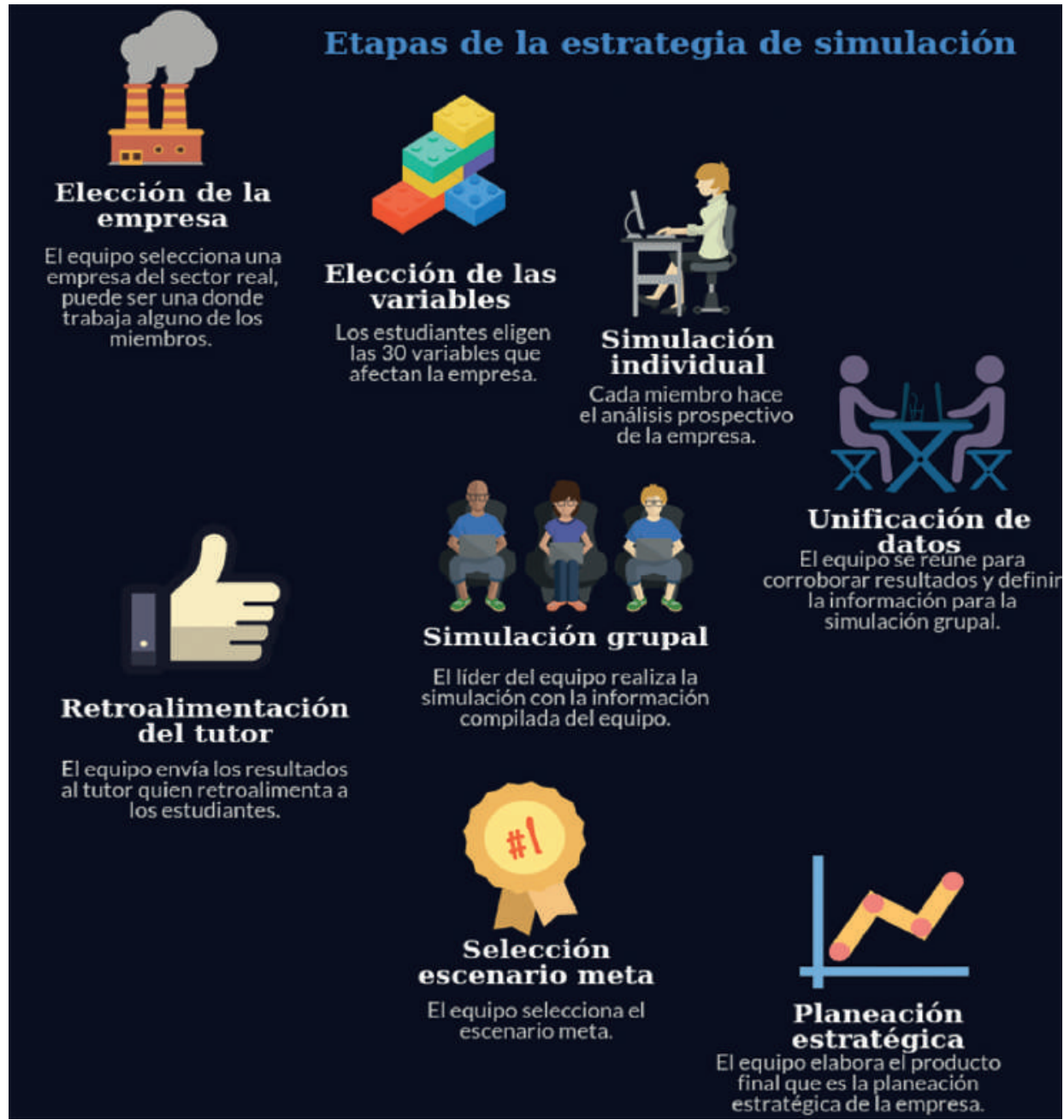

Figura 1. Etapas de la estrategia pedagógica de simulación.

Fuente: Elaboración propia (2017).

Como producto de la experiencia de aprendizaje los estudiantes entregan un documento que contiene el análisis prospectivo que la descargan de los resultados del simulador y la estrategia empresarial.

Los estudiantes trabajan el proyecto asignado con la empresa del sector real, que ellos eligieron, de manera que el resultado final es un proyecto para su aprendizaje (Moursund, 1999) y para su vida, porque si hacen trabajo con una empresa en la cual trabajan ofrecen soluciones a contextos reales. 
La motivación intrínseca parte del propio sujeto, de su interés y disposición hacia el disfrute de algo (Aguado, 2005). Para la experiencia se incluye un componente que favorece el aprendizaje motivacional y aumenta el interés del estudiante, este elemento se propone desde el reto, que se gesta a través de un personaje que es un gerente el cual le va indicando los retos que debe realizar el estudiante como si estuviera en una empresa real.

Asimismo, se creó un personaje guía que acompaña al estudiante durante el proceso de simulación. Este personaje se llama Mila y su objetivo es orientar al aprendiz en cada uno de los pasos que debe realizar en la simulación, en algunos casos brinda explicaciones cortas de la teoría y en otros momentos imparte instrucciones de las tareas que debe realizar el estudiante. Este personaje es transversal a varios proyectos de simulación de la institución.

La experiencia de simulación además cuenta con una guía metodológica que orienta las competencias a desarrollar en todo el proyecto, le explica a los estudiantes cómo será su proceso de simulación y les da indicaciones para los entregables, asimismo, los criterios de evaluación que se tienen para toda la propuesta.

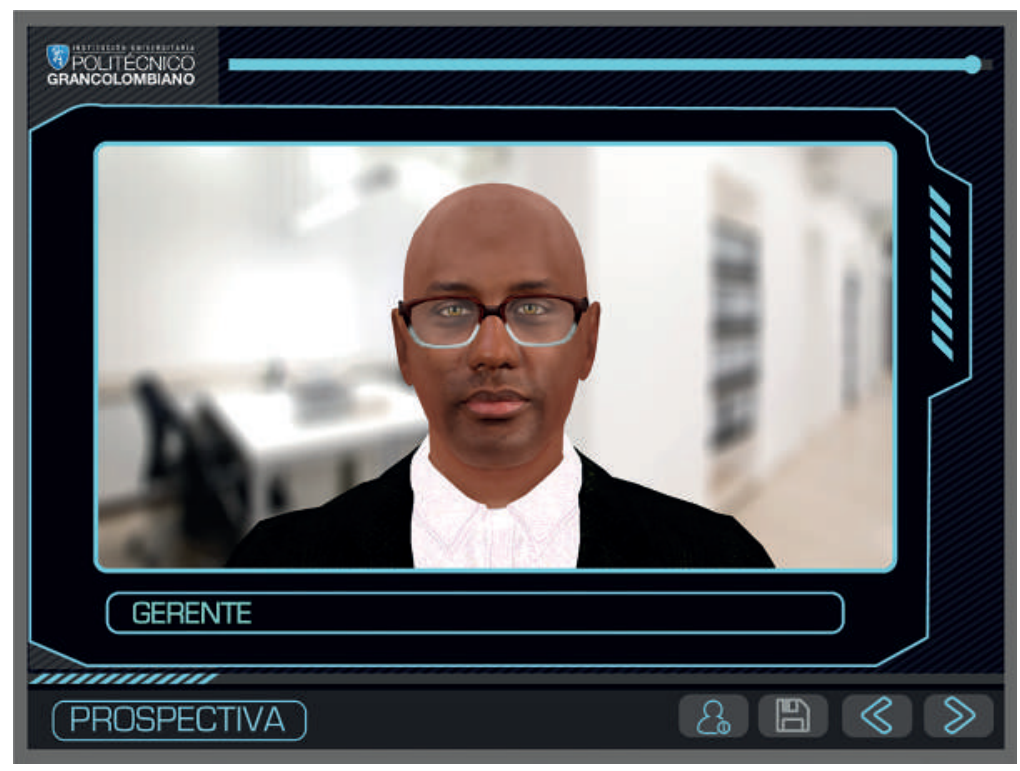

Figura 2. Gerente general de la empresa para la simulación.

Fuente: Politécnico Grancolombiano. 


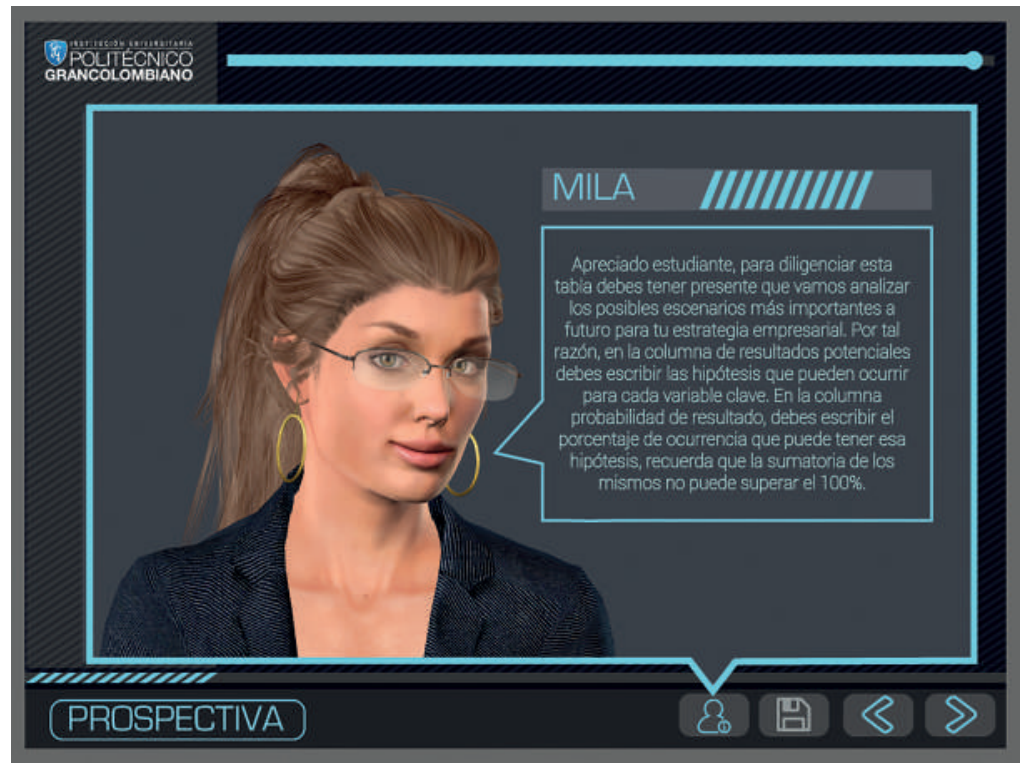

Figura 3. Personaje de ayuda al estudiante.

Fuente: Politécnico Grancolombiano.

Por otro lado, para la simulación es fundamental el trabajo colaborativo y los compromisos del estudiante con su equipo, pues una de las situaciones que se han evidenciado son las malas prácticas que tienen los estudiantes para trabajar colaborativamente, entre ellas: la preferencia por trabajar de manera individual para lo cual se dividen los trabajos para que cada miembro del grupo realice el proyecto de aula de un módulo, de esa manera, uno aprende y los demás quedan inscritos en el proyecto. Otra mala práctica es que solo trabaja uno del grupo y los otros solo escriben el nombre. Otra es que algunos estudiantes nunca se hacen presentes y sus compañeros deben asumir el trabajo de todo el equipo. En este caso el simulador está pensado para que todos trabajen porque la simulación grupal se debe hacer con el compilado hecho en la simulación individual. Si el estudiante no simula individualmente ninguno de los miembros del grupo puede acceder a la del grupo, esto ejerce una presión social para que todos se comprometan con el equipo. También existe la figura del líder, quien digita los datos del grupo para la simulación, por ende, si el grupo quiere un líder eficiente debe responder con el equipo, y si el líder es eficiente el trabajo de todo el equipo fluye.

Para lograr una transparencia el simulador elige aleatoriamente los miembros del grupo y el líder de este, esto se hace por varias razones, la primera de ellas es que no existan grupos incompletos y que no quede todo el proceso como 
única responsabilidad del líder y que los demás no se comprometan con el trabajo. De igual manera, el hecho de que sean aleatorios se hace con el sentido de emular lo que pasa en un ambiente laboral, donde el individuo debe estar en capacidad de trabajar con cualquier persona sin prejuicio alguno. Esta práctica hace parte de la implementación inicial del módulo y cuando llegan a la parte colaborativa ya están comprometidos con el equipo y se deben producir los resultados esperados.

\section{Modelo para la simulación}

El origen del análisis prospectivo se remonta al año 1945 cuando el Departamento de Defensa de los Estados Unidos crea el proyecto Rand CO. mediante el cual se da origen al laboratorio de ideas y se desarrollan las primeras técnicas de análisis del futuro como el método Delphi, Dalkey y Olaf (1962) y el análisis morfológico descrito por Baena (2009). Sin embargo, es en Francia donde se desarrolla y estructura el concepto de análisis prospectivo que hoy conocemos. La denominada escuela francesa nació con el aporte de Bertrand de Jouvenel, en Mojica (2006), en donde manifiesta que existen muchos futuros posibles denominados futuribles. Una década después esta escuela se fortalece con las ideas de Godet (2000) que unifica los conceptos de prospectiva con la planeación estratégica, tal vez su mayor aporte radique en la unificación de herramientas técnicas para el análisis con el propósito de dar un sustento metodológico al análisis prospectivo.

Mojica (1992) define la prospectiva como "La identificación de un futuro probable y deseable, que depende del conocimiento que tenemos, sobre las acciones que el hombre quiera emprender; $y$ son los actores quienes deciden qué se debe conservar y qué se debe cambiar".

Al partir del hecho de la existencia de diferentes futuros para un negocio es necesario identificarlos y tenerlos en cuenta:

- Futuro posible: Es todo aquello que puede suceder en el futuro

- Futuro probable: Son los futuros que pueden suceder de acuerdo con la aplicación de métodos estadísticos que brindan cierto nivel de confianza.

- Futuro deseable: Es el futuro que más se ajusta a las necesidades de la compañía con base en los futuros probables.

- Futuro factible: Finalmente, el futuro factible, es aquel que es posible, 
probable y deseable y se puede llevar a cabo. Este es el denominado escenario meta en el cual la compañía debe direccionar su planeación estratégica.

Sin embargo, para llegar al escenario meta es necesario valerse de diferentes herramientas de análisis estratégico que permitan identificar las tendencias clave del negocio. La herramienta por excelencia para la identificación de tendencias es el análisis PESTEL; este análisis aplicado a la prospectiva se encarga de identificar los posibles fenómenos políticos, económicos, sociales, tecnológicos, ecológicos y legales a los que la empresa tendrá que hacerle frente en un horizonte de diez o quince años. Como complemento al análisis externo, la compañía también debe analizar cómo se encontrarán sus posibles aspectos internos en el futuro.

Para el desarrollo de estos análisis es importante apoyarse en herramientas como el método Delphi o panel de expertos, con el fin de que la identificación de tendencias sea lo más objetiva posible.

Luego de identificar las tendencias clave pare el negocio se deben clasificar, con este propósito se desarrollaron las matrices de análisis estructural de las cuales nos enfocamos en la matriz de impactos cruzados y en el análisis MICMAC.

La matriz de impactos cruzados permite cuantificar las tendencias de acuerdo con su nivel de dependencia e influencia con respecto a las demás variables. La dependencia se refiere a que tanto depende el resultado de la variable analizada de los resultados que se den cada una de las tendencias clave del negocio (estas se califican en una escala de cero a tres donde cero es una dependencia nula y tres es una dependencia alta). Mientras que las influencias evalúan qué tanto influye la variable a analizar en el resultado de las demás tendencias clave del negocio. Al igual que con las dependencias estas se califican en una escala de cero a tres donde cero es una influencia nula y tres es una influencia alta (Arango y Cuevas, 2014).

De la sumatoria de los valores numéricos obtenidos en la matriz de impactos cruzados, se obtienen los puntos del grafico para el análisis MIC MAC. Este gráfico tiene cuatro cuadrantes o zonas que son: 
- Zona de poder: en esta zona se encuentran las tendencias sobre las cuales se debe desarrollar la estrategia de la compañía, ya que en esta se ubican las tendencias que tienen mucha influencia en el resultado de las demás y en contraste su resultado depende poco de otras variables.

- Zona de conflicto: en esta zona se encuentran las tendencias de riesgo para la compañía, son variables que tienen una influencia importante sobre el resultado de otras, pero su resultado depende de variables que no son del control de la compañía, por tal motivo, estas variables se deben gestionar para mitigar los riesgos de sus resultados potenciales.

- Zona de resultado: en esta zona se ubican las tendencias que tienen poca influencia en las demás, pero que a su vez su resultado depende en gran medida de otras variables, estas son tendencias que potencialmente podrían pasar a la zona de conflicto convirtiéndose en variables de riesgo para la compañía.

- Zona de autonomía: en esta zona se ubican las tendencias que tienen el menor impacto en el futuro de la compañía. Ya que sus niveles de influencia y dependencia son bajos.

De acuerdo con estas zonas del análisis MIC-MAC se identifican las tendencias clave para la estrategia ubicadas en la zona de poder y las tendencias de riesgo ubicadas en la zona de conflicto. Para cada una de ellas se deben desarrollar las hipótesis o posibles resultados potenciales que podría tener cada una. Para esta etapa es importante recurrir de nuevo al método Delphi con el objetivo de lograr resultados más precisos.

Para el desarrollo del simulador se empleó la lógica utilizada en mercados de predicciones mediante la cual para cada variable existe un número determinado de resultados potenciales, en nuestro caso tres, los cuales deben ser exhaustivos y excluyentes; esto quiere decir que los resultados deben cubrir el total de las probabilidades para sumar un total del $100 \%$ y por otro lado, excluyente se refiere a que si se diera la hipótesis $A$, como consecuencia no se puede dar la hipótesis B ni la hipótesis C, (Tziralis y Tatsiopoulos, 2012). Bajo esta premisa se desarrolla la matriz de hipótesis del simulador.

Finalmente, a partir de las hipótesis propuestas se identifican los diez escenarios más probables mediante la combinación de todas las hipótesis potenciales que son susceptibles de tener ocurrencia simultánea, la construcción de los escenarios se da gracias a los principios básicos utilizados para la construcción de árboles de decisión. Dentro de los principios tomados de los árboles de 
decisión para ser aplicados en el simulador se encuentran:

- Se analizan todas las posibles soluciones

- Permite analizar las probabilidades y resultados

Con un análisis tipo grafos de probabilidades se obtienen las rutas más relevantes, llegando así a los diez escenarios de mayor probabilidad de ocurrencia. Finalmente, el estudiante selecciona de los diez escenarios, el escenario meta. Si bien, sobre el escenario meta se define la planeación estrategia de la compañía, se debe tener en cuenta para los diez escenarios más probables es recomendable hacer el análisis cualitativo y cuantitativo de riesgos para definir los planes de acción a seguir en el caso que existan desvíos con respecto al escenario meta.

\section{Desarrollo de la experiencia de aprendizaje}

El modelo de análisis que se utiliza en la simulación es creación del autor, como ya trató en este documento. Uno de los aportes más significativos es unificar diferentes metodologías de análisis estratégico y prospectivo para que el estudiante pueda llegar de una manera más sencilla a la identificación del escenario meta. Para este proyecto primero fueron identificadas las herramientas de análisis idóneas, después se depuraron y se estructuró la metodología, para ser llevada a un software. Lo que significa que la herramienta tecnológica se puso al servicio de un desarrollo metodológico que funciona sin un simulador, porque el estudiante podría aplicarlo en otros ambientes de aprendizaje no mediados con tecnología.

Con el equipo de coatuores se trabajó la implementación de la metodología como una estrategia de aprendizaje a través del aprovechamiento de las TIC. Se estructuró la estrategia pedagógica y la implementación de la metodología en una herramienta de software, para ello se contó con un equipo de pedagogos, diseñadores e ingenieros que trabajaron de acuerdo con los requerimientos académicos.

El estudiante para simular debe elegir treinta tendencias que considere serán claves en el futuro de la compañía y que corresponden a variables internas o externas. Cada variable debe ser clasificada de acuerdo con los cuadrantes del análisis DOFA (debilidad, oportunidad, fortaleza, amenaza). Adicionalmente debe determinar el impacto de la variable en una escala que va de 0 a 3 , donde 0 es un impacto nulo y 3 es un impacto alto. De las treinta variables el simulador elige las de mayor impacto, y el estudiante debe seleccionar las diez principales. 
De esta manera, el proceso de simulación le exige al estudiante un alto nivel de análisis porque si llega a evaluar inadecuadamente sus variables afectarán los resultados de la simulación.

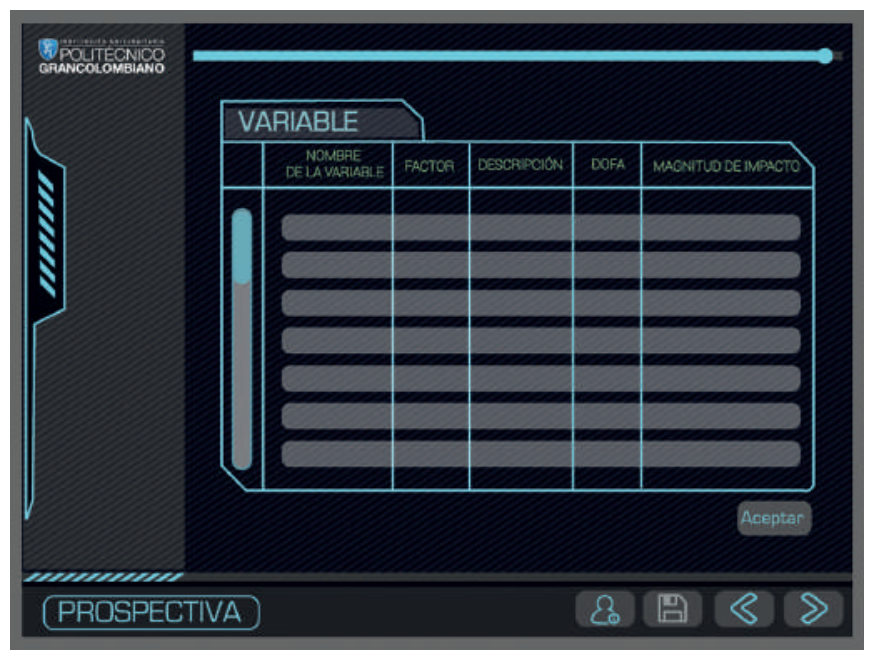

Figura 4. Escenario donde el estudiante ingresa la información de las variables en el simulador.

Fuente: Politécnico Grancolombiano.

Cuando elige las diez variables el simulador le genera la matriz de impactos cruzados, allí evaluará los niveles de dependencia e influencia de cada variable con respecto a las demás. El estudiante califica la relación entre variables siendo 0 Magnitud nula y 3 Magnitud alta.

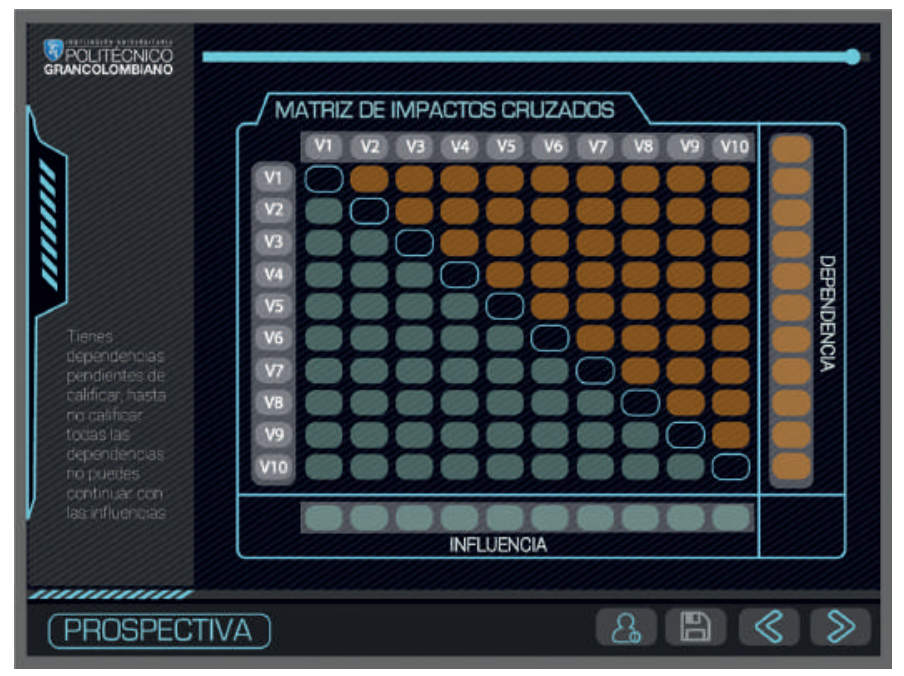

Figura 5. Escenario de la Matriz de Impactos Cruzados.

Fuente: Politécnico Grancolombiano. 
Con estos datos se genera el gráfico MIC MAC, el cual ubica todas las variables dentro de los cuadrantes del gráfico. De este gráfico el software selecciona las variables ubicadas en la zona de poder y en la zona de conflicto. Las variables que quedan fuera de la zona de poder y conflicto son descartadas para el análisis posterior, lo que significa depuración de variables para la creación de los escenarios.

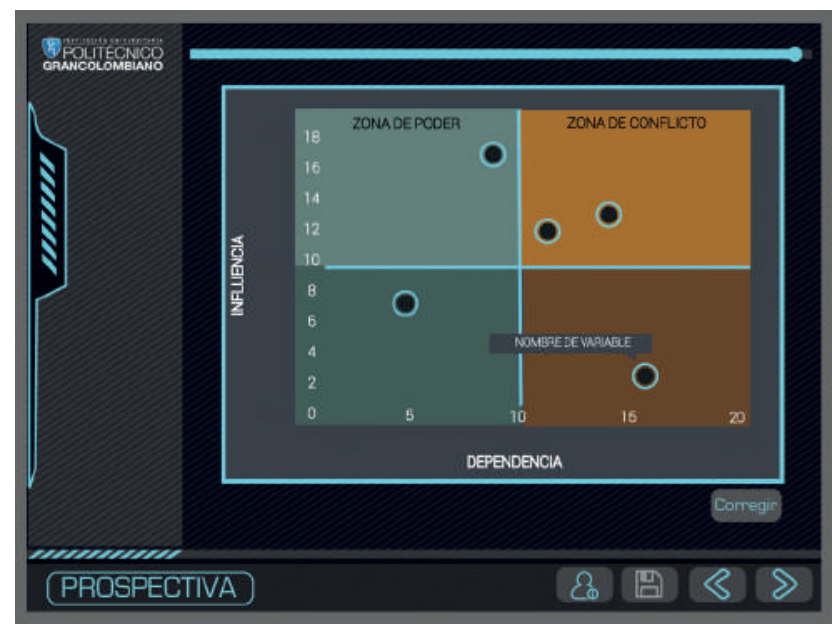

Figura 6. Escenario del gráfico MIC MAC.

Fuente: Politécnico Grancolombiano.

Con estas variables seleccionadas el estudiante procede a realizar las hipótesis para cada variable teniendo en cuenta los casos en los cuales existe alta dependencia entre variables.

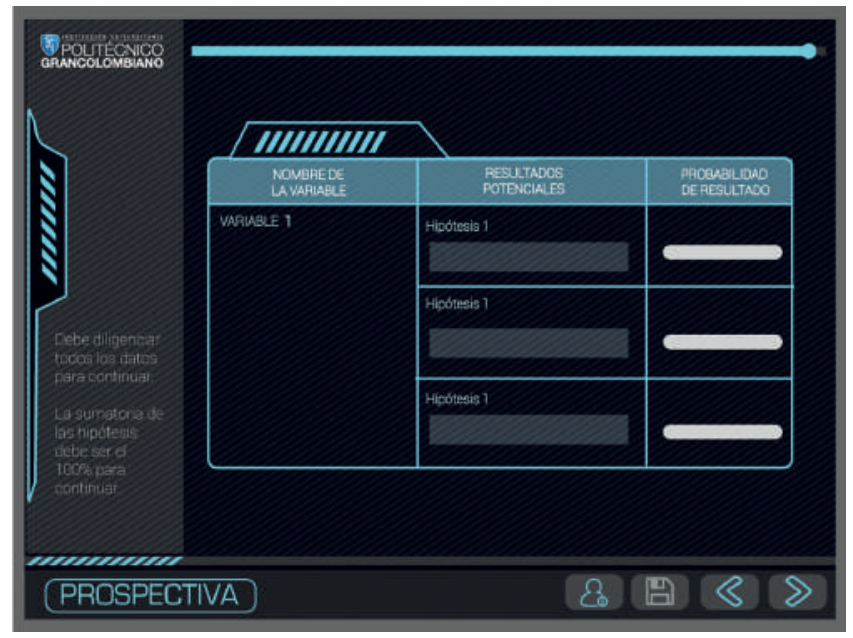

Figura 7. Escenario de la matriz de hipótesis.

Fuente: Politécnico Grancolombiano. 
A estas hipótesis el estudiante les asigna una probabilidad de ocurrencia de tal forma que el sistema hace una programación de grafos para elegir las rutas más probables y de esta manera arma los diez escenarios de mayor probabilidad de ocurrencia, los cuales se le muestran al estudiante y debe elegir el escenario meta.

El simulador le provee al estudiante los insumos para que con el escenario meta diseñe la planeación estratégica de la compañía. De aquí en adelante depende de un trabajo colaborativo donde el equipo redacta y construye el plan estratégico de la compañía para los próximos diez años, y finalmente, entrega al tutor un documento con los análisis realizados.

\section{Resultados obtenidos}

Los resultados del proyecto son el simulador individual y grupal y el espacio para el tutor. En el espacio individual el estudiante puede practicar las veces que desee con el fin de que adopte la metodología. En el espacio grupal, el equipo debe definir las variables y las hipótesis de manera mancomunada. El espacio dentro del simulador para la revisión y retroalimentación del tutor es el lugar donde revisa cada fase de la simulación hecha por el grupo y hace las retroalimentaciones necesarias. La simulación individual no es calificable, pero es requisito para acceder a la etapa grupal.

Además de la herramienta se elaboraron la guía metodológica para el estudiante y el instructivo de manejo de la herramienta. La primera orienta y da las instrucciones de cómo elaborar su proyecto y el proceso de simulación. El segundo es un instructivo de manejo de la herramienta. Los dos con el fin de constituir una experiencia completa de aprendizaje.

Se desarrolló una interface pensada en el vídeo juego que hace que la simulación sea muy dinámica, con unos personajes de instrucción e interacción para el estudiante que orienten los procesos y las tareas para el estudiante.

Para la institución quedan los desarrollos en html en código fuente que permite facilidades de programación para herramientas futuras. Todos los proyectos son construidos desde la perspectiva lego, es decir, que pueden pertenecer a este módulo $u$ otros similares. La misma visión le permite que se desarrolle por partes lo que significa que este simulador puede ser en futuro una parte $o$ componente de uno más grande. 


\section{Conclusiones}

La primera conclusión tiene que ver con la inexistencia en el mercado de un software que a través de una metodología ordenada permita la identificación de escenarios futuros en un contexto empresarial aplicable a cualquier tipo de empresa u organización desarrollada en una interfaz amigable y pedagógica.

El simulador puede ser aplicado a cualquier tipo de empresa y en cualquier etapa de su ciclo de vida, lo que facilita el análisis estratégico empresarial de largo plazo. Además, este permite desarrollar una experiencia de aprendizaje teórico-práctico, donde el estudiante se enfoca su trabajo esencialmente en el análisis y en el pensamiento crítico.

El desarrollo del simulador de Prospectiva como herramienta pedagógica, es un punto de partida para mejorar la calidad académica de los trabajos realizados por los estudiantes, del mismo modo, al estar diseñado para aplicar en empresas reales es una herramienta que fortalece la relación con el medio externo mediante el desarrollo de la investigación aplicada a la solución de problemáticas empresariales reales.

\section{Bibliografía o referencias}

Aguado, L. (2005). Emoción, Afecto y Motivación. Madrid: Alianza Editorial.

Akella, D. (2010). Learning together: Kolb's experiential theory and its application. Journal of Management and Organization, 16(1), 100-112.

Arango Morales X. y Cuevas Pérez V. (2014) Método de análisis estructural: matriz de impactos cruzados multiplicación aplicada a una clasificación (micmac). Universidad Autónoma de Nuevo León. Recuperado de: http://eprints. uanl.mx/6167/1/24.\%20capitulo\%20Metodologia\%20-\%20MICMAC\%20 \%28Direcci\%C3\%B3n\%20del\%20libro\%20a\%20la\%20venta\%20ttpwww.tirant. commexlibro9788416062324\%23\%29.pdf

Baena Paz, Guillermina; (2009). Prospectiva por qué y para qué: la historia que muchos no quieren leer. Estudios Políticos, Mayo-Agosto, 109-127.

Dalkey y Olaf, $(1962,07)$. An experimental aplication of the dephi metod to use of experts. Rand Co. Obtenido 09, 2017, de https://www.rand.org/content/dam/rand/pubs/ research_memoranda/2009/RM727.1.pdf

Godet, M., Monti, R., Meunier, F., \& Roubelat, F. (2000). La caja de herramientas de la prospectiva estratégica. Laboratoire d'Investigation Prospective et Stratégique.

Larmer, J. (2015). Project-Based Learning vs. Problem-Based Learning vs. X-BL.

Recuperado de: http://www.edutopia.org/blog/pblvs-pbl-vs-xbl-john-larmer [Consultado 10/09/2017] 
Mojica, F. (1992) La prospectiva. Técnicas para visualizar el futuro. Legis editores; Bogotá, $340 \mathrm{p}$.

Mojica F. (2006) Concepto y aplicación de la prospectiva estratégica. Revista Med Volumen 14. P (122-131). Recuperado de: http://www.umng.edu.co/ documents/63968/77289/RMed2006art15.pdf

Moore, D. (2013). For interns, experience isn't always the best teacher. The Chronicle of Higher Education. Recuperado de: http://chronicle.com/article/For-InternsExperience-Isnt/143073/ [Consultado 10/09/2017]

Moursund, D. (1999). Project-based learning using information technology. Eugene, OR, EUA: International Society for Technology in Education.

Quiroga D. (2008) Metodología para hacer prospectiva empresarial en la sociedad de la información y el conocimiento. Revista Economía y Administración № 70. Universidad Autónoma de Occidente; Cali.

Ryan, (2017, 01). Strategic Risk A cornerstone of risk transformation. Deloitte and Touche. Obtenido 09, 2017, de https://www2.deloitte.com/global/en/pages/risk/articles/ implementing-risk-transformation-in-organizations.html

Tziralis G. y Tatsiopoulos I. (2012) Prediction markets: an extended literature review. The University of Buckingham Press. Recuperado de: http://dx.doi.org/10.5750/jpm. v1i1.421

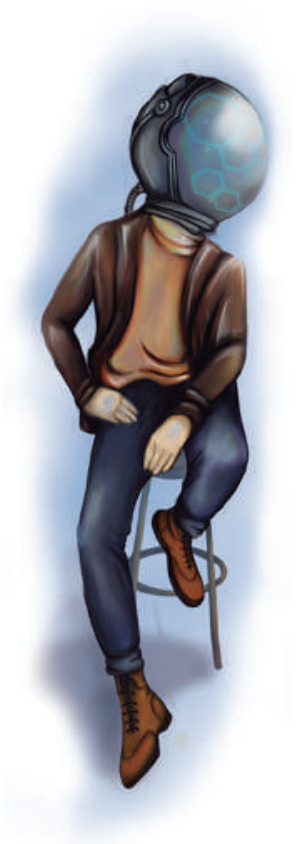




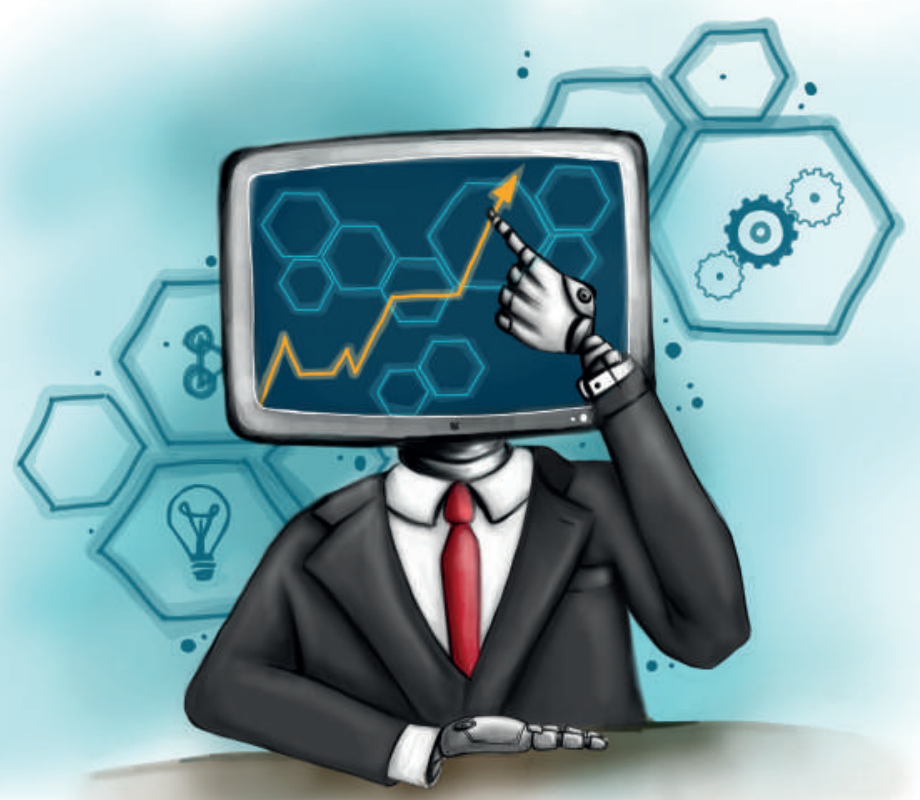

- Capítulo 3 -

\section{Simulador de gestión financiera para Administración Financiera}

\section{Autores}

Hernando Espitia López. Administrador financiero y de sistemas, Especialista en Gerencia de Comercio Internacional y Master en Relaciones y Negocios Internacionales de la Universidad Militar Nueva Granada. Experiencia en análisis 
de riesgo y crédito empresarial en entidades financieras, Gerente de oficina Banco BBVA Colombia, consultor en Banca privada, gerente en empresas de servicios de personal, tecnología y producto especializado, como docente universitario más de 10 años, tanto en pregrado como posgrado, en modalidad presencial y virtual, en el área financiera, bancaria y comercio internacional.

Correspondencia: hespitia@poligran.edu.co

Luis Martín Trujillo Flórez. Ingeniero Electricista Universidad Nacional de Colombia, Máster en Edición Literaria Universidad de Salamanca España. Master en Ambientes Virtuales de Aprendizaje Universidad de Panamá. Especialista en Ambientes Virtuales Centro de Altos Estudios Argentina. Coordinador del Laboratorio de innovación pedagógica Virtual del Politécnico Grancolombiano.

Correspondencia:mtrujilo@poligran.edu.co

\section{Diseñador de interfaces del simulador}

Mónica Carrero Becerra. Diseñadora gráfica e ilustradora del Politécnico Grancolombiano. Tecnóloga en multimedia del Servicio Nacional de Aprendizaje. Actualmente se desempeña como diseñadora del Laboratorio de innovación pedagógica del Politécnico Grancolombiano.

Correspondencia:mncarrero@poligran.edu.co

\section{Resumen}

En el área financiera se trabajan diversos tipos de simulación numérica y de resultados, sin embargo, son pocas los que se centran en el análisis financiero que conduzcan a la acertada toma de decisiones. La presente experiencia presenta un simulador de análisis financiero estructurado desde lo pedagógico y pensado para aprendices que se enfrentan a contextos reales. El propósito es que los estudiantes puedan dar respuesta a situaciones de análisis en empresas del sector real, esta experiencia se convierte en una estrategia pedagógica que se aplica a toda el área de finanzas con la construcción de diversos simuladores que permitan dar cuenta de la parte práctica y faciliten la adquisición de competencias desde el hacer y la aplicación del saber. 


\section{Palabras claves}

Simulador de análisis financiero, aprendizaje situacional, innovación educativa en finanzas.

\section{Introducción}

El aprendizaje en el área financiera es una labor que adelanta tanto la academia como el sector financiero y se enfoca en mostrar las bondades y ámbitos de aplicación de los análisis en beneficio de los individuos y las sociedades, ya que en muchos casos, tanto las empresas como las personas no acceden al sistema financiero por desconocimiento, lo que limita sus posibilidades de crecimiento, en especial en pequeñas y medianas empresas que al no indagar profundamente en su situación financiera encuentran negativas en la aprobación de créditos y la pérdida de otras alternativas de financiación.

En el área financiera existen varios modelos matemáticos que facilitan la obtención y proyección de los datos para el análisis. La mayoría de ellos se han convertido en aplicativos en Excel, otros se extrapolaron en aplicativos webs que permiten realizar diversos cálculos, análisis, tablas de amortización y cotización de divisas entre otros. Muy pocos salen de lo numérico para abordar el análisis financiero. De igual manera, no tienen un enfoque didáctico o no están pensados para el aprendizaje. Allí radica la razón fundamental de esta experiencia educativa que consiste en el desarrollo de un modelo de simulación que involucra los componentes financiero, analítico y pedagógico. La herramienta es un complemento al contenido del módulo o asignatura de Administración Financiera, ya que se aplica en módulos virtuales y en cursos presenciales para apoyar la labor de aprendizaje en el aula. El estudiante desarrolla paralelamente los contenidos del módulo con su actividad de simulación, el propósito es que la herramienta dé cuenta de la parte práctica porque aplica lo que los estudiantes trabajan de forma teórica en los contenidos del módulo.

La estrategia de simulación se enfoca en el análisis de los estados financieros comparados de dos períodos contables y respecto al sector económico, entre tanto, el estudiante debe aplicar tanto la parte operativa como la de análisis. El simulador le asigna al estudiante una compañía de manera aleatoria de una base de datos ya constituida de empresas reales de diversos sectores económicos, esto se hace bajo la primicia que el estudiante debe estar en 
capacidad de analizar financieramente cualquier tipo de empresa, de esa manera puede confrontar sus competencias con el mercado laboral.

Con la empresa asignada el estudiante debe realizar un análisis financiero inicial, después viene una segunda fase donde debe enfocarse al análisis integral de los estados financieros.

El proceso de simulación se hace de dos maneras, individual y grupal, el trabajo que debe desarrollar en grupo lo hace con una empresa distinta a la asignada de manera individual, lo que significa que analiza dos empresas diferentes en el transcurso del módulo. Para ello el estudiante debe apoyarse en los diferentes contenidos del aula para su adecuado desempeño en la actividad, pues lo que aborda en la simulación está sincronizado con los núcleos temáticos del módulo.

\section{Marco teórico}

\section{Problemática que atiende}

Administración Financiera es un módulo o asignatura transversal que soporta varios programas de la Facultad de Ciencias Administrativas, Económicas y Contables y de la Facultad de Mercadeo en la Institución Politécnico Grancolombiano. El módulo o asignatura no corresponde a un semestre específico ya que varía de acuerdo, al programa tecnológico o profesional en el que se imparte, su aplicación es válida para los programas de modalidad virtual y presencial debido a la unificación de los sílabos para las 2 modalidades. El estudiante para cursarlo requiere conocer las bases sobre los estados financieros de una compañía, como el de la situación financiera y el de resultados.

El módulo en virtual lo cursan once programas académicos de la institución, cinco de ellos profesionales y seis tecnólogos, llegando a aproximadamente 2600 estudiantes por semestre. En la modalidad presencial la asignatura la cursan ocho programas, seis de ellos profesionales, uno de tecnología y una carrera técnica, atendiendo una población cercana a quinientos estudiantes por semestre. Lo que significa que más de tres mil personas lo cursan en la institución. 
El histórico de los últimos tres semestres, de acuerdo con el Centro de Información de la Organización (ClO) del Politécnico Grancolombiano (2017) indica que el porcentaje promedio de pérdida es del $11,3 \%$ con una nota promedio en ambas modalidades de 3,6. De tales datos se puede evidenciar un nivel significativo de pérdida, además el promedio de calificación no es alto.

El aprendizaje de finanzas involucra varias competencias transversales que el estudiante debe desarrollar en su proceso como: resolución de problemas, búsqueda de información, análisis y síntesis, manejo de herramientas tecnológicas, aprendizaje autónomo, trabajo en equipo y desarrollo de la ética y la responsabilidad. Para el aprendizaje específico del módulo o asignatura la competencia principal es el análisis histórico de información financiera, soportado en el análisis vertical, horizontal, indicadores financieros y manejo del capital de trabajo, con el fin de emitir o diagnosticar un concepto de la situación financiera de la empresa. Todo con el propósito final de tomar decisiones que potencialicen las fortalezas que tiene la organización. De igual manera se propende porque le estudiante corrija aquellas actividades que puedan estar afectando la rentabilidad y proyección de la empresa, con especial énfasis en cuentas como cartera, inventarios, márgenes de rentabilidad, proveedores y estructura financiera.

Con este nivel de complejidad en el desarrollo de las competencias el equipo de tutores en el área de finanzas como parte de su política de mejoramiento académico, aplicó a los docentes de finanzas una encuesta que pretendía identificar las principales dificultades que tienen los estudiantes en el aprendizaje de las finanzas. De acuerdo con la encuesta diseñada por la tutora Yolanda Rocío Vargas y los resultados obtenidos, se estima que la principal falla en los estudiantes es el análisis e interpretación de resultados (Vargas L., 2017).

Hoy en día el acceso a la información y los cálculos financieros son relativamente sencillos de hacer debido al desarrollo tecnológico que facilita los cálculos, por lo que los mayores problemas están asociados a la interpretación, análisis y depuración de la información que reciben las personas, en el caso de estudio particular se enfoca en el análisis e interpretación de estados financieros. A partir de esta dificultad se desprende el objetivo fundamental de la experiencia de aprendizaje que consiste en el diseño pedagógico, elaboración y desarrollo de un simulador que permita la interpretación y el análisis financiero a través de un ejercicio específico de índole práctica que por la configuración de la herramienta resulta diferente para cada estudiante. Un propósito derivado de 
formación es incentivar el trabajo autónomo, la aplicación y apropiación de la teoría de acuerdo con los comportamientos reales.

De acuerdo con el diseño de la experiencia de aprendizaje basada en la simulación, se pretende que el estudiante trabaje las competencias propias de módulo como las transversales. El simulador se enfoca en la comprensión por parte del usuario de la información financiera y su utilidad en la toma de decisiones, desmitificando que sea un asunto meramente de personas de finanzas ya que las decisiones en una organización pueden ser tomadas por la gerencia o el consejo directivo sean o no financieros.

El simulador acorde con los contenidos del módulo cuenta con un marco de aplicación básica para un gerente general, un gerente financiero o dueño de una empresa, quienes deben tomar decisiones de un alto nivel de responsabilidad, ya que deben responder por el manejo de los recursos a cargo y de su aumento de valor.

\section{Antecedentes}

En general, en el sector financiero se encuentran simuladores asociados a los servicios y productos que venden, como la colocación de crédito en todas sus líneas de financiación, la inversión en activos financieros de bajo riesgo, seguros de vida, salud y sobre activos fijos, modelos pensionales y en la negociación de divisas principalmente, todos enfocados en generar un resultado en cifras, bien sea para calcular el valor de la cuota, los rendimientos esperados, valor de la pensión futura esperada, valor prima del seguro y cotizaciones en línea de divisas internacionales, tanto en entidades nacionales como internacionales, pero ninguno de ellos tiene como objetivo un proceso de educación y puesto que la información suministrada en muchos casos es confusa le dificulta al cliente potencial la toma de decisiones, ya que cada entidad muestra la información de manera distinta y deja en las manos del cliente todo el proceso del análisis e interpretación de resultados, lo que en muchos casos puede llevar al cliente a tomar decisiones erróneas o inadecuadas.

Como parte de la indagación se analizaron las siguientes herramientas:

SIMDEF (Simulación de Toma de Decisiones Financieras) trabajado por Michelsen Consulting Ltda, desarrollado en 1978 en el Reino Unido. Consiste en un caso de finanzas dinámico en múltiples períodos, en cada uno de ellos, 
el estudiante toma una decisión que se verá reflejada en su desempeño, todos los estudiantes tienen la misma empresa, además el juego de datos inicial para cada grupo de estudiantes será idéntico y de acuerdo con las decisiones del equipo cambiarán sus estados financieros, de tal forma que los participantes mejorarán en su conocimiento de las decisiones financieras y de las decisiones generales. Los estudiantes no compiten económicamente, lo hacen en los resultados. Cada equipo tiene la oportunidad de explicar su desempeño en una sesión de sustentación final. Cada equipo recibe un juego inicial de estados financieros, incluyendo un Estado de Resultados, un Balance y una Hoja de Síntesis Ejecutiva retratando las operaciones de la empresa. (Michelsen Consulting Ltd., 2016).

SIMDEF es un simulador interesante y desde lo financiero genera una experiencia interesante para el estudiante. Utilizado en diferentes espacios académicos, por algunas instituciones de educación superior, entre ellas, La Universidad de Pamplona, Universidad Autónoma de México, Universidad Libre, Universidad Católica de Valparaíso y el Tecnológico de Monterrey entre otras. Sin embargo, su desarrollo gráfico es pobre, se centra en los datos, está constituido bajo el programa Excel, lo que puede provocar que no sea tan atractivo para el estudiante.

Simulador de previsión financiera y Gestión de riesgos (Financial simulation), es un simulador en línea que permite incluir supuestos de riesgo en los pronósticos financieros a través de una línea con el comportamiento histórico y otra con el proyectado. También sirve para el análisis de valoración y las pruebas de depreciación. Analiza las probabilidades de inversión financiera, optimiza las estrategias financieras y permite un trabajo de simulación con respecto al riesgo financiero. Se puede consultar en la página: https://simulationfinance.com/.

Es una herramienta que funciona online, gratuita y se puede emplear como parte de una estrategia de aprendizaje, está centrada en el análisis de riesgos financieros, no está pensada desde el aprendizaje, aunque es muy intuitiva.

SICIEM - Análisis financiero es empleado por varias universidades entre ellas la Universidad Minuto de Dios, es ideal para la toma de decisiones de acuerdo con la estructura financiera de la empresa. La misma universidad cuenta con varias herramientas adquiridas para el área administrativa, contable y económica que complementan la oferta a sus estudiantes. Revisar en: http://uvd.uniminuto. edu/boletin/instructivo_aulas/simuladores.html\#micampus 
Sin embargo, la apuesta de la Institución Politécnico Grancolombiano además de adquirir algunas de las herramientas de simulación en el mercado, es posicionar el Laboratorio de Innovación Pedagógica Virtual como desarrollador de proyectos propios que no están en el mercado, que nazcan desde las necesidades del aula y que correspondan a los programas curriculares a través de desarrollos de software propios. Los proyectos son propuestos por los Departamentos Académicos, diseñados, estructurados y guionados por tutores y docentes de la institución. El desarrollo, diseño gráfico y programación son hechos con recursos económicos y humanos de la institución. Además, tiene la ventaja de abarcar proyectos de otra índole como: realidad aumentada, vídeo juegos, realidad virtual, ambientes virtuales de aprendizaje (AVA), storytelling educativo, etc.

La universidad ha invertido recursos en desarrollar este tipo de herramientas para aplicar en sus aulas y para dejarlos a disposición de la comunidad académica, también hay empresas especializadas en desarrollar simuladores para entidades educativas en casi todos los campos de aprendizaje que toman el papel de proveedores para los desarrollos de software.

En muchos casos, durante la formación, la enseñanza experiencial es relevante y con mayor razón si hablamos de tecnología, ya que el objetivo es que la persona aprenda a dominar una actividad particular. Para el Politécnico es claro que el proceso no puede ser únicamente práctico o teórico, por tal razón la experiencia de simulación es un complemento en la formación teóricopráctica que promueve la Universidad a sus estudiantes.

\section{Estrategia de aprendizaje}

El simulador de gestión financiera que se está desarrollando pretende que a través de una interacción individual del estudiante con la herramienta, este afiance y aplique el conocimiento teórico en un ejercicio práctico.

Para el área de finanzas se estableció una estrategia transversal a todos los simuladores del área, por lo tanto, el diseño y estructuración se hace desde la perspectiva de un aprendizaje situacional, que se refiere al proceso de aprendizaje basado en situaciones didácticas aisladas, o en el ejercicio de habilidades o destrezas didácticas simples, en la práctica de comportamientos didácticos, enmarcados en situaciones reales tal y como se producen en un ambiente real (Biencito, Domínguez y García, 2005) 
La simulación es vista como un conjunto de situaciones didácticas en las cuales los estudiantes deben alcanzar diversos objetivos: realizar el análisis vertical, y horizontal, hallar indicadores de cobertura, emitir o diagnosticar un concepto de la situación financiera de la empresa. Tales objetivos o tareas se convierten en la ruta de aprendizaje porque llevan al estudiante a realizar un análisis financiero integral con sus componentes más importantes.

Como parte del aprendizaje situacional dado para la experiencia de simulación en finanzas se proponen tres principios que deben tener los diferentes tipos de simuladores que se desarrollen para el área: experimentación académica en el que los estudiantes deben realizar procesos experimentales dentro de la herramienta, entrenamiento o ejercitación que sirve para imitar situaciones de aprendizaje utilizando parámetros reales y, por último, control del aprendizaje en el cual el simulador debe servir para determinar en qué medida los estudiantes han asimilado los conocimientos teóricos y los evidencian en la práctica.

Los simuladores, aunque tienen diferencias son de tipo de análisis de información, lo que significa que la herramienta es adecuada para que el estudiante mejore sus procesos de comprensión y análisis de la información que lo conduzcan a la adecuada toma de decisiones. Por lo tanto, los simuladores financieros del Politécnico Grancolombiano deben considerar las siguientes tres condiciones: Que sirvan para la interpretación de la información, es decir, el estudiante extrae información del simulador y debe darle sus propias interpretaciones y justificarlas; deben servir para el análisis de la información, significa que, el estudiante ejemplifica modelos, saca conclusiones de datos, deduce y hace inferencias lógicas, causales, predictivas, etc.; $y$, por último, es necesario que permitan desarrollar el pensamiento hipotético, el estudiante debe considerar las soluciones alternativas, formular hipótesis y comprobarlas a través de la evaluación de resultados.

A nivel educativo encontramos simuladores más vivenciales que facilitan el trabajo operativo y se centran en un usuario que está aprendiendo, se preocupan en que el estudiante tenga una vivencia que lo motive, para ello se diseñó un ambiente donde el estudiante ingresa, selecciona un rol laboral relacionado al análisis financiero, lo recibe una asistente quien lo ubica en su lugar de trabajo y le va asignando las tareas que debe ir desarrollando, dichas tareas serán evaluadas por el gerente general y su equipo directivo.

El estudiante puede asumir uno de tres roles y según el que elija tiene un objetivo diferente dentro de la simulación. Los tres tipos de rol son: analista de riesgo, 
revisor financiero y consultor financiero. El objetivo dentro de la simulación, si es analista su papel se enfoca a hacer los balances para asignación de cupo de crédito. Si es revisor supervisa falencias de la compañía, y si es consultor debe proponer planes de mejora. Así la competencia principal sea la interpretación de estados financieros, el hecho de abordarla desde diversos roles produce que la argumentación y el análisis sea diferente, generando así una experiencia acorde a los diferentes cargos que puede asumir el futuro profesional en el campo laboral.

El simulador está planteado para ser más exigente en lo analítico, por lo tanto, en la primera etapa orienta al estudiante en lo parte operativo del análisis vertical, horizontal y de indicadores financieros, de tal forma que aprende cómo se determina cada dato del análisis, tanto en lo que respecta a la participación porcentual de cada cuenta, como a su variación de un período a otro y en el cálculo de cada indicador financiero; después procede a evaluarlo a través de unas preguntas aleatorias y son individuales de acuerdo a la empresa que le fue asignada. Más que una respuesta numérica, está pensado como un empleado que le da soluciones a su gerente como lo muestra la figura 1.

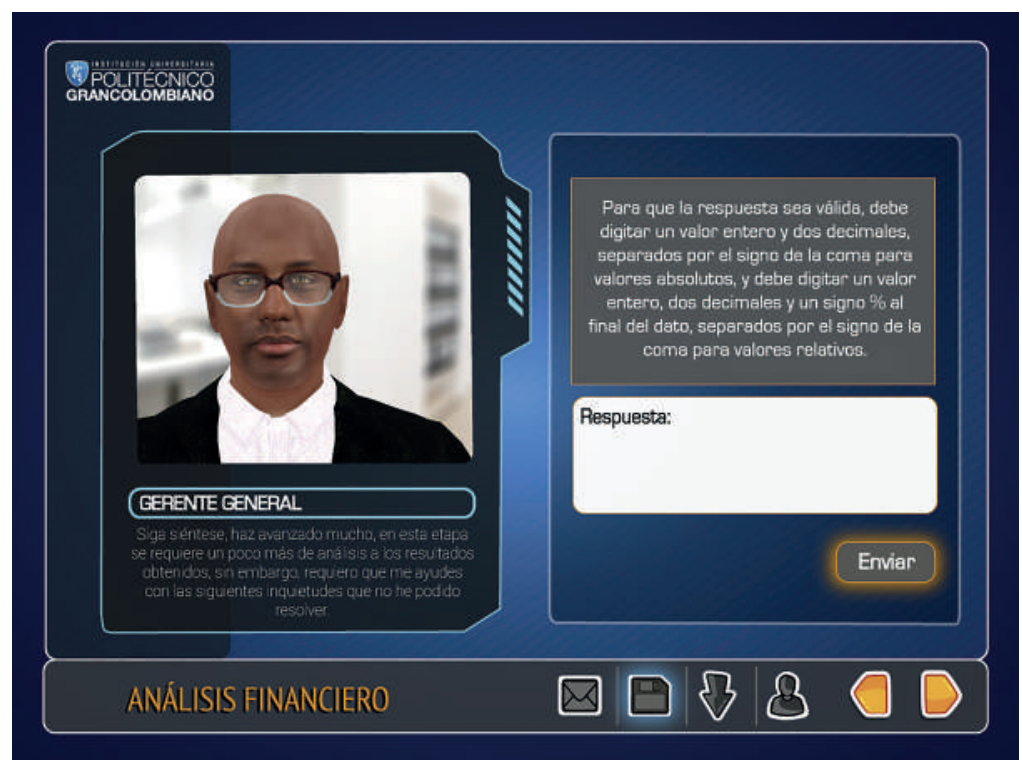

Figura 1. El estudiante debe responder al gerente una serie de preguntas para argumentar su análisis financiero.

Fuente: Politécnico Grancolombiano (2017). 
En la segunda parte del simulador, el objetivo es evaluar la parte interpretativa y analítica del estudiante, en la cual se debe emitir un concepto de la empresa asignada desde un inicio respecto de su situación financiera. Información que se complementa con los datos cuantitativos del sector económico respectivo, destacando los aspectos positivos de la misma. Tales aspectos pueden ser susceptibles de mejora, el estudiante debe hacer especial énfasis en identificar aquellos puntos en los que la empresa debe reforzar rápidamente, para lo cual debe elaborar un informe para que el tutor emita retroalimentación individual.

En una tercera fase del simulador, se evalúa el trabajo colaborativo basado también en un análisis financiero de una empresa asignada aleatoriamente, es decir, para la experiencia grupal se recurre a una segunda empresa de manera aleatoria. De igual manera el simulador asigna los grupos. Se conserva la filosofía que laboralmente las personas deben ser capaces de trabajar en cualquier equipo, por lo tanto, el simulador nombra un líder que trabaja los datos numéricos y cuenta con espacios colaborativos de trabajo grupal. Los estudiantes de un equipo deben desarrollar un estudio completo donde incluyen el análisis de los estados financieros, de los indicadores de apalancamiento y evolución del capital de trabajo, con el fin de determinar la generación de valor. En esta fase el tutor evalúa la calidad del análisis y la capacidad de argumentación grupal e individual, asimismo, su interacción con los otros participantes y la capacidad de trabajar colaborativamente. Se ha identificado, y de manera más evidente en los estudiantes virtuales, la dificultad para trabajar en equipo. Cómo es una competencia blanda muy requerida en el campo laboral se pretende que la experiencia de simulación la fortalezca.

Al final del proceso los insumos dados por el líder y los aportes en las argumentaciones de cada uno de los miembros del equipo se consolidan en un informe que el estudiante descarga y el líder envía al tutor para su retroalimentación.

La secuencia metodológica de la simulación está directamente relacionada al avance temático del módulo o asignatura, evaluando en cada etapa lo que estudió el alumno en la sección teórica, pretendiendo así lograr los objetivos planteados para el módulo. El propósito del simulador es práctico, por eso no se centra en explicar cómo se hacen los cálculos financieros, tampoco tiene desarrollos conceptuales extensos como parte de los escenarios de simulación, por el contrario, lo que busca es que el estudiante tenga posibilidad de experimentar y pueda medirse así mismo en la forma cómo aplica los conocimientos en la praxis. 


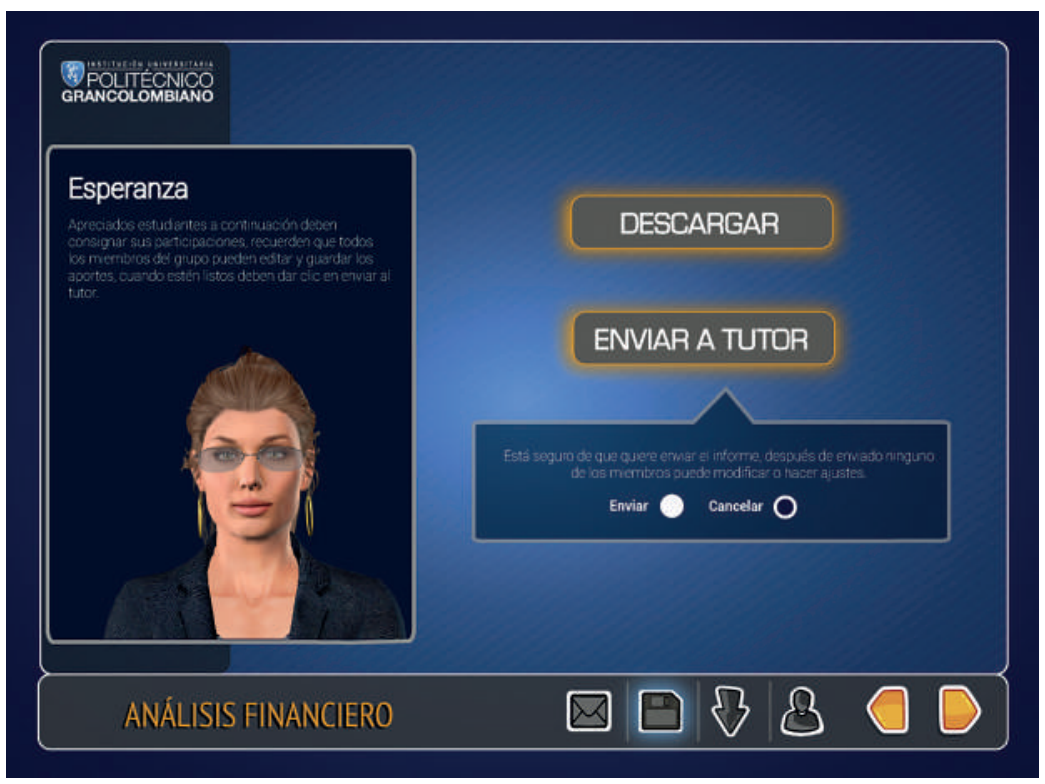

Figura 2. Envío del trabajo final al tutor por parte del equipo.

Fuente: Politécnico Grancolombiano (2017).

Cada empresa asignada es distinta para cada estudiante en la experiencia individual, la cual se toma de una base de datos de diversos sectores financieros para que el estudiante se prepare para analizar financieramente cualquier tipo de organización, pues no se sabe con certeza en qué empresa va a ser contratado. La base de datos la construye el tutor a partir de datos de los sectores reales, esto permite ingresar más compañías, sacar aquellas que han salido del mercado, provocando que la asignación de empresas sea dinámica y diversa para los estudiantes. Como cada experiencia es personal esto reduce las posibilidades de copia o plagio en la población estudiantil y lo vuelve un compromiso del estudiante con su aprendizaje.

La motivación es compleja en ambientes virtuales y para que se dé en espacios de aprendizaje con adultos debe ser significativa, se ha detectado que es altamente relevante para los aprendices adultos tener claro el objetivo de cada actividad y cómo la pueden aplicar en su quehacer diario. Según Brophy (2004), el término motivación es un constructo teórico que se emplea para explicar la iniciación, dirección, intensidad y persistencia del comportamiento, especialmente de aquel orientado hacia metas específicas. Por tal razón la experiencia de aprendizaje también se diseñó con ese componente 
motivacional que pretende que la simulación se convierta en un reto personal donde el estudiante se enfrenta a un escenario real y obtenga una vivencia formativa y enriquecedora a través de un ambiente virtual.

\section{Modelo para la simulación}

El simulador para gestión financiera es una herramienta que le ayuda al estudiante a alcanzar las competencias definidas para el módulo o asignatura de Administración financiera, en especial en lo que se refiere a interpretar acertadamente los estados financieros de una empresa, al ser una competencia transversal para cualquier persona que adelanta estudios relacionados a la administración, gestión de empresas o procesos de ventas y endeudamiento su propósito educativo se vuelve fundamental para conocer y aplicar en debida forma la lectura de los estados financieros de cualquier empresa. Por tal razón el simulador fue hecho como herramienta de apoyo fundamental para orientar la toma de decisiones. El modelo utilizado para el simulador está basado en la metodología del análisis vertical y horizontal que son de uso general en el área financiera y se apoya en los indicadores financieros y de cobertura donde el análisis vertical busca establecer la importancia de cada una de las cuentas dentro del total de los activos, igual respecto a los pasivos y patrimonio, esto se logra asignándole a cada cuenta el porcentaje de participación de la cuenta respecto al total, con esta información, podemos hacer seguimiento a las cuentas más relevantes y así establecer su evolución en el tiempo.

Este análisis también nos brinda los parámetros de cómo está conformada la estructura financiera de la empresa en cuanto a su endeudamiento con capital externo y con el capital interno (patrimonio). Por su parte, con el pasivo corriente y el activo corriente se puede establecer un análisis respecto al capital de trabajo de la empresa y a su liquidez para atender adecuadamente sus obligaciones. En el activo no corriente, se podrá establecer la relevancia de estas cuentas en la generación de valor y su relevancia en la actividad económica que desarrolla que debe guardar relación directa con el pasivo no corriente y el patrimonio, ya que la financiación de bienes de capital debe ser a largo plazo.

En el estado de resultados, la participación de cada cuenta se mide desde el total de ventas, así se puede establecer en términos porcentuales el costo, los gastos, la utilidad entre otros. Aquí todas las cuentas son importantes para el análisis. 
En el análisis horizontal, la actividad que se realiza es determinar la variación porcentual y nominal de cada cuenta del balance y del estado de resultados de un período a otro, se revisa la variación en especial de las cuentas más relevantes del balance y del estado de resultados, esto tomado del análisis vertical, cada variación se revisa si tiene o no una evolución coherente respecto a las demás cuentas, en especial la evolución de las cuentas de ingresos, costos y las que tiene relación directa con éstas, como es cartera, inventarios y proveedores.

El análisis financiero se complementa muy bien con los indicadores financieros que también hacen parte del simulador y que facilitan la toma de decisiones, ya que se enfocan en aquellos aspectos de los cuales un gerente o directivo debe fijarse, entre estos indicadores están:

Indicadores de liquidez: miden la solvencia de la empresa en el corto plazo, como es el capital de trabajo, que se determina sacando la diferencia entre el activo corriente y el pasivo corriente, que establece si la empresa posee los recursos necesarios para cubrir todo su pasivo corriente. También se tiene dentro de los indicadores de liquidez, la razón corriente, que toma exactamente las mismas cifras, pero divide el activo corriente sobre el pasivo corriente, dando un indicador de solvencia en el que se espera sea mayor a la unidad, entre más alto mejor, sin embargo, si está muy alto significaría que la empresa tiene muchos recursos improductivos lo que definitivamente reduce la rentabilidad. Por último en estos indicadores se aplica la Prueba Ácida que es básicamente la misma de razón corriente pero restando del activo corriente el valor de los inventarios, lo que lleva a un índice de solvencia menor que una razón corriente: Este afecta especialmente a las empresas comercializadoras o productoras, para una empresa de servicios, termina siendo muy similar, y se basa en el hecho que no es posible monetizar rápidamente los inventarios a menos que se den una ofertas que lastimarían el flujo de la empresa.

Indicadores de actividad: miden la eficiencia o la rapidez con la cual rotan las principales cuentas del balance respecto a su actividad del estado de resultados, con ellos se puede establecer el promedio en que se recibe el dinero una vez se hace la venta, cuanto tiempo permanece un inventario en la empresa antes de ser vendido, cuantos días nos demoramos en pagarle a los proveedores después de recibir las mercancías, lo que nos permite formar un flujo de efectivo y así establecer un estimado de capital de trabajo requerido. 
Indicadores de crecimiento: esta información también se visualiza en el análisis horizontal, pero al determinarlos de forma aislada, se hace el énfasis que requiere en los rubros de ventas y de utilidad, tener claro estos porcentajes permiten medir como está la empresa respecto al sector e identificar si la evolución ha sido producto de decisiones propias de la empresa o más por condiciones macroeconómicas externas.

Indicadores de rentabilidad: establecen tanto la rentabilidad de las ventas, como la rentabilidad de los activos y del patrimonio, esta información es de gran interés para los accionistas o socios, que son la razón de existir de la empresa, por lo que se pueden considerar de gran importancia y en lo que finalmente se debe enfocar la empresa.

Indicadores de endeudamiento: permiten establecer el nivel de deuda de la empresa respecto al total de activos, nivel de deuda a corto y largo plazo, y apalancamiento financiero.

Indicadores de apalancamiento: establecen el GAO (grado de apalancamiento operativo) qué mide que tanto depende la empresa del cumplimiento de sus metas de ventas, o qué tan afectado quedaría en caso de no cumplimiento, ya que mide la eficiencia y productividad sobre los gastos fijos. El otro es el GAF (grado de apalancamiento financiero) que mide si el endeudamiento financiero genera recursos por encima de sus costos y a la vez permite establecer si se cuenta con los recursos para cubrir dichos gastos financieros.

El modelo de simulación incorpora todo el componente financiero que se acaba de explicar, sin embargo, como se mencionó en la estrategia pedagógica no se queda únicamente en lo numérico sino que incluye el avatar de un gerente que pide a sus colaboradores (los estudiantes) la rendición de cuentas a través de preguntas y con verifica los resultados de los cálculos financieros hechos por los alumnos. Posteriormente el gerente les solicita sugerencias financieras de acuerdo al rol laboral que cada participante haya seleccionado. Superada esta etapa, en la sesión grupal el gerente les solicita el informe con el análisis completo de otra compañía, conclusiones y sugerencias financieras.

\section{Desarrollo de la experiencia de aprendizaje}

Para el desarrollo del simulador se inició el proceso con el análisis del sílabo del módulo de Administración Financiera y se trazaron las competencias 
que se desarrollarán a través de la experiencia de acuerdo con las falencias que se diagnosticaron en los estudiantes, como ya se mencionó en el marco teórico. Una vez se definieron los propósitos de aprendizaje se tomó el análisis financiero y se elaboró un modelo matemático para la programación en Excel. Inicialmente se pensó en extrapolar las operaciones de la hoja de cálculo a la herramienta, sin embargo, al ver que era necesaria una base de datos de empresas y que los resultados numéricos varían de acuerdo con cada compañía, se incluyeron los cálculos numéricos en la base de datos para que el simulador los tome de acuerdo a las necesidades de simulación, de esa manera, las preguntas del gerente se vuelven propias para cada estudiante.

Por tal razón, uno de los componentes más complejos y extensos fue la elaboración de la base de datos que tiene alrededor de 16000 empresas con sus estados financieros, análisis vertical, horizontal e indicadores definidos para dos años de operación de cada una de ellas. De igual manera, la base de datos cuenta con un banco de preguntas con respuestas automáticas del simulador, esto genera una versatilidad para el equipo de tutores que pueden modificar la base de datos sin interferir en la programación del simulador, permitiendo el ingreso y salida de empresas, la inclusión o retiro de preguntas para cada cohorte de estudiantes.

Se creó el mapa conceptual donde se especifica de forma detallada cómo operar cada parte del simulador, qué sucede en cada etapa, cómo se evalúa en cada una de ellas. Las acciones que hacen el estudiante, el tutor y el simulador, para ello se descompuso la competencia en el ser, hacer, y saber, y se determinó un diagrama de tareas de acuerdo con cada uno de los roles establecidos. Para complementar el proceso se planeó la interacción de la herramienta con el material del módulo y sus actividades evaluativas.

A partir del mapa, se elaboró el guion donde fueron incluidos dos personajes de interacción el gerente y Esperanza (Mila) quien toma el papel de asistente de gerencia, guía al estudiante y le indica las labores debe realizar. El personaje de Esperanza evolucionó de asistente a guía del estudiante en todos los simuladores del área de administración con el fin de darle una identidad a la estrategia de simulación y su nombre cambió a Mila. Por su parte, el gerente general de la empresa en la que se labora el estudiante, en el ejercicio, le solicita los resultados y retroalimenta respecto a las respuestas dadas.

El guion se desarrolla con similitudes a un guion multimedia, pero con variaciones propias de un desarrollo de software. Para la construcción de los 
escenarios o interfaces se trabajó la escaleta que describe cada escenario gráfico con el fin de que estos sean diseñados de acuerdo con los requerimientos de los expertos temáticos o autores.

Para el área financiera se estableció una línea de diseño que combina los colores institucionales con un ambiente virtual de vídeo juego, personajes animados en 3D y con escenarios renderizados en 3D según las necesidades o peticiones del guion.

El ambiente gráfico para los tres simuladores financieros se aprecian en la gráfica 3.

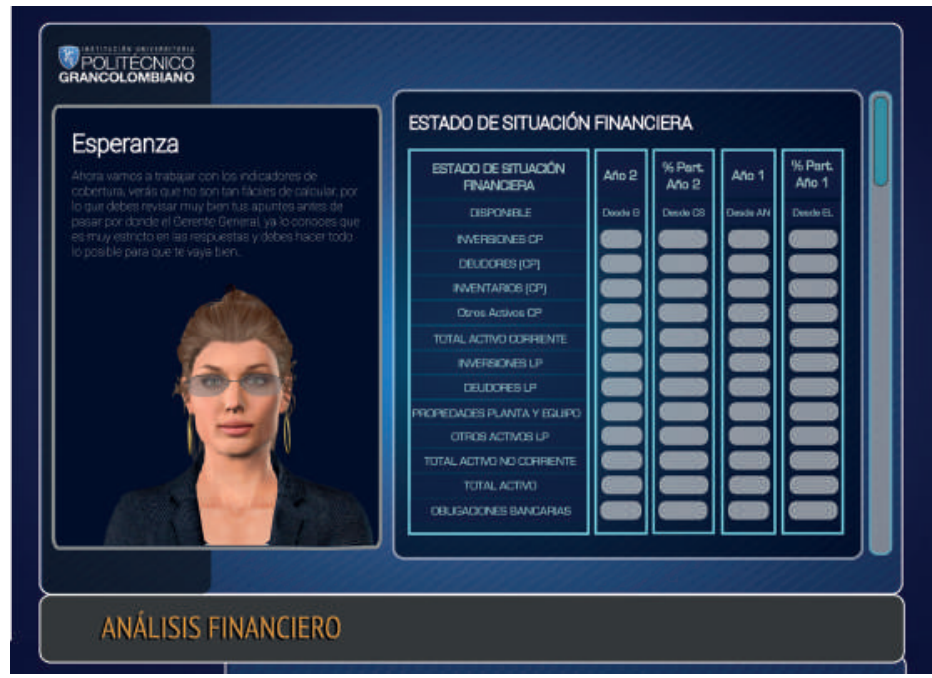

Figura 3. Ambiente gráfico para los simuladores financieros.

Fuente: Politécnico Grancolombiano (2017).

El avatar es un personaje animado en 3D con diálogos disponibles en audio, sin embargo, se dejan visibles los diálogos en texto para la población estudiantil sorda de la Institución.

Con el fin de convertir la simulación en una experiencia completa de aprendizaje se construyó la guía didáctica para el estudiante que explica las diferentes actividades y recomendaciones metodológicas que debe seguir el estudiante para su simulación. No es un tutorial de manejo de la herramienta, es una guía metodológica de lo que debe hacer en la simulación

Para la programación se tomaron los guiones y de manera interdisciplinaria entre académicos, diseñadores gráficos, animadores, y programadores se 
realizó la programación y desarrollo de software. El sistema no es interactivo entre grupos, cada equipo toma sus decisiones y no afectan a las de los otros participantes o equipos.

\section{Resultados obtenidos}

La primera experiencia fue la versión beta del simulador que funciona de manera individual, actualmente está en desarrollo la sección grupal que tiene la dificultad de interactuar con los sistemas de información de la institución. Se está realizando la integración para que desde el simulador se realice la gestión académica. Continúa la fase de implementación del simulador en las aulas y de los estudios posteriores para evaluar los resultados obtenidos por los estudiantes y el impacto al módulo con la experiencia de la simulación.

La siguiente fase es continuar con la estrategia pedagógica para el área de finanzas que se propone realizar otros simuladores para los módulos financieros, estos son: Simulador en Finanzas corporativas para proyectar los estados financieros y el flujo de caja apoyándose en los datos históricos y en las perspectivas del sector y según las condiciones entregadas; Simulador en finanzas internacionales que deberá tomar los históricos y las variables de precios de las divisas para generar los resultados de acuerdo a las decisiones tomadas por los estudiantes; Simulador de inversión de renta variable para invertir en el mercado de renta variable, renta fija y derivados de la Bolsa de Valores de Colombia (BVC).

\section{Conclusiones}

Se espera con esta herramienta el estudiante pueda medir adecuadamente su conocimiento y aplicación sobre los temas desarrollados, buscando que con un proceso de aprendizaje continuo y dinamizador se acentúe su motivación para realizar las tareas de índole financiera que son necesarias en su vida profesional.

\section{Bibliografía o referencias}

Biencito C., Domínguez G. y García J. (2005) La necesaria imbricación entre aprendizaje y formación. El simulador situativo como tecnología adecuada para la formación de formadores. Revista Complutense de Educación Vol. 16 Núm. 2 Págs. 645 - 671. 
Madrid, Universidad Complutense. Disponible en: https://revistas.ucm.es/index. php/RCED/article/viewFile/RCED0505220645A/16001

Brophy. J. (2004) Motivating students to learn. Taylor \& Francis. New Jersey, Lawrence Elbaurn Asociates Inc. Publishers.

Decreto 3022 (27 de diciembre de 2013). Superintendencia Financiera. Obtenido de: https://www.superfinanciera.gov.co/SFCant/Normativa/NIIF/dec3022_13.pdf

Michelsen Consulting Ltd. (2016) Manual Básico del Participante SIMDEF (Simulación de Toma de Decisiones Financieras). Disponible en: http://www.labsag.co.uk/ manualesv5/SIMDEF-BASICO.pdf

Otal, S.H. (2010). Learning Bussines Administration Using Simulation. Developments in Bussiness Simulation and Experimental Learning, 210 - 220.

Politécnico Grancolombiano. (12 de 09 de 2017). Centro de Información de la Organización Politécnico Grancolombiano. Obtenido de http://newcio.poligran. edu.co/EST/AA/SitePages/VariablesAcademicas.aspx

Vargas L., Y. (2017). Encuesta inconvenientes en el aprendizaje de las finanzas. Bogotá. Sin publicar.

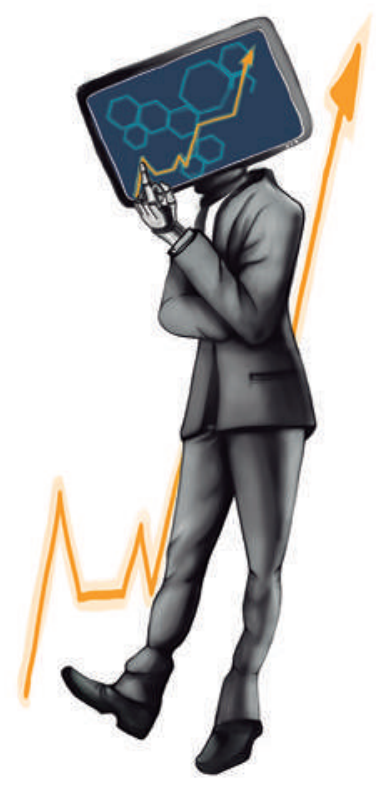




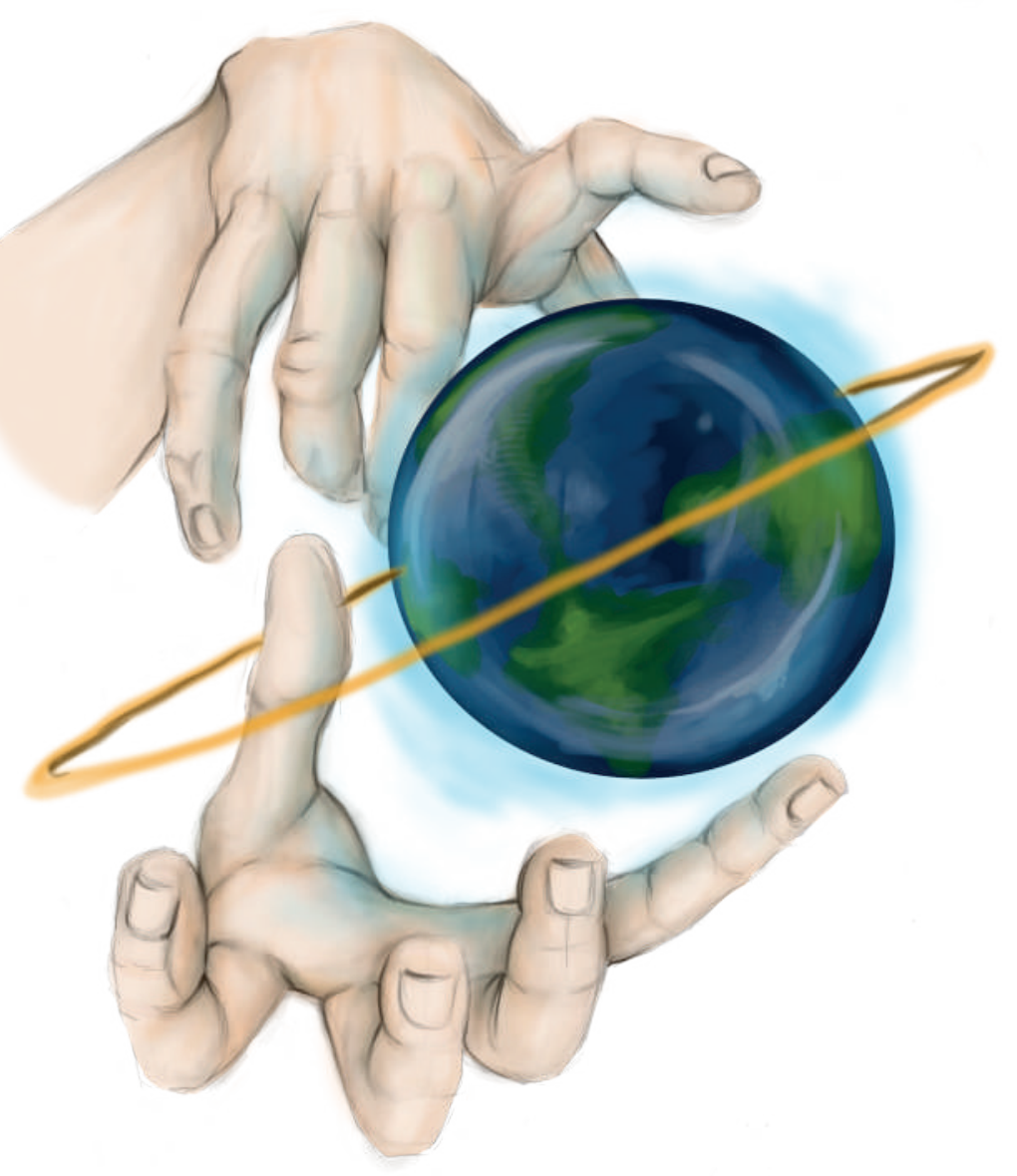

- Capítulo 4 -

\section{Simulador de Mercado de Capitales}

\section{Autores}

Juan Carlos Rojas Paredes. Administrador de Empresas de la Pontificia Universidad Javeriana, Especialista en Administración Financiera de la universidad EAN y Master en Dirección Financiera del Instituto Europeo de Posgrado. Experiencia de 14 años en el sector financiero como director de crédito de Leasing Aliadas, subgerente comercial de Leasing Bolívar, 
Coordinador de Formación en la Bolsa de Valores de Colombia y Fincon \& MIS Manager en Citibank (Citirecovery España). Experiencia en el sector real de 10 años como subgerente administrativo en Administradora JCR Ltda, jefe de planeación financiera en el Grupo Hosa, Gerente Administrativo y Financiero de International Travel Education y Gerente Administrativo y Financiero de Risk \& Financial System. Experiencia como docente universitario en pregrado y posgrado de 13 años en el área financiera.

Correspondencia:jcrojaspa@poligran.edu.co

Luis Martín Trujillo Flórez. Ingeniero Electricista de la Universidad Nacional de Colombia, Máster en Edición Universitaria de la Universidad de Salamanca, Máster en Ambientes Virtuales de Aprendizaje Universidad de Panamá (En curso). Especialista en Ambientes Virtuales de Aprendizaje del Centro de Altos Estudios de Argentina. Coordinador del Laboratorio de innovación pedagógica e Investigación en Educación Virtual.

Correspondencia:mtrujilo@poligran.edu.co

\section{Diseñador de interfaces del simulador}

Mónica Carrero Becerra. Diseñadora gráfica e ilustradora del Politécnico Grancolombiano. Tecnóloga en multimedia del Servicio Nacional de Aprendizaje. Actualmente se desempeña como diseñadora del Laboratorio de innovación pedagógica del Politécnico Grancolombiano.

Correspondencia:mncarrero@poligran.edu.co

\section{Resumen}

Son múltiples los simuladores que se encuentran en el mercado para la compra y venta de acciones, esta experiencia inicia con una indagación de las diferentes herramientas de simulación con el fin de conocer la funcionalidad para analizar las falencias y virtudes de cada una de ellas. Con los resultados del análisis diseñar un simulador de mercado de capitales que se adapte a las necesidades académicas que permita una experiencia de aprendizaje más estructurada para los estudiantes, de esa manera, ellos puedan adquirir la competencia de Interpretar, diagnosticar y tomar decisiones de inversión en 
el mercado de renta variable, en el caso colombiano, el mercado administrado por la Bolsa de Valores de Colombia (BVC).

\section{Palabras claves}

Simulador de mercado accionario, aula tríadica, experiencias de aprendizaje.

\section{Introducción}

En el ambiente universitario de pregrado, posgrado y maestría se utilizan simuladores de negocios, internacionalización, banca, finanzas, marketing, hotelería, y de retail; que son diseñados y vendidos por compañías especializadas en este tema. La presente experiencia consiste en el diseño, planeación y desarrollo de un simulador en el mercado de capitales, el cual nace como ejercicio de la práctica docente buscando otras formas de mejorar los procesos de aprendizaje en el estudiante y desarrollado por la Institución Politécnico Grancolombiano.

Este proyecto tiene como innovación educativa llevar una experiencia de simulación de inversión en renta variable guiada como parte de una estrategia de aprendizaje. Con el propósito de que el estudiante adquiera habilidades de análisis, valoración y toma de decisiones de compra y venta en el mercado accionario, permitiendo analizar los resultados obtenidos.

El papel del tutor es significativo ya que la estrategia se centra el desarrollo de las competencias del estudiante con respecto a la toma de decisiones de compra y venta con responsabilidad, a partir de un análisis e investigación del mercado que lo conduzca a la reducción significativa del error, preparándolo para el mercado bursátil real. El tutor es la persona que guiará y orientará al estudiante con un entrenamiento adecuado para esa buena toma de decisiones.

\section{Marco teórico}

\section{Problemática que atiende}

A nivel educativo algunas instituciones tienen como requisito que los estudiantes participen en simulaciones de bolsa, en Colombia se trabaja regularmente 
la Bolsa Millonaria y al final obtienen una calificación por su participación, comúnmente al tener un costo, estas participaciones son grupales, por lo tanto, muchas decisiones se toman de manera colaborativa, algo positivo, pero poco real si se compara con el quehacer diario de un corredor de bolsa. No significa que no sea una experiencia valiosa para el estudiante, sino que existe un nicho interesante de oportunidad de mejora.

Otro aspecto que se encontró en la indagación es que las simulaciones no son guiadas, dependen de la forma individual como la aborda el participante, permitiéndole un proceso de autoevaluación de acuerdo con los resultados de las decisiones tomadas. Lo que significa que pueden llegar a un resultado, pero no tener certeza de que tan acertada fue la decisión tomada.

En definitiva, con las experiencias descritas, la problemática que se encuentra es que existe una simulación en el mercado que puede adaptarse y aplicarse en contextos educativos, sin embargo, no está concebida desde el aprendizaje y para aprendices. Por eso, la propuesta de innovación educativa consiste en mejorar las prácticas de simulación existentes tanto en el mercado bursátil como en la academia.

En la revisión fueron detectadas algunas diferencias con la estrategia de aprendizaje que se propone en esta experiencia, entre ellas:

- El proceso de simulación es controlado por el tutor, a diferencia de los programas de bolsa que dependen del calendario de cada proveedor o herramienta. Esto permite que el simulador se pueda adaptar a los requerimientos de la modalidad, sea virtual o presencial.

- La hora de apertura y cierre y la cantidad de ruedas son fijadas por el tutor. Lo que favorece que la simulación pueda acomodarse a las necesidades o particularidades de la población estudiantil.

- Los estudiantes cuentan con el apoyo de un tutor experto en el tema que los asesorará en el transcurso del proceso.

- El simulador cuenta con avatares que guían al estudiante durante todo el proceso de simulación.

- Los estudiantes antes de comenzar la simulación deben presentar una prueba diagnóstica, la cual deben aprobar para poder iniciar la simulación.

- Los estudiantes deben sustentar la toma de decisiones que realizan desde la rueda seis (6) hasta la rueda veinte (20). 
- Durante la simulación los estudiantes realizan entregas a su tutor que permiten evaluar su desempeño.

- Al finalizar la simulación el tutor efectúa una retroalimentación a cada estudiante.

- Como los datos del nemotécnico y precios de cierre son alimentados por el tutor se puede simular con la información de cualquier bolsa de valores del mundo.

Estas diferencias se vuelven ventajas para el proceso de aprendizaje, porque la herramienta se adapta a las necesidades académicas, por ejemplo, la mayoría de los estudiantes virtuales son trabajadores, por lo tanto, es complejo para ellos simular en horas laborales (8 a.m. a 4 p.m.) que son los horarios de funcionamiento de la bolsa de valores de Colombia. En esta experiencia el tutor fija las horas de apertura y cierre de las ruedas permitiéndoles a los estudiantes simular en horarios más acordes a su contexto estudiantil. Este principio se aplica a otras características que tiene el simulador, como son la fijación del nemotécnico por parte del tutor, o que los estudiantes deban argumentar cada una de las decisiones tomadas.

\section{Antecedentes}

Las experiencias de simulación en el mercado de valores no son nuevas, las más populares se han realizado en Europa y se encuentran en España y Alemania, un ejemplo es Infobolsa (http://www.infobolsa.es/) que tiene como valor agregado la posibilidad para que los usuarios cuenten con la información actualizada de las diferentes cotizaciones del mundo y con índices de diferentes productos. Si se quiere usar a nivel profesional, incluye un sistema de pago.

En Colombia una de las primeras experiencias fue hecha por Adcap Colombia Demo (asesores en valores), que contaba con concursos en línea. Esta compañía contaba con un demo para que las personas hicieran seguimiento a las acciones y que se arriesgaran a invertir con $\$ 250$ millones. Lastimosamente esta experiencia ya desapareció del mercado. También encontramos dos experiencias de simulación en el mercado de capitales, la primera es la Bolsa Millonaria efectuada por la Bolsa de Valores de Colombia (BVC) que tiene una regularidad semestral donde los estudiantes deben pagar para obtener la experiencia de simulación. La segunda a nivel empresarial la tiene el grupo AVAL en la cual el usuario ingresa y simula unas ruedas de negociación, sin 
embargo, la experiencia es individual y lo que se logra es que aprenda a través del ensayo y error.

A continuación, vamos a ver diferentes estrategias de simulación del mercado de valores y posteriormente explicaremos las diferencias que tienen con la experiencia de aprendizaje propuesta para este proyecto:

Yahoo Finance inversión global (https://es-us.finanzas.yahoo.com/screener/ new) es una herramienta diseñada para introducir a las personas en la inversión. Esta plataforma cuenta con una agencia de noticias con información del mercado en tiempo real, algunas recomendaciones en el mercado y acceso al comportamiento a todas las bolsas del mundo. A través de esta plataforma el inversionista podrá armar sus portafolios de inversión y podrá acceder a programas de educación financiera de forma sencilla y sin altos costos.

Credicorp Capital Colombia anteriormente Correval, (https://www. credicorpcapitalcolombia.com/etrading/demo) es una opción gratuita, pionera en E-trading (entrenamiento como corredor de bolsa), ofrece un demo para aprender a invertir en acciones.

Startbull (http://www.startupranking.com/startbull) es un simulador interactivo, una plataforma flexible, dirigida a quienes tienen intenciones de entrar al mercado. Funciona a través de asesorías que realizan entre los mismos usuarios realizando recomendaciones de inversión a otros usuarios a través de un chat. Asimismo, tiene opciones para armar portafolios de inversión.

Oanda (https://www.oanda.com/lang/es/forex-trading/) es un simulador ideal para incursionar en el mercado de divisas. Es una plataforma de Forex y cuenta con asesoría especializada.

Pro real time (https://www.prorealtime.com/es/) es una buena herramienta si lal intención es iniciar la inversión de dinero de forma simulada. Es considerado por los expertos como el programa referente en línea. La descarga es gratuita y se especializa en el análisis que es gratuito en el nivel básico y con cobro en el completo.

Sistema de bolsa virtual (http://www.labolsavirtual.com/) es una de las páginas web de referencia en simulaciones de bolsa en línea. Aquí el usuario puede replicar cualquier tipo de comportamiento que se de en Ibex-35 (índice de la bolsa española). También permite realizar competiciones entre usuarios y da acceso a operaciones más avanzadas. Esta web es gratuita y cuenta con acceso a cursos del mundo bursátil. 
La bolsa abierta (https://www.caixabank.cat/particular/bolsayderivados/ bolsayderivados_es.html) es un sistema para clientes del Caixa Bank y se puede usar desde cualquier Smartphone Android. En la aplicación se pueden conocer todas las evoluciones en las divisas y la cotización de los diferentes valores sumados a las estadísticas semanales, mensuales o incluso anuales. También ofrece la posibilidad de comprar acciones y a su vez cuenta con un cuadro de diálogo (chat) para compartir experiencias.

Impok (http://www.impok.com/) es un espacio donde los usuarios dan a conocer sus decisiones y logros y permiten que otros usuarios del mercado aprendan de ellos. Esta opción, se puede usar en IPhone y Android.

Metatrader 4 (https://www.metatrader4.com/es) no es propiamente un simulador de bolsa, es una opción creada para que los usuarios puedan vender y comprar acciones en tiempo real. Tiene versiones para computador y teléfonos inteligentes.

Metastock (https://www.metastock.com/) este sistema es idéntico al anterior, sólo que es pago, cuenta con pequeñas guías de entrenamiento y con traders profesionales.

Etoro (https://www.etoro.com/es/) otro espacio para aprender, que además conecta a traders de todo el mundo con un usuario novato que aún no sepa bien que movimientos debe hacer.

Indagando las diferentes herramientas que se encuentran en el mercado, algunas son gratuitas y otras pagas. Sin embargo, ninguna se trabaja desde una visión pedagógica, son herramientas financieras donde los estudiantes pueden simular, y lo que se ha hecho comúnmente desde la academia es adaptar la herramienta a una estrategia de aprendizaje diseñada por el docente o tutor según sea el caso. Este proyecto se desarrolla en sentido contrario, no se parte de la herramienta, sino del diseño pedagógico y desde allí se llega a la herramienta de simulación, creando de esa manera una experiencia educativa diferente.

\section{Estrategia de aprendizaje}

La experiencia se desarrolla para aplicarse en el módulo de Mercado de Capitales de forma teórica- práctica. Es una herramienta gratuita para los estudiantes de la institución que estén cursando el módulo. El propósito es 
que aprendan la teoría de manera paralela a su experiencia de simulación con el fin de evidenciar los conceptos vistos en su módulo. Esto permite preparar al estudiante en el saber y el hacer.

Para implementar la experiencia educativa se pensaron dos fases de simulación que debe desarrollar el estudiante.

La primera, una simulación de prueba que cuenta con cinco ruedas y busca afianzar al estudiante en el quehacer del corredor de bolsa, es autocontenida y la evaluación depende únicamente de los resultados en la rentabilidad que obtiene el estudiante, al finalizar se hace un ranking y la calificación dependerá únicamente del desempeño del estudiante, es autocontenida, es decir, el simulador califica al estudiante de acuerdo a la rentabilidad final obtenida tal como funciona la medición de un corredor de bolsa en una empresa real. Como parte del proceso de preparación para la simulación se realiza una evaluación diagnóstica para el estudiante dentro del simulador, si la aprueba puede ingresar a la simulación, si la reprueba debe volver a presentarla porque la idea es el estudiante tenga algunos conocimientos básicos necesarios para la simulación. La figura 1. Muestra el resultado de la prueba diagnóstica.

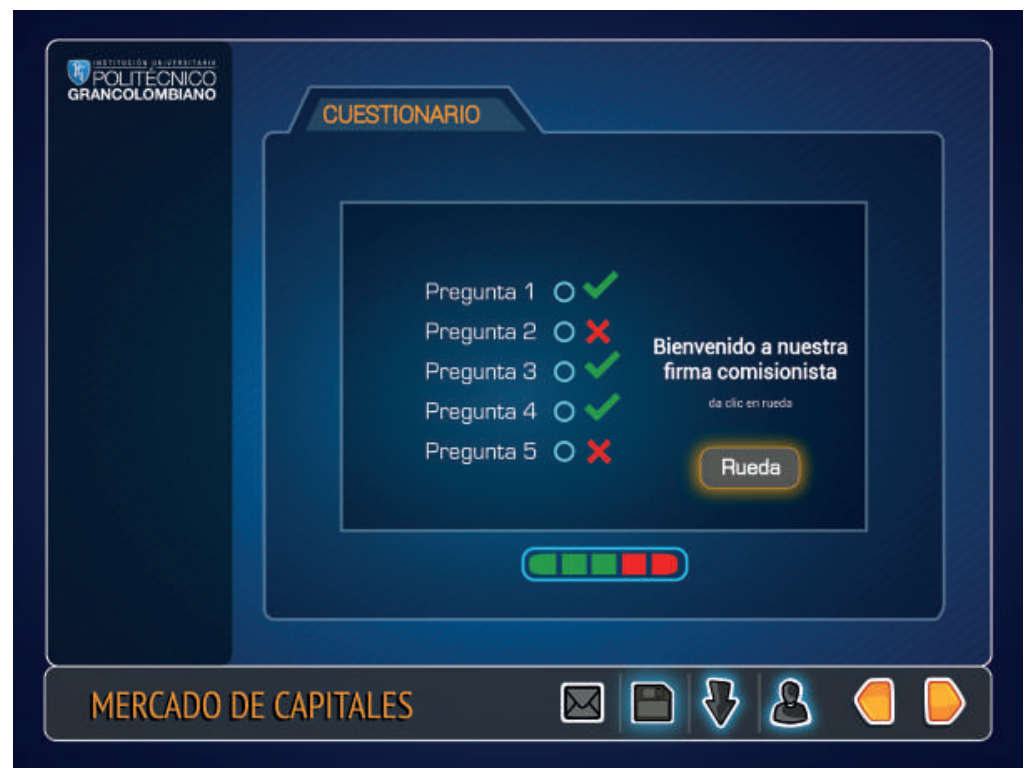

Figura 1. Resultado de la prueba diagnóstica.

Fuente: Politécnico Grancolombiano. Diseño: Carrero M. (2017) 
La segunda, una simulación argumentada que cuenta con 15 ruedas (de la 6 a la 20) para tener una experiencia total de 20 ruedas. Se evalúa primordialmente las decisiones que toma el estudiante y no los resultados obtenidos no son medidos, sino que se centra en la argumentación que hace el alumno de las decisiones tomadas en el simulador. En este caso, el ejercicio académico es más amplio, porque la experiencia de simulación es guiada por el tutor y el estudiante debe justificar cada una de sus inversiones, generando que asuma su papel de corredor de bolsa. Su papel va más allá de la justificación porque debe realizar un análisis fundamental antes de tomar la decisión. La argumentación es la acción más importante para el proceso de aprendizaje y se efectúa con el fin de:

1. Verificar el proceso de indagación en el mercado bursátil para prever posibles comportamientos en los precios de las acciones que cotizan en la BVC. Con el propósito que los estudiantes estén informados de lo que está sucediendo a nivel económico, político y social tanto en Colombia como en otras partes del mundo y que inciden en la cotización de una empresa en bolsa.

2. Buscar que el estudiante se responsabilice por cada una de las decisiones que toma.

3. Evidenciar la adquisición de los conocimientos del módulo por parte de los estudiantes llevándolos a la praxis y que a su vez ellos confronten los nuevos aprendizajes con los que tenían.

El tutor es fundamental porque debe incitar al estudiante a no tomar decisiones con ligereza, sino a que realice un proceso de indagación tanto del mercado como de las tendencias macro y microeconómicas para tomar la decisión más acertada.

Para crear una experiencia de aprendizaje más cercana a la realidad de un corredor de bolsa se optó por realizarla de manera individual de forma que cada persona responda por sus decisiones de compra o venta, de acuerdo a lo que sucede en el mercado. Por otro lado, pretende emular la situación real del quehacer diario del corredor de bolsa quien regularmente toma sus decisiones de manera solitaria. Finalmente, para lograr evidenciar cual es el proceso que cada alumno desarrolla en el proceso de indagación para la toma de decisiones y por eso debe argumentarlas. Para el estudiante la experiencia de aprendizaje tiene una ventaja adicional, la posibilidad de practicar con la información que está sucediendo en el mercado accionario en tiempo real. 
Como fundamento pedagógico se tomó el planteamiento del aula triádica, que nace de la propuesta de Robert Sternberg sobre la inteligencia que lleva el mismo nombre y que propone tres subteorías que forman la inteligencia humana: la contextual, la experiencial, y la componencial. La subteoría contextual sugiere la habilidad de un individuo de construir y formar su propio ambiente para que pueda mostrar y utilizar sus habilidades, intereses, y valores. La subteoría experiencial tiene que ver con la habilidad creativa de resolver problemas cotidianos y tratar con la novedad. La subteoría componencial explica el comportamiento inteligente de un individuo, los componentes internos, los componentes de ejecución y los componentes de adquisición (Shanon, 2013). El aula tríadica busca interrelacionar en el proceso de aprendizaje el accionar de estas tres subteorías en una experiencia integrada. En este caso, el estudiante debe utilizar sus habilidades e intereses como corredor de bolsa para resolver un problema de su quehacer diario en la toma adecuada de decisiones de manera responsable y argumentada. Integra la teoría vista en el aula con un ejercicio de simulación que pone en juego su inteligencia triádica para realizar la compra o venta de acciones y obtener la mayor rentabilidad.

Para completar el componente triádico, a la experiencia de simulación se le adicionó una estrategia de gamificación, la cual se basa en la construcción de un ranking de acuerdo con la rentabilidad obtenida según las inversiones realizadas por cada estudiante. Dicho ranking también tiene el fin de llevarlo al reto personal. El objetivo es generar una acción motivacional que significa apropiar en la labor diaria de un corredor de bolsa desde el ser. De tal manera que se abordan las tres dimensiones para la adquisición de la competencia.

La gamificación no es un videojuego, y vale la aclaración porque la simulación de este proyecto no se construye desde el juego, se construye desde la toma de decisiones. La gamificación, es utilizar mecánicas asociadas al videojuego, para presentar al alumno una serie de retos de aprendizaje, que cuanto el alumno lo haya cumplido, generará una recompensa a corto plazo dimensionada a la complejidad del reto (Parente, 2016). El reto es la mayor rentabilidad según las inversiones que realice el estudiante y el elemento de gamificación está en las diez mejores posiciones en el ranking, quien obtenga el primer puesto en la simulación de prueba tiene una recompensa en su calificación. Para la segunda simulación como el centro es la argumentación, se mantiene el elemento de gamificación, pero no tiene un valor en la calificación. La figura 2. Muestra el ranking y el elemento de gamificación para los diez primeros lugares, vale la pena aclarar que todos los estudiantes aparecen en el ranking sin importar la posición que ocupen. 


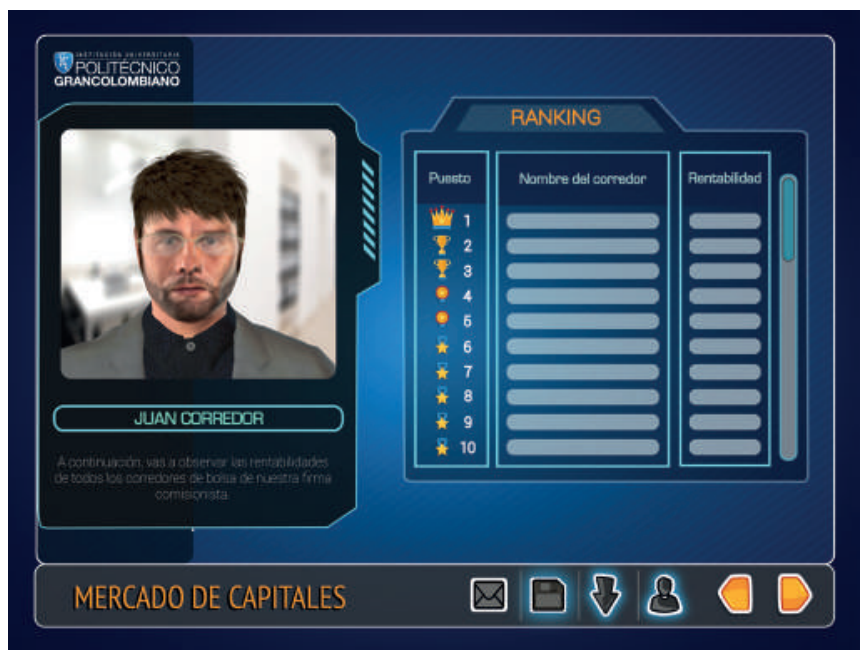

Figura 2. Ranking de posiciones de los estudiantes.

Fuente: Politécnico Grancolombiano. Diseño: Carrero M. (2017)

De igual manera, la gamificación se está empezando a emplear en entornos corporativos como estrategia para aumentar la competitividad, dado que representa una nueva forma de organizar procesos de trabajo más eficientes y productivos mediante las técnicas utilizadas en los videojuegos. En este sentido, la capacidad de las organizaciones para ser más competitivas y rentables aumentará de forma proporcional a su implantación (Parente, 2016).

La experiencia de simulación también tiene varios aspectos que le permiten al participante un aprendizaje significativo, que es el proceso según el cual se relaciona un nuevo conocimiento o información con la estructura cognitiva del que aprende de forma no arbitraria y sustantiva o no literal. Esa interacción con la estructura cognitiva no se produce considerándola como un todo, sino con aspectos relevantes presentes en la misma, que reciben el nombre de subsumidores o ideas de anclaje (Ausubel, 2002). En esta experiencia el estudiante debe argumentar cada decisión tomada, recibe una orientación y una retroalimentación de un experto para que tome mayor conciencia de las decisiones que tomó. Es fundamental que el estudiante tome conciencia y convierta en algo significativo las implicaciones que tienen las decisiones que toma y la responsabilidad que tiene con las mismas para su futuro desempeño como profesional y personal. 
Al final del proceso recibe una certificación en competencias para corredor de bolsa, lo que lo configura como una experiencia integral de aprendizaje.

El modelo de simulación se correlaciona con lo visto en la parte teórica del módulo y tiene en cuenta los siguientes aspectos:

1. Objetivo y plazo de la inversión: Los objetivos de una inversión hacen referencia a las metas a lograr en términos de riesgo, plazo y retornos esperados. El estudiante como primer paso debe establecer dichos objetivos para tomar una decisión de inversión. Dentro de la simulación todas las inversiones son a corto plazo con el fin de que puedan acompañar el desarrollo del módulo o curso y por el tiempo que dura el mismo.

2. Derechos como accionistas de una empresa: Las acciones son una alícuota de una compañía, es decir, que cuando un inversionista adquiere acciones se vuelve socio de esta. Estos títulos de participación otorgan a sus propietarios unos derechos económicos que consisten en negociar libremente las acciones, participar de la valorización y dividendos, y recibir activos en caso de liquidación de la sociedad. Además, adquiere unos derechos políticos que permiten al accionista la participación en la asamblea general y revisar los libros contables de la compañía. El estudiante en su papel de corredor de bolsa en la parte teórica del módulo o curso debe saber los derechos y deberes que tiene al invertir en acciones. $Y$ al tomar decisiones debe conocer el tipo de acción en la que invierte (ordinarias, privilegiadas, preferenciales) cada tipo de acción tiene unas características diferentes, las ordinarias tiene voz y voto, las privilegiadas tienen voz, voto y un dividendo privilegiado por máximo máximo cuatro años, las preferenciales no tienen ni voz ni voto. En el nemótécnico de la simulación se puede identificar el tipo de acción, sin embargo, el estudiante debe saberlo para una adecuada toma de decisiones.

3. Mercados en los que se pueden negociar acciones. Para la compra y venta de acciones existe el mercado primario que es el espacio en se negocian los títulos valores que salen por primera vez al mercado bursátil, y en el mercado secundario se negocian los títulos valores que ya se encuentran en el mercado bursátil, es decir que están en circulación y en manos de los inversionistas. Para el modelo de simulación el alumno solo trabajará en el mercado secundario porque se basa en los datos de las empresas que conforman el Colcap. 
4. Rentabilidad de las acciones: La utilidad de las acciones es variable, puesto que sólo se conoce en el momento de liquidar la inversión y depende del resultado que alcance la compañía. Existen dos elementos que componen la rentabilidad de las acciones: a) Valorización: si el precio de la acción de la empresa se incrementa frente al precio de compra, y se decide vender, de esa manera se obtiene una utilidad. En el caso contrario, el valor de la acción se desvaloriza y al vender se obtiene una perdida. b) Dividendos: si la sociedad en la que somos accionistas genera utilidades y la asamblea de accionistas decide repartir las utilidades, cada uno de los socios recibirá un dividendo que puede estar representado en dinero o acciones. Para el proceso de simulación el estudiante podrá comprar y vender acciones generando situaciones de ganancia o pérdida, o donde una decisión precipitada no le permita ampliar sus utilidades. Para finalizar el proceso se realiza una última rueda de cierre donde se vende todo el portafolio para determinar la utilidad o pérdida de dinero en el ejercicio de simulación. De acuerdo con esa rentabilidad se genera el ranking con el cual el estudiante podrá comparar la efectividad que tuvieron sus decisiones en comparación con las de sus compañeros.

5. Elección de las acciones en que se desea invertir. Esta decisión depende de las necesidades y preferencias de cada inversionista. La rentabilidad de las acciones es variable y cada empresa tiene un comportamiento diferente. Es decir, algunas tienden a ser más volátiles, por lo que su precio disminuye y aumenta con mayor velocidad según la actividad de la empresa emisora y su situación económica. Mientras que otras son más estables y el movimiento de su precio sólo se percibe en el largo plazo. El alumno debe investigar la volatilidad y situación económica de las empresas en las que desea invertir con el fin diseñar un portafolio que le permita diversificar el riesgo y maximizar las utilidades, y de esta manera sustentar la toma de decisiones en cada una de las ruedas de la simulación.

La experiencia de simulación lleva al estudiante a una certificación en competencias propias de un corredor de bolsa como si estuviera en el mercado bursátil real. Sin embargo, no es solamente la simulación, es una experiencia de aprendizaje integral que involucra los conceptos vistos, un proyecto de entrega con un componente investigativo y argumentativo. Es una experiencia evaluativa que está relacionada con el reto personal y la toma de decisiones. 
Desde otra perspectiva, la institución en sus programas virtuales, debido a la alta cobertura que tiene en todo el país, permite que el estudiante pueda tener un acercamiento al mercado bursátil colombiano, mientras que las simulaciones investigadas tienen una amplia difusión en las instituciones de educación superior y se centra en las grandes y medianas ciudades, aquí se lleva la experiencia a las poblaciones y todos los miembros de la comunidad educativa sin distinción de dónde esté ubicado, permitiendo una cobertura y un conocimiento más amplio de la actividad accionaria.

\section{Modelo para la simulación}

Para comprender el modelo de simulación que se empleó para este proyecto es fundamental entender el funcionamiento de la Bolsa de Valores de Colombia y el papel del comisionista de bolsa en la compra y venta de acciones, pues el simulador replica el desempeño que tiene comisionista en la BVC.

La Bolsa de Valores es un lugar donde se encuentran los compradores y vendedores de títulos valores. Inicialmente las bolsas de valores funcionaban en un salón llamado rueda, donde a diario se realizaba la rueda a viva voz, allí se reunían los Comisionistas de Bolsa para la realización de negociaciones de compra y venta de valores en un mercado libre y abierto. En Colombia, la rueda a viva voz funcionó hasta marzo de 1.999 para la Bolsa de Bogotá, Medellín y Occidente. A partir de abril de ese mismo año se implementó el sistema electrónico de transacciones en las tres bolsas y evolucionaron de la rueda a viva voz a la rueda electrónica. El primero de julio del año 2001 los tres mercados administrados por las Bolsas de Valores en Colombia se integraron, dando origen a la Bolsa de Valores de Colombia. En la actualidad la BVC realiza la rueda electrónica del mercado accionario en el horario de 9:30 a.m. a 4:00 p.m. hora de New York.

Actualmente, la Bolsa de Valores de Colombia tiene un sistema transaccional que permite negociar valores mediante la conjunción de ofertas de compra y venta. Donde intervienen los comisionistas de bolsa que son profesionales expertos en la consecución y colocación de capitales, quienes orientan a los inversionistas sobre el estado actual de los negocios, indicándoles las alternativas que pueden utilizar para invertir el dinero, suministrando elementos de juicio útiles para tomar una decisión.

Asimismo, las sociedades comisionistas de bolsa (SCB) desarrollan un mandato especial, que es el contrato de comisión; este contrato, de acuerdo con lo dispuesto por el artículo 1287 del Código de Comercio, consiste en "una 
especie de mandato por el cual se encomienda a una persona que se dedica profesionalmente a ello, la ejecución de uno o varios negocios, en nombre propio, pero por cuenta ajena". Esto significa que en el momento de realizar la negociación el comisionista no actúa a nombre del quien le encargó efectuar el negocio sino "a nombre propio", es decir, como si estuviera comprando para sí; lo que sucede es que el negocio lo realiza por las instrucciones que le impartió su cliente.

En el contrato de comisión para la compra y venta de título valores el comisionista de bolsa debe:

- Desempeñar directa y personalmente la comisión (Código de Comercio de Colombia, Decreto 410 de 1971. Diario Oficial No. 33.339 del 16 de junio de 1971. Art. 1291)

- Realizar los actos comprendidos dentro de los negocios que le son encargados por sus clientes y los necesarios para su ejecución (Código de Comercio de Colombia, Decreto 410 de 1971. Diario Oficial No. 33.339 del 16 de junio de 1971. Art. 1263).

- Entregar a los clientes todo provecho directo o indirecto que obtenga en ejercicio de la comisión, de manera que sólo pueden recibir la remuneración convenida para cada negocio (artículo 1265 C.Co).

- Respetar los límites del encargo (Código de Comercio de Colombia, Decreto 410 de 1971. Diario Oficial No. 33.339 del 16 de junio de 1971. Art. 1266).

- Separarse de las instrucciones impartidas cuando circunstancias desconocidas o ignoradas por los clientes que le hagan suponer razonablemente que éste habría dado su aprobación para ello (Código de Comercio de Colombia, Decreto 410 de 1971. Diario Oficial No. 33.339 del 16 de junio de 1971. Art. 1266).

- Suspender la ejecución del encargo cuando se presenten casos no previstos por los clientes, a menos que la urgencia y el estado del negocio no permitan demora alguna o estuviere facultado para obrar a su arbitrio, caso en el cual debía actuar según su prudencia y en armonía con la costumbre de los comerciantes diligentes (Código de Comercio de Colombia, Decreto 410 de 1971. Diario Oficial No. 33.339 del 16 de junio de 1971. Art. 1277)

A continuación, abordaremos la manera en que el estudiante realizará la simulación. En primera medida el aprendiz contará con una simulación de prueba que tendrá únicamente cinco ruedas con el fin de afianzarse con el 
simulador y con el rol del comisionista de bolsa. El propósito es que el estudiante comprenda el desarrollo del mercado de renta variable administrado por la BVC. Esta simulación será de respuesta automática por parte de la herramienta, tendrá una evaluación diagnóstica de conocimientos previos antes de iniciar la simulación. De acuerdo con la posición que ocupen tendrán un componente de motivación con la gamificación y un incentivo en la calificación.

En la una segunda simulación, el estudiante trabajará durante quince ruedas, en ellas deberá tomar decisiones de compra y de venta. Asimismo, deberá sustentar en cada una la toma de decisiones.

El aprendiz ingresa al simulador, se registra y a partir de ese momento el tutor puede hacer un seguimiento a las decisiones que tome. Allí encuentra el avatar que le da las indicaciones de cómo debe realizar la rueda. Luego ingresa a un escenario donde aparecen los precios de cierre de las empresas que conforman el Colcap. Dichos precios son alimentados por el tutor antes de iniciar cada rueda. De esa manera el estudiante ya tiene la posibilidad de comprar y vender acciones. El alumno también cuenta con un capital inicial para sus inversiones, dicho monto es igual para todos los participantes y fijado por el tutor.

El estudiante realizará tres entregas, cada una correspondiente a una fase del proceso de la siguiente manera:

- Fase uno: inicia en la tercera semana cuando el estudiante realiza cinco ruedas con el fin de familiarizarse con el simulador. El último día hábil de la esta semana el simulador venderá automáticamente el portafolio de cada estudiante y dependiendo al puesto que ocupe cada uno se le asignará una nota.

- Fase dos: Esta fase inicia en la quinta semana del módulo de mercado de capitales donde volverán a ingresar al simulador durante quince ruedas (las cinco primeras ruedas corresponden a esta fase), ya deben sustentar cada una de la toma de decisiones que efectúan en cada rueda. Al finalizar la semana los estudiantes deben subir al aula virtual un informe individual de máximo cinco hojas sobre el desempeño obtenido durante las primeras cinco ruedas y sustentar la razón de su posición en el ranking.

- Fase tres: Esta fase inicia en la sexta semana y finaliza en la séptima. Durante esta fase los estudiantes continuarán con el portafolio que tenían en la semana cinco, donde tomara decisiones de compra y de venta durante diez ruedas más y sustentando cada una de ellas. El último día hábil de la dicha semana el simulador 
venderá automáticamente el portafolio de cada estudiante y este podrá descargar el informe con la sustentación de las decisiones tomadas en la segunda y tercera fase para que el tutor retroalimente el trabajo.

El aprendiz ingresa al simulador, se registra y a partir de ese momento el tutor puede hacer un seguimiento a las decisiones tomadas por el estudiante. Allí encuentra el avatar que le da las indicaciones de cómo debe realizar la rueda. Luego ingresa a un escenario donde aparecen los precios de cierre de las empresas que conforman el Colcap. Dichos precios son alimentados por el tutor antes de iniciar cada rueda. De esa manera el estudiante ya tiene la posibilidad de comprar y vender acciones. El estudiante también cuenta con un capital inicial para sus inversiones, dicho monto es igual para todos los participantes y este es fijado por el tutor.

Dentro del simulador estará un avatar de nombre Mila que es un personaje de ayuda que guía al estudiante y lo orienta en todo el proceso para que realice adecuadamente la simulación.

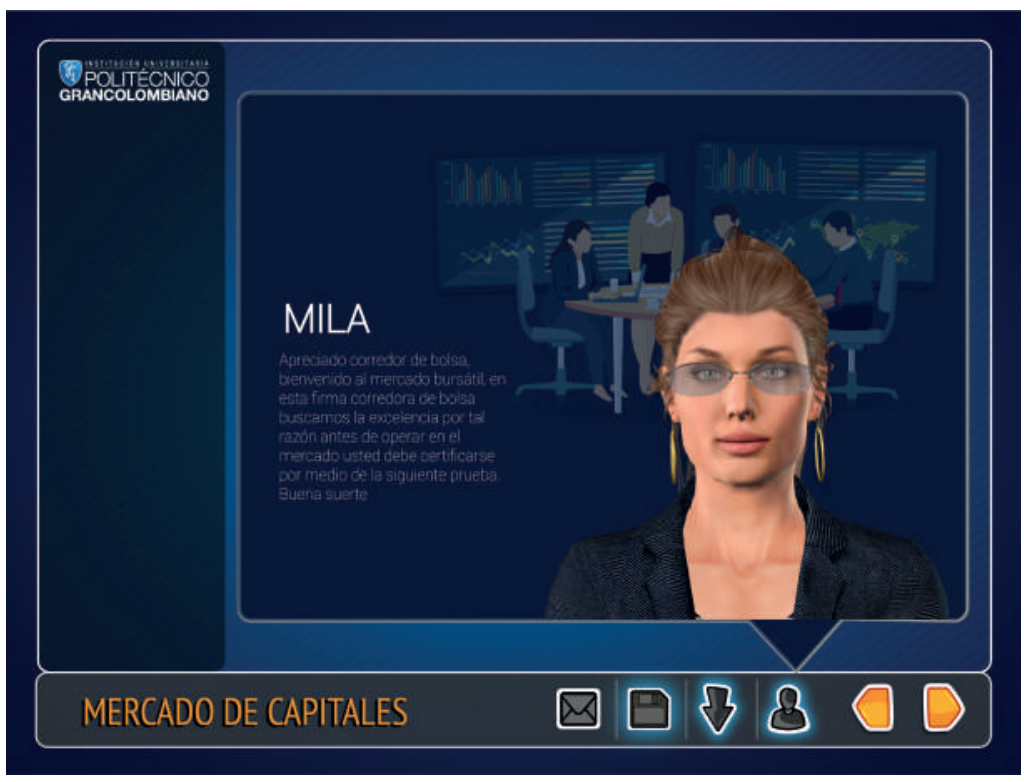

Figura 3. Avatar de acompañamiento al estudiante - Mila.

Fuente: Politécnico Grancolombiano.

Existe otro personaje denominado Juan Corredor que representa un corredor de bolsa, que informa los resultados de las ruedas y el ranking de los estudiantes, 
con el fin de enmarcar la simulación en un ambiente más cercano a la realidad. Ver figura 4.

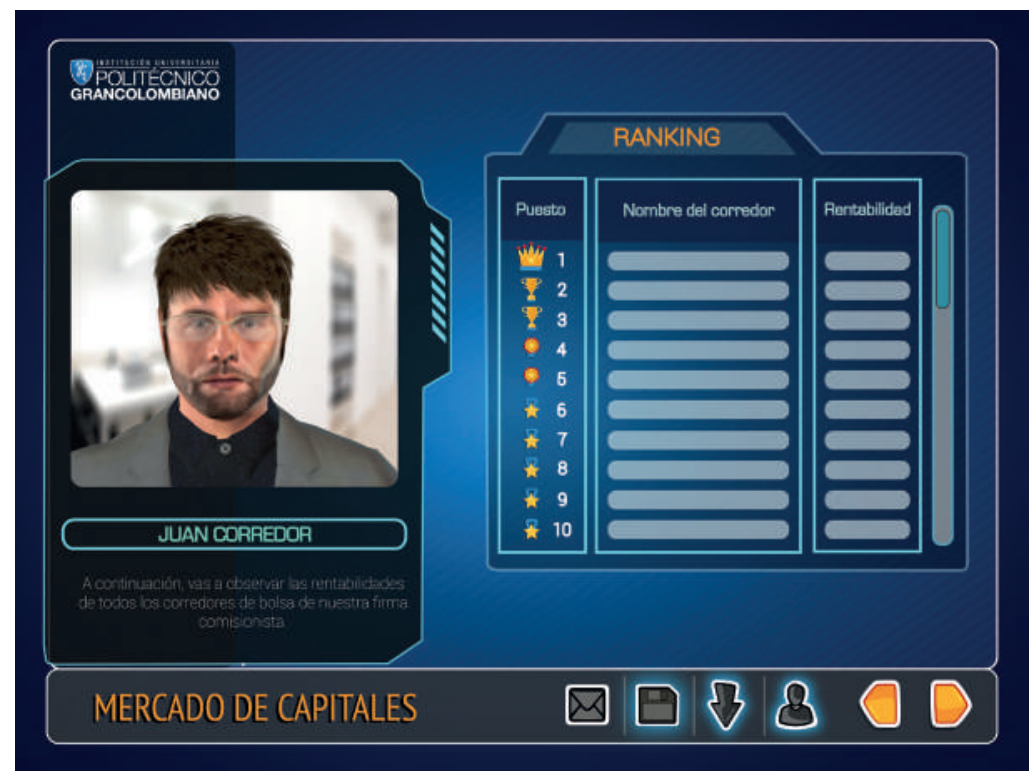

Figura 4. Avatar Juan Corredor.

Fuente: Politécnico Grancolombiano.

Uno de los puntos principales para la experiencia de aprendizaje consiste en desarrollar en los estudiantes las competencias de interpretar, diagnosticar y tomar de decisiones de inversión en el mercado de renta variable administrado por la BVC.

Igual que en una bolsa de valores, cada rueda tiene horario de apertura y cierre con la gran ventaja que, al ser fijado por el tutor, este horario se acomoda a las particularidades de nuestros estudiantes. Como el ingreso regular de los estudiantes a las aulas virtuales se hace después de las seis de la tarde, el horario para la rueda en la simulación es desde las 4:00 p.m. hasta las 11:55 p.m.

El estudiante decide qué acciones comprar o vender y el simulador le muestra el capital que ha invertido, el dinero que tiene disponible y al finalizar la rueda le calcula la rentabilidad. Con el último dato, lo ubica en un ranking con el fin de generar competitividad al interior del grupo y que exista una mayor motivación personal que lo rete a obtener mejores resultados. Dicha tabla de posiciones funciona con elementos de gamificación para que se enmarque en torno al juego ampliando así su estimulación hacia el proceso. 


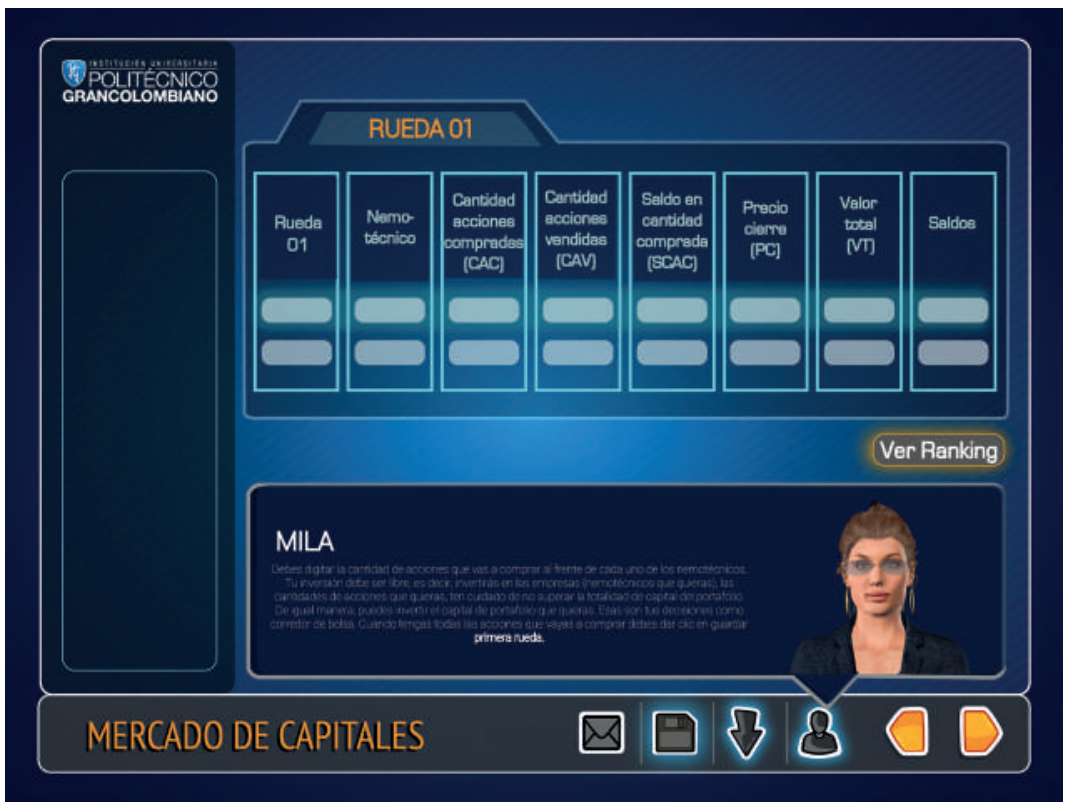

Figura 5. Ingreso de datos para la compra y venta de acciones.

Fuente: Politécnico Grancolombiano.

El tutor juega un papel fundamental dentro de este proceso porque es quien establece los parámetros para la simulación y hace la carga permanente de los precios de cierre de las empresas que conforman el Colcap reportados por la BVC. Además, dinamiza el proceso del estudiante y retroalimenta el desempeño y las decisiones tomadas por cada uno de ellos con el fin de orientarlo de una mejor forma. En otras palabras, toma el rol de un coaching educativo en el proceso del estudiante.

\section{Desarrollo de la experiencia de aprendizaje}

El proceso se inició con la indagación de las herramientas, después se plantearon las diferencias y se buscaron los puntos de mejora desde lo pedagógico. Inicialmente se pensó en un simulador de bolsa y en las diferencias que podría tener con los otros existentes en el mercado, por eso se pensó en un personaje de ayuda que guiara el proceso, después en la posibilidad de que el tutor fijará los horarios, en la cantidad de ruedas y en el monto de dinero con la que contará el estudiante para hacer la inversión. 
Por otro lado, fue necesario analizar la preparación que debe tener el estudiante para afrontar la simulación, por tal razón, diseñamos una evaluación diagnóstica para acceder.

Debido a la dificultad de que la información de la BVC, a pesar de ser pública, pertenecía a la Bolsa de Valores, se optó por que fuera el tutor quien subiera la información del nemotécnico casi de forma involuntaria y se creó la posibilidad de que el simulador sirviera para cualquier mercado bursátil del mundo.

El diseño del funcionamiento del simulador fue credo junto con el mapa de funcionamiento de este y las acciones de los personajes. Se decidió adoptar a Mila como el avatar de ayuda para todos los simuladores de la facultad de Ciencias Administrativas Económicas y Contables. También se adicionó un personaje llamado Juan Corredor, como corredor de bolsa, y su misión es mostrarle los resultados y el ranking de posiciones a cada persona.

Para hacer más cercana la experiencia del alumno a la que vive un corredor de bolsa real se incluyó la posibilidad de una segunda ronda de simulación grupal, la cual fue transformada en una simulación individual argumentada.

Con los guiones terminados se inicia la programación, con el fin de mantener una línea gráfica para los programas de finanzas, se toma la decisión que todos los simuladores del área financiera conserven la línea gráfica que es acorde con la imagen institucional.

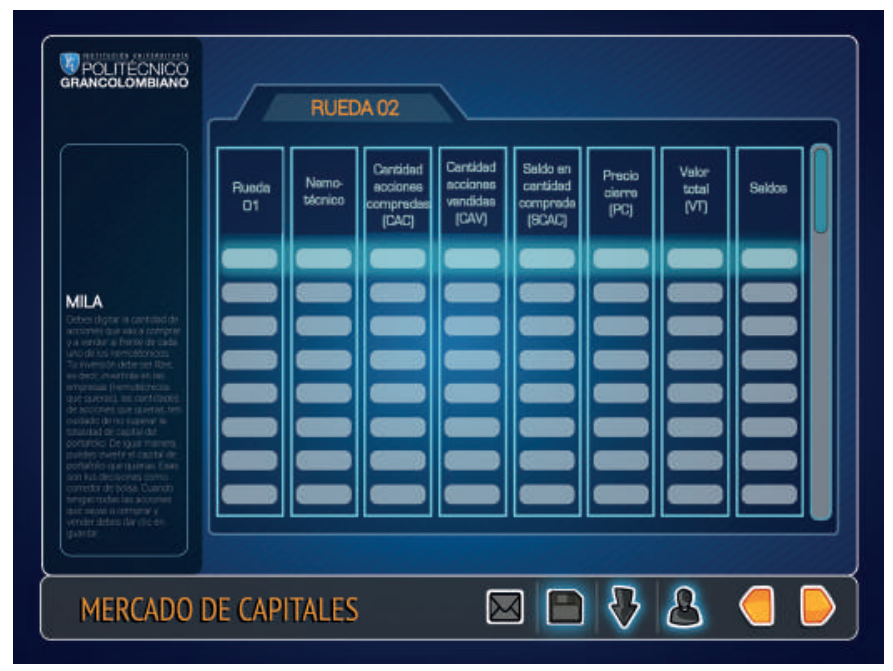

Figura 6. Línea gráfica del simulador de mercado de capitales.

Fuente: Politécnico Grancolombiano. 
Se cuenta con una botonera de navegación que se conserva para los simuladores financieros de la institución. Esta permite descargar los informes, avanzar en los escenarios y mostrar el personaje de ayuda.

Terminada la programación se hace la verificación del funcionamiento del simulador, se realizan los ajustes y se abre en el aula virtual.

Se implementa la posibilidad de certificar por parte de la institución la adquisición de competencias como corredor de bolsa.

\section{Resultados obtenidos}

Dentro de los resultados está el análisis de las herramientas presentes en el mercado, que evidenció que todos tienen fortalezas y debilidades. Algunas de las que se encontraron son: que las herramientas son rígidas y no se adaptan a las necesidades académicas, que no tienen acompañamiento durante la simulación y que para acceder a algunos de ellos se debe pagar.

El diseño se centró en desarrollar un simulador donde los estudiantes pueden participar de forma individual o grupal. En el transcurso de la simulación los participantes contarán con el apoyo de un tutor experto en el tema, que los guiará en el proceso de la simulación. Adicionalmente los estudiantes podrán tomar sus decisiones de compra y venta basadas en lo que está ocurriendo en el día a día del mercado de valores.

Se obtiene al final un simulador con características propias que le permite estar a la vanguardia de los que existen en el mercaxdo. Se espera mejorar los resultados de los estudiantes en la adquisición de competencias para interpretar, diagnosticar y tomar decisiones de inversión.

Se obtiene una experiencia de aprendizaje integral que incluye una guía didáctica para el estudiante: Una redefinición de la labor tutorial.

\section{Conclusiones}

Una de las ventajas más grandes del simulador de mercado de capitales es que es modular, es decir, se están desarrollando en la Institución otros simuladores financieros que al integrarse entre sí pueden tratar todos los aspectos financieros a nivel empresarial. 
En el mercado se encuentran herramientas robustas que sirven para un todo, sin embargo, no son útiles para un estudio específico, aquí al ser modular puede adaptarse fácilmente a las dos situaciones, trabajar en un módulo en específico o integrar los diversos simuladores y trabajar situaciones más globales que aborden competencias transversales en el futuro profesional.

Como los precios de cierre y los nemotécnicos son cargados por el tutor en una base de datos se puede trabajar con la información de cualquier bolsa de valores del mundo, convirtiéndose en una de las mayores ventajas a nivel académico porque se puede aplicar en diversos contextos educativos a nivel de mercado de renta variable porque todas las herramientas en el mercado van asociadas a un solo mercado de valores.

\section{Bibliografía o referencias}

Ausubel, D. P. (2002). Adquisición y retención del conocimiento. Una perspectiva cognitiva. Ed. Paidós. Barcelona.

Parente D. (2016) Gamificación en la Educación. p.11 y 18. En: Contreras R. y Eguia J. (2016). Gamificación en aulas universitarias. Barcelona, Instituto de comunicación Universidad Autónoma de Barcelona. Recuperado en: http://incom.uab.cat/ download/eBook_incomuab_gamificacion.pdf

Shanon A. (2013) La teoría de las inteligencias múltiples en la enseñanza de español. Salamanca: Universidad de Salamanca. Recuperado en: http://www3. gobiernodecanarias.org/medusa/ecoblog/yrodmar/files/2015/05/inteligenciasmultiples-AliciaMarieShannon.pdf

Cámara de Comercio de Colombia (1971). Código de Comercio de Colombia, Decreto 410. Bogotá.

\section{Webigrafía}

Caixa Bank. Herramientas e información bursátil. Bolsa y derivados. Recuperado de: https://www.caixabank.cat/particular/bolsayderivados/bolsayderivados_es.html

Credicor Capital de Colombia. Credicorp Digital. Recuperado de: https://www. credicorpcapitalcolombia.com/etrading/demo

Etoro. España. Bitcoin, Ethereum, Ripple y más. Recuperado de: https://www.etoro.com/ 
es/

Yahoo. Buscador de finanzas. Recuperado de: https://es-us.finanzas.yahoo.com/screener/ new

Impok. Herramienta de gestión de inversiones. Recuperado de: http://www.impok.com/

La bolsa virtual. Simulador de bolsa online. Recuperado de: http://www.labolsavirtual. com/

MetaStock. Líder mundial en herramientas de análisis de mercados. Recuperado de: https://www.metastock.com/

Meta trader 4. Plataforma comercial para el mercado fórex. Recuperado de: https://www. metatrader4.com/es

Oanda. Plataforma de negociación en línea. Recuperado de: https://www.oanda.com/ lang/es/forex-trading/

Pro real time software. Plataforma de bolsa y gráficos intuitivos. Recuperado de: https:// www.prorealtime.com/es/

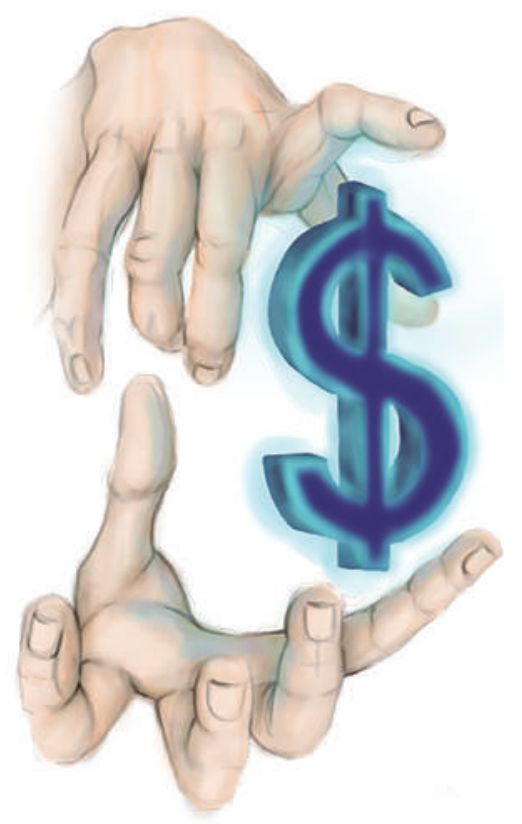




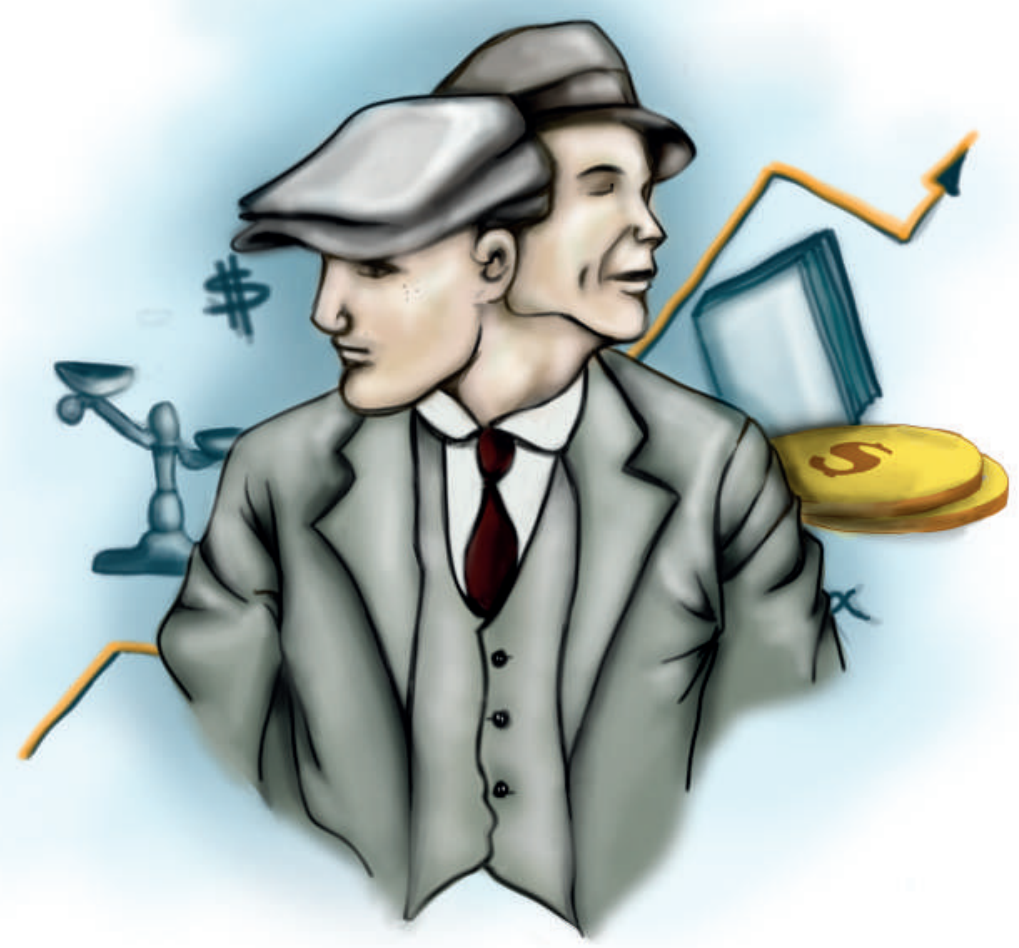

- Capítulo 5 -

\section{Simulador de evaluación financiera de proyectos}

\section{Autores}

Yolanda Rocío Vargas Leguizamón. Administradora de Empresas con énfasis en finanzas del Politécnico Grancolombiano, Especialista en Gerencia de Finanzas del Politécnico Grancolombianoy Master en Dirección y Asesoramiento 
Financiero de la Universidad de la Rioja Experiencia en análisis financiero en áreas de Riesgo y crédito empresarial en entidades financieras, Colpatria y Banco Comercial AVvillas. Estudios de riesgo en pymes y microcrédito, empresas corporativas y constructor. Desempeño como consultor financiero manejando el proyecto de Fondo Emprender, verificando la viabilidad en proyectos de inversión para capital semilla, siendo coordinador y capacitador del equipo de consultores. Experiencia en operaciones de factoring y descuento de contratos y financiación de vehículos de transporte público. Cuatro años de experiencia como docente universitario en el área financiera.

Correspondencia:yvargas/@poligran.edu.co

Luis Martín Trujillo Flórez. Ingeniero Electricista Universidad Nacional de Colombia, Máster en Edición Literaria Universidad de Salamanca España. Master en Ambientes Virtuales de Aprendizaje Universidad de Panamá. Especialista en Ambientes Virtuales Centro de Altos Estudios Argentina. Coordinador del Laboratorio de innovación pedagógica Virtual del Politécnico Grancolombiano.

Correspondencia:mtrujilo@poligran.edu.co

\section{Diseñador de interfaces del simulador}

Mónica Carrero Becerra. Diseñadora gráfica e ilustradora del Politécnico Grancolombiano. Tecnóloga en multimedia del Servicio Nacional de Aprendizaje. Actualmente se desempeña como diseñadora del Laboratorio de innovación pedagógica del Politécnico Grancolombiano.

Correspondencia:mncarrero@poligran.edu.co

\section{Resumen}

El presente documento obedece a la descripción del proceso realizado en el desarrollo de una herramienta de simulación que facilita la evaluación financiera de proyectos como una experiencia de aprendizaje. El proyecto surge de la necesidad de entregar a los estudiantes un apoyo pedagógico con el fin de fortalecer las competencias propuestas en el módulo de Evaluación de Proyectos además de retomar conceptos y procedimientos de módulos previos. 
Por su parte teniendo en cuenta el seguimiento de los resultados de los estudiantes en el módulo o asignatura y de acuerdo con la percepción de los tutores o docentes, se diseña una estrategia pedagógica que requiere como apoyo el desarrollo de un software que simule la evaluación de un proyecto de inversión, integrando ayudas metodológicas, para construir un ejercicio profesional que emula un ambiente laboral.

El presente documento describe el proceso de concepción del proyecto y planeación a través del trabajo colaborativo entre el área de finanzas y el Laboratorio de innovación pedagógica de la Institución Universitaria Politécnico Grancolombiano. Y presenta la experiencia pedagógica con cada una de las fases de simulación que permitan en los estudiantes un aprendizaje significativo y una adecuada adquisición de las competencias.

\section{Palabras claves}

Simulación, evaluación financiera de proyectos, modelos financieros, proyecto de inversión, aprendizaje por retos, aprendizaje por simulación.

\section{Introducción}

El desarrollo de simuladores en el área financiera no es algo nuevo, muchas organizaciones y programas de estudio han realizado diversas experiencias, algunas de ellas exitosas y se aplican en el ámbito educativo y empresarial, por ejemplo, el simulador de la Bolsa de Valores de Colombia (BVC). En diferentes entidades del sector financiero, entre ellas, el Grupo AVAL, cuentan con otro tipo de simuladores, así como, entidades que otorgan recursos de capital semilla como Fondo emprender, Red de emprendedores Bavaria, Innova Colombia.

Sin embargo, no existe un simulador en la evaluación financiera de proyectos que cubra desde el análisis financiero hasta la prospectiva económica que permita analizar la viabilidad de una empresa o de un proyecto de inversión al corto, mediano y largo plazo. Por tal razón, la innovación de esta experiencia de aprendizaje consiste en elaborar un simulador que se integre en las aulas para que así el estudiante pueda: aplicar conceptos generales de proyectos de inversión, desarrollar habilidades para trabajar los métodos de decisión, interpretar adecuadamente los resultados y analizar los posibles escenarios financieros. 
El estudiante debe aplicar los conocimientos adquiridos en la evaluación financiera de proyectos. Sin embargo, la estrategia está pensada para enlazar el área financiera, con los conocimientos económicos, contables, legales, en fin, diversas disciplinas que requiere el estudiante en su quehacer profesional. Para el futuro profesional en las áreas administrativas y financieras esta experiencia pedagógica no sólo evidencia las competencias adquiridas, sino que lo prepara para una realidad laboral.

Durante la ejecución de la experiencia de aprendizaje el estudiante debe integrar sus habilidades investigativas para ser aplicadas en un reto; para ello, deberá indagar temas de actualidad relacionados con el sector económico y al tipo de proyecto de inversión que va a trabajar en el simulador. El reto consiste en analizar la viabilidad financiera de una empresa o un proyecto de inversión, por lo tanto, los estudiantes deben utilizar las variables macroeconómicas colombianas y tener en cuenta la situación económica del país.

La experiencia, además, pertenece a un proyecto más amplio que intenta contar con varias herramientas de apoyo en el área financiera que el estudiante encontrará en sus aulas virtuales, de esa manera, se construye una experiencia integral de aprendizaje que enfrentan al estudiante con situaciones financieras de la empresa y le facilitan la apropiación de sus competencias.

\section{Marco teórico}

\section{Problemática que atiende}

Para iniciar con la problemática es fundamental comprender el contexto del módulo o asignatura de Evaluación de Proyectos para las modalidades presencial y virtual, el cual es transversal a todos los programas de la facultad de Ciencias Administrativas Económicas y Contables (para esta experiencia se toman las dos modalidades debido a que los sílabos son iguales en sus contenidos y temas a trabajar). Se concibe a la herramienta como parte integral del módulo o asignatura o para así complementar de forma práctica lo visto en la parte teórica.

Este módulo o asignatura presenta los conceptos de costos usando la metodología de costeo directo. Así como, los conceptos básicos financieros y aborda los principales métodos para la decisión financiera en proyectos de inversión, teniendo en cuenta los procedimientos para el cálculo del costo de capital y la construcción de los estados financieros entre ellos, el estado de 
resultados, el estado de situación financiera y el de flujo de caja libre. Concluye con el estudio del análisis de sensibilidad de acuerdo con la prospectiva del negocio, sector económico, país, etc.

Este módulo o asignatura corresponde al último semestre de las tecnologías de la Institución Universitaria Politécnico Grancolombiano y en el caso de programas profesionales es de semestres avanzados, $\left(6^{\circ}, 7^{\circ}, 8^{\circ}\right.$ dependiendo del programa). Se espera que los tecnólogos o profesionales cuenten con herramientas conceptuales suficientes en su disciplina para integrar los conocimientos de las ciencias administrativas en la evaluación financiera de proyectos, la cual es usada en todos los campos y es relevante en la mayoría de carreras administrativas, toda vez que las organizaciones a nivel general desarrollan constantemente proyectos, resultado de su plan estratégico, que sin duda demandan recursos económicos para su puesta en marcha.

Lo aprendido en el módulo o asignatura es útil tanto en el ámbito laboral como en las finanzas personales; logrando aplicar este conocimiento a decisiones financieras u otro tipo de inversiones como la compra y financiación de un inmueble o un vehículo. Significa que el panorama de aplicación es amplio porque se aplica a múltiples situaciones.

Para comprender la problemática se hizo una revisión del rendimiento académico en los últimos tres periodos académicos, donde es evidente que el módulo o asignatura reviste cierto grado de dificultad para los estudiantes como lo muestran las tablas 1 y 2.

\section{Tabla 1. Resultados Académicos Modalidad Virtual}
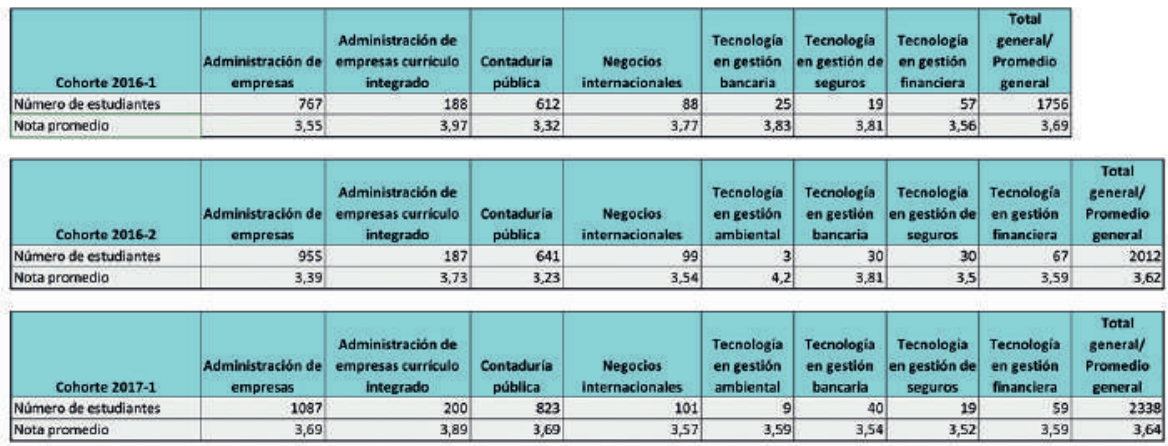

Fuente: Elaboración propia a partir de datos recopilados del Centro de Información de la Organización (CIO) del Politécnico Grancolobiano. Cohorte 2016- 6- 2017-2. 


\section{Tabla 2. Resultados Académicos Modalidad Presencial}

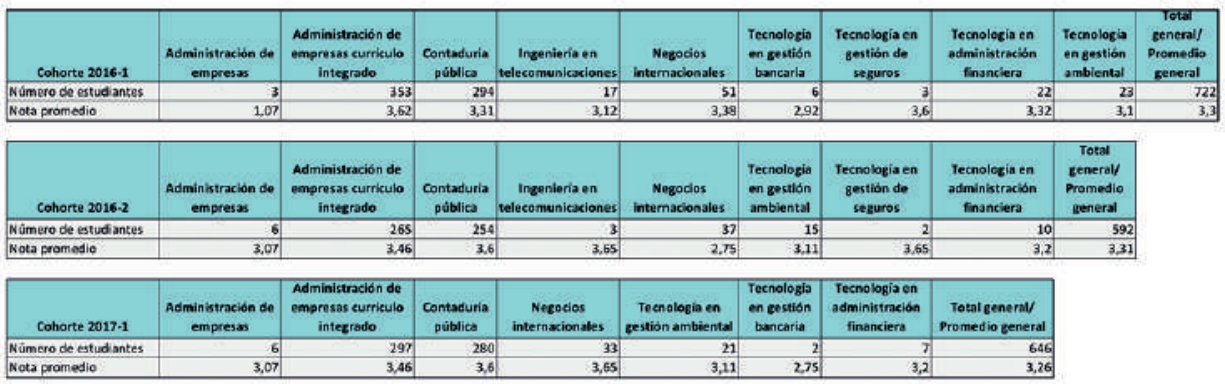

Fuente: Elaboración propia a partir de datos recopilados del Centro de Información de la Organización (CIO) del Politécnico Grancolombiano. Cohortes 2016- 1 - 2017-2.

En la tabla 1 se ven los promedios los estudiantes virtuales alcanzan notas de 3.6 sin llegar a ser sobresalientes. En la tabla 2, se aprecia que la nota promedio en los tres periodos analizados oscila en 3.3, considerando estos resultados como bajos para la asignatura.

En las tablas 3 y 4 están los resultados académicos por rangos de aprobación para las modalidades presencial y virtual.

Tabla 3. Calificaciones por rangos Modalidad Presencial.

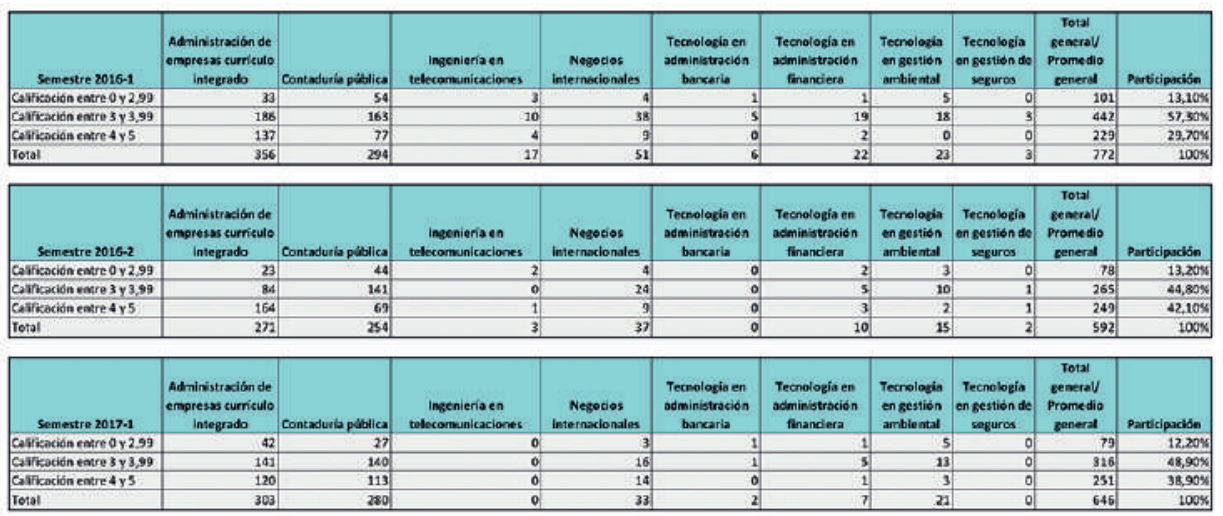

Fuente: Elaboración propia a partir de datos recopilados del Centro de Información de la Organización (CIO) del Politécnico Grancolombiano. Semestre 2016- 1 - 2017-2. 
Tabla 4. Calificaciones por Rangos Modalidad Virtual.
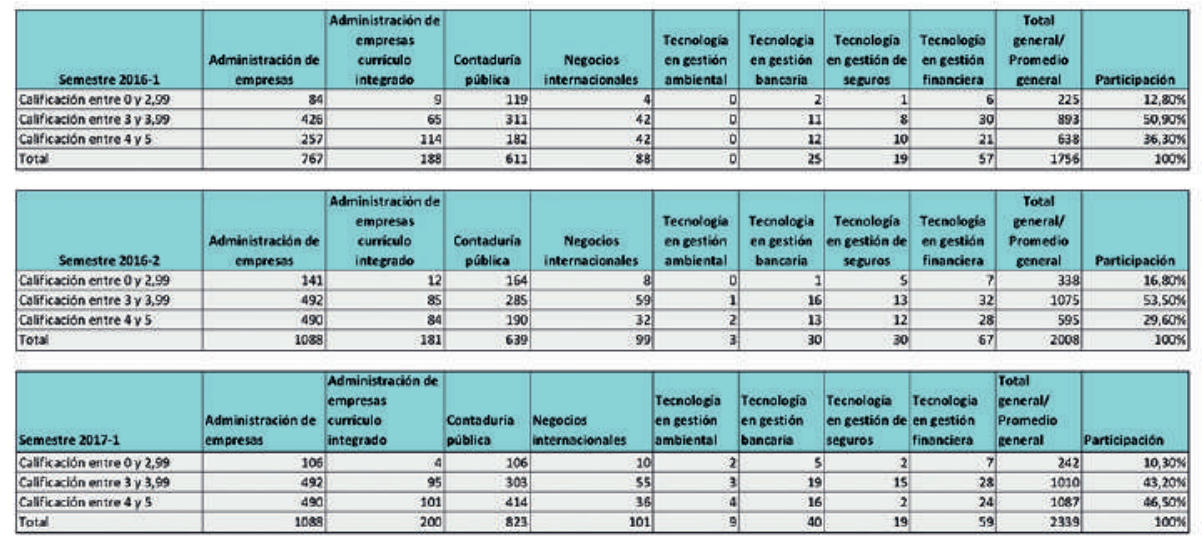

Fuente: Elaboración propia a partir de datos recopilados del Centro de Información de la Organización (CIO) del Politécnico Grancolombiano. Cohortes 2016- 1 - 2017-2.

Se observa en las tablas 3 y 4 que el porcentaje de estudiantes que no aprueba el módulo o asignatura en las dos modalidades oscila en el 13\%. Por su parte, la mayor concentración de notas se encuentra en el rango de 3.0 a 3.99. En la modalidad virtual encontramos que en este rango (de 3.0 a 3.99) se ubica en el $49 \%$ de los estudiantes. En modalidad presencial, en los tres semestres observados el $50 \%$ de los estudiantes se encuentra en dicho rango.

Los resultados académicos en general son cercanos para las dos modalidades, y la mayoría de los estudiantes aprueba de manera aceptable sin llegar a ser sobresalientes. Esto generó el primer interrogante para el equipo de tutores y docentes: ¿Cómo lograr mejores resultados en los estudiantes?

Por otro lado, se realizó un sondeo con 17 tutores/docentes de los cuales el $56 \%$ han sido facilitadores en modalidad virtual y presencial, el $44 \%$ sólo en modalidad presencial. Todos ellos pertenecen al área de finanzas de la Institución. El sondeo fue hecho sobre la percepción que tienen frente a las deficiencias encontradas en los estudiantes que cursan el módulo o asignatura. En primer lugar, se encuentra que las bases son deficientes en conocimientos matemáticos, logrando una calificación de 4,18 sobre 5 . Siendo 5 el mayor grado de dificultad y 1 el menor grado de dificultad. En segundo lugar, se encuentra la poca capacidad de interpretar y analizar resultados de los estudiantes con una calificación de 4.0. En tercer lugar, está el manejo deficiente de conocimientos contables, con una ponderación de 3.94. Finalmente se manifiesta que la falta de interés por el área financiera que es de 2.71 lo que significa que los 
estudiantes si se interesan por el módulo o asignatura, pero deben fortalecer los conocimientos previos. La tabla 5 muestra los resultados del sondeo.

Tabla 5. Percepción de los decentes de finanzas de la IUPG de las dificultades en los estudiantes

\begin{tabular}{|c|c|c|c|c|}
\hline Docente & $\begin{array}{c}\text { Falta de interés } \\
\text { en el área } \\
\text { financiera }\end{array}$ & $\begin{array}{c}\text { Deficientes } \\
\text { conocimientos } \\
\text { contables }\end{array}$ & $\begin{array}{c}\text { Deficiones } \\
\text { conocimientos } \\
\text { matemáticos }\end{array}$ & $\begin{array}{l}\text { Deficiente } \\
\text { capacidad de } \\
\text { análisise } \\
\text { interpretación } \\
\text { de resultados }\end{array}$ \\
\hline HERNANDO ESPITIA LOPEZ & 3 & 4 & 4 & 5 \\
\hline MARTINEZ CONTRERAS RONALD MAURICIO & 4 & 4 & 2 & 5 \\
\hline DORIS CAICEDO TORRES & 4 & 2 & 2 & 2 \\
\hline IVAN FRANCISCO TUNJANO PINZON & 4 & 3 & 3 & 3 \\
\hline CESAR AUGUSTO SALAMANCA RODRIGUEZ & 4 & 4 & 5 & 4 \\
\hline RUBEN DARIO MARTINEZ AMADO & 1 & 5 & 5 & 4 \\
\hline JOHANN GARCIA LOPEZ & 3 & 4 & 4 & 2 \\
\hline MONROY JUAN PABLO & 3 & 4 & 5 & 4 \\
\hline KALED ROLANDO ROJAS SANTANA & 2 & 4 & 5 & 3 \\
\hline GERMAN ALFREDO BUENAVENTURA CARDENAS & 2 & 4 & 4 & 4 \\
\hline HERNANDO RODRIGUEZ FIGUEROA & 2 & 4 & 4 & 4 \\
\hline CARDENAS MOLINA MARY LOURDES & 3 & 5 & 5 & 4 \\
\hline Luis Eduardo Rincon Valero & 1 & 3 & 4 & 5 \\
\hline JUAN CARLOS ROJAS PAREDES & 3 & 4 & 5 & 5 \\
\hline Jaime Andres Rojas Garcia & 3 & 4 & 5 & 4 \\
\hline LEONARDO NIÑO FABIAN & 3 & 4 & 5 & 5 \\
\hline EDGARD QUIROGA AARON & 1 & 5 & 4 & 5 \\
\hline Promedio & 2,71 & 3,94 & 4,18 & 4,00 \\
\hline
\end{tabular}

Fuente: Elaboración propia a partir de formulario office.

Se realizó dentro del sondeo algunas preguntas abiertas y en la mayoría los tutores/docentes coinciden que un inconveniente es el poco tiempo de estudio que los estudiantes dedican al módulo o asignatura. Otra falencia que se evidencia es el deficiente manejo del Excel, fundamental por los cálculos que deben realizar los estudiantes.

Por ende, la problemática se transforma de ¿Cómo lograr mejores resultados en los estudiantes?, a ¿Cómo lograr que los estudiantes apliquen los conceptos financieros y matemáticos dentro de un contexto empresarial, que les permita 
evidenciar la utilidad de los resultados numéricos obtenidos a través del análisis e interpretación de estos en la evaluación de proyectos para la adecuada toma de decisiones?

Con esta nueva mirada, se empezó el diseño de una estrategia pedagógica que consistió en la construcción de un proyecto de investigación formativa, donde el equipo de tutores/docentes estableció unos sectores económicos de análisis para los proyectos de inversión. Por su parte, los estudiantes debían crear una empresa y bajo un instructivo aplicar los conceptos y procedimientos vistos en el módulo con el propósito de analizar la viabilidad financiera del proyecto. Esta estrategia tuvo la dificultad que los estudiantes por si solos no lograban realizar todas las fases con éxito. Obviamente con resultados erróneos la interpretación no correspondía a la realidad financiera de la empresa.

Después se implementó para los estudiantes una plantilla en Excel con el fin de estandarizar los procedimientos a realizar y facilitarle los cálculos. Los resultados fueron mejores, la plantilla ayudó a los estudiantes, pero no es intuitiva para su orientación.

Aún faltaba llevar a cabo una experiencia más profunda con un escenario de ensayo y error donde el estudiante pudiera realizar pruebas para que así pudiera analizar los cambios de acuerdo con la variación de los datos. Por tal razón, fue creada una experiencia de aprendizaje que consistió en la planeación, diseño y desarrollo de un simulador para la evaluación financiera de proyectos. Dicho simulador integra varios aspectos que amplían la experiencia de aprendizaje, en primera medida ayuda a mejorar los resultados académicos; motiva a los estudiantes porque los confronta en un escenario cercano a la realidad, direcciona su proceso de aprendizaje a través de un avatar guía y diversos personajes de interacción que lo integran a un contexto empresarial en un ambiente virtual, lo insta al análisis y la interpretación de resultados de forma individual y colaborativa, lo obliga a un trabajo activo en equipo, al desarrollo de habilidades de liderazgo, comunicación, negociación. Es decir, ayuda al desarrollo de habilidades duras y blandas necesarias en el futuro profesional.

\section{Antecedentes}

Una vez se indagó acerca de las experiencias académicas en la cuales intervienen el uso de simuladores, se encontraron diferentes disciplinas que los usan a menudo para acercar al estudiante a la realidad. En el área financiera se encontraron simuladores en temas especializados como: simulador para 
estudiar el mercado de criptomonedas (Cocco, 2017), al igual que juegos sobre finanzas personales, como el caso de Simulated interactive financial education game (Estados Unidos Patente no US20100248192 A1, 2010). Algunos simuladores más cercanos a nuestro desarrollo, relacionados con la enseñanza de la contabilidad y la toma de decisiones financieras, a través de un software desarrollado en visual basic (Otal, 2010). Sin embargo, para el tema específico de evaluación financiera de proyectos, no se encontraron ejemplos de experiencias de simulación.

Existen algunos antecedentes de herramientas similares hechas en Excel para el cálculo contable y matemático, similar a la plantilla creada por la autora principal del proyecto. Sin embargo, no se encontró una experiencia de simulación con escenarios de interacción con el estudiante y la predicción prospectiva financiera. Lo que enmarca a este proyecto como una experiencia única para el aprendizaje.

\section{Estrategia de aprendizaje}

Como ya se mencionó, propendiendo por la calidad académica a través de este proyecto se pretende integrar una herramienta de simulación con el fin de dinamizar la práctica académica, para que ellos entiendan los conceptos financieros en un escenario simulado. De igual manera, el aprendizaje será significativo para el proceso de formación dado que la herramienta invita al estudiante a integrar diversos conocimientos disciplinares a medida que se avanza en su simulación.

Para tal fin se creó un modelo matemático para la evaluación financiera de proyectos que le permitiera al estudiante conocer la viabilidad de un proyecto de inversión. Dicho modelo es aplicable tanto para proyectos de inversión como empresas que van a ser creadas en diferentes sectores ya sea de productos o servicios. El primer paso fue sintetizar dicho modelo matemático para el uso de los estudiantes que les permitiera realizar los cálculos para cada una de las etapas de la evaluación financiera. Esto se sintetizó en la plantilla en Excel, la cual se empezó a emplear durante la cursada del módulo o asignatura.

Contando con la plantilla en Excel se inicia el diseño de la experiencia de aprendizaje, por lo tanto, se recurre a metodologías activas centradas en el hacer del estudiante, por lo tanto, se trabajó el aprendizaje por retos porque involucra activamente al estudiante en una situación problémica real, relevante 
y de vinculación con el entorno, la cual implica la definición de un reto y la implementación de una solución (Laboratorio de innovación pedagógica Tecnológico de Monterrey, 2016).

El reto fundamental de esta experiencia es lograr que los estudiantes apliquen los conceptos financieros dentro de un contexto empresarial que les permita evidenciar la utilidad de los resultados numéricos obtenidos a través del análisis e interpretación de los mismos para la adecuada toma de decisiones. Al final del proceso el estudiante debe argumentar la decisión de invertir o no en el proyecto, o si se debe concentrar en mejorar aspectos que le permitan una mayor rentabilidad.

El reto se trabajó desde la emulación, se parte del supuesto que el estudiante es un evaluador financiero de proyectos y debe valorar un proyecto de inversión. A partir de este supuesto se inicia la construcción de un proyecto de aula donde el estudiante debe resolver el reto en tres etapas. En la primera de ellas será asignado a cada equipo la industria y el tamaño de la empresa que debe simular; lo que tiene como fin que el estudiante investigue sobre la situación económica y financiera del sector y las empresas de tamaños similares, así a partir de estos supuestos y de los datos investigados ingresa los parámetros del proyecto de inversión, tales como: inversión inicial, costos fijos, costos variables, financiación, cantidades, precios, entre otros.

El primer resultado del proceso es el informe de cada una de las decisiones tomadas en estos supuestos, los cuales son revisados por el tutor quien retroalimentará el proceso y realizará las recomendaciones pertinentes.

La segunda etapa consiste en visualizar los estados financieros que el simulador genera a partir de los supuestos ingresados y realizar un análisis de este, en esta etapa existe la posibilidad de corregir algunos de los supuestos de ser necesario, además el simulador realiza el cálculo del costo de capital teniendo en cuenta el dato de beta de la industria para mercados emergentes que debe investigar cada equipo según su industria. Con el costo de capital el simulador calcula los métodos de decisión VAN, TIR y RBC, para que finalmente el equipo realice su análisis. El estudiante debe obtener y analizar los resultados de los estados financieros previsionales a cinco años, se le solicita al estudiante sustentar cómo será la estructura de la empresa en cuanto a su financiación, generación de utilidades, generación de recursos de efectivo en el flujo de caja, etc. Este análisis junto a los resultados conforma el segundo resultado del proceso o segundo informe con cada una de las interpretaciones del equipo. 
El simulador cuenta en su interior con una herramienta para el trabajo colaborativo similar a una wiki con la cual se puede evidenciar la participación de cada integrante, de esa manera el tutor puede saber cuál fue el nivel de participación de cada miembro del equipo. El tutor interviene en el proceso de aprendizaje realimentando la simulación de cada equipo y las argumentaciones dadas.

La etapa final corresponde al análisis de sensibilidad, donde a partir de unas variables predeterminadas, el equipo decide cual o cuales, de ellas van a modificar para revisar los resultados en un escenario optimista, uno probable y uno pesimista. En este caso el estudiante realiza variaciones (puede ser en todas o seleccionar algunas de las variables) como el número de unidades, el precio, los costos fijos y/o los costos variables, analiza los cambios que tienen los resultados y posteriormente debe justificar cada uno de los supuestos. Igual que en las anteriores etapas el equipo debe sustentar cada una de sus decisiones para generar el informe final, sumado a las conclusiones y recomendaciones generales al proyecto de inversión. El proceso finaliza con las recomendaciones para que el proyecto sea financieramente viable. El tutor/ docente también deberá retroalimentar esta fase final.

Como ya se explicó, la propuesta pedagógica se construye bajo el aprendizaje por retos, visto el reto como una actividad, tarea o situación que implica al estudiante un estímulo y un desafío para llevarse a cabo (Observatorio de Innovación Educativa del Tecnológico de Monterrey, 2016). En este caso, el reto fundamental es que el equipo al realizar los cálculos del proyecto asignado, este sea viable al final del proceso, para ello el equipo de estudiantes debe ingresar los supuestos, revisar los resultados obtenidos y hacer los ajustes pertinentes argumentando cada una de las decisiones.

De acuerdo con el Observatorio de Innovación Educativa del Tecnológico de Monterrey (2016) "Los estudiantes analizan, diseñan, desarrollan y ejecutan la mejor solución para abordar el reto de una manera que ellos y otras personas pueden verlo y medirlo". En este caso los estudiantes tienen un proyecto de inversión y deben desarrollar una solución financiera para que se convierta en una empresa viable. Para ello utilizan el modelo financiero, el cual se lleva a la programación del simulador, es decir, el estudiante durante la simulación de forma imperceptible al seguir la ruta de navegación aplica el modelo financiero propuesto desde lo académico. 
Cada proyecto de simulación tiene diferentes formas de trabajarse, este en particular, la herramienta de simulación se programó de acuerdo con un modelado financiero que representa la realidad de forma simplificada. Funciona con un modelo matemático-financiero y cuenta con una serie de inputs o datos de entrada que el estudiante incluye y una serie de outputs o resultados que se desprenden de él (Fiering y Hufshmith, 1966). El simulador de evaluación financiera de proyectos es una herramienta que permite involucrar diversos supuestos para el proyecto de inversión con el fin de generar resultados financieros, que permitan la toma de decisiones. Una vez sean ingresados todos los supuestos en el simulador sobre el proyecto de inversión, generará de forma automática los estados financieros previsionales, el estado de resultados, el estado de situación financiera y el flujo de caja del proyecto; así mismo, arrojará los métodos de decisión como valor presente neto, tasa interna de retorno y relación beneficio costo.

El simulador le permite al estudiante realizar los cambios requeridos para verificar el impacto de las variables en los resultados, así él puede identificar qué variables generan mayores impactos y cuáles deben considerarse para realizar la simulación definitiva y que el proyecto sea financieramente viable.

Si bien es muy importante la obtención de los resultados numéricos, el proyecto se centra en el análisis de estos, por eso algunos de los cálculos los facilita la herramienta de simulación. El objetivo es que el estudiante se concentre en recomendar cuáles deben ser las decisiones adecuadas, por tal razón dentro de la estrategia de aprendizaje se piensa en una simulación individual donde el estudiante pueda variar los valores fundamentales y ver los efectos que dichos cambios le producen al proyecto. De igual manera, evaluar otros escenarios financieros variando costos, gastos, unidades producidas o precio, con el objeto de determinar estrategias ante cambios en la prospectiva económica.

La experiencia de la simulación cuenta con una guía metodológica que orienta al estudiante, le explicita el reto y le indica cómo será su proceso de simulación con sus entregables y bajo qué criterios será evaluado.

El estudiante encuentra dos espacios de simulación, el primero es individual denominado Espacio de Entrenamiento, al cual todos los estudiantes podrán ingresar y realizar la simulación según la empresa asignada por el simulador con el fin de practicar, sin valor en nota. El segundo espacio, denominado Simulación, se trabaja en equipo, sólo el líder puede ingresar los datos numéricos, por tal razón el equipo debe ponerse de acuerdo para que sean 
los datos definidos por todos los miembros. En esta simulación cada miembro del equipo tendrá espacios para sustentar cada una de sus decisiones, la información consignada allí se edita entre todos los integrantes en un espacio de edición de texto similar a una forma de Wiki dejando registro de cada una de las actividades de cada miembro del equipo. Este espacio de Simulación genera el informe que se le entrega al tutor para evaluar.

\section{Etapas de la estrategia pedagógica}
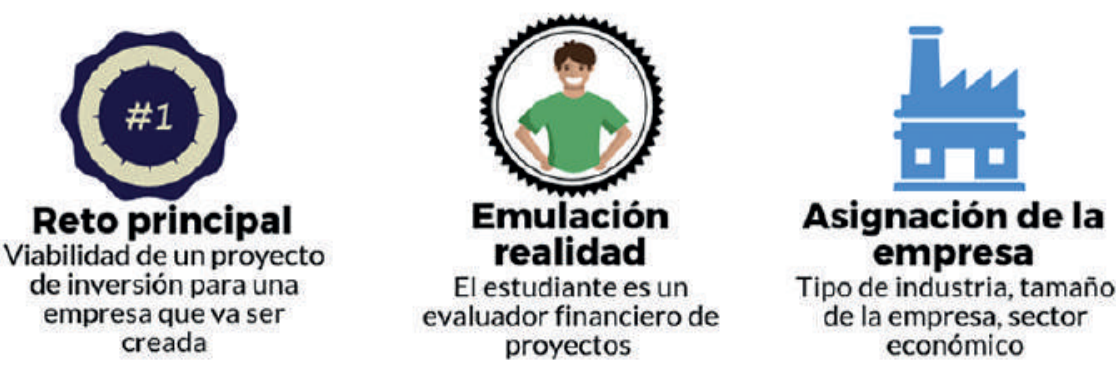

\section{Reto 1: Supuestos iniciales}

Investigar la situación económica y financiera del sector

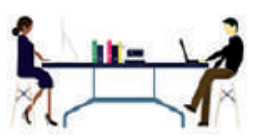

Ingresar los parámetros del proyecto de inversión

\section{Reto 2: Estados financieros}

A partir de los supuestos realizar los análisis y corregir los supuestos

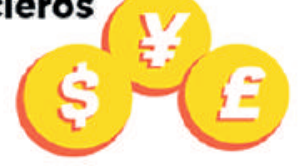

Obtener y analizar los resultados de los estados financieros provisionales a 5 años

\section{Reto 3: Analísis de sensibilidad}
Decidir cuales variables afecta, modificarlas, revisar los resultados en un escenario optimista y en uno pesimista

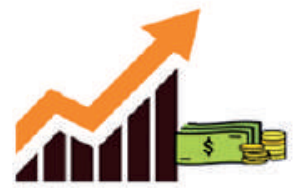

Analizar los cambios justificarlos, sustentar sus decisiones, conclusiones y recomendaciones para que el proyecto sea financieramente viable

Figura 1. Etapas de la estrategia pedagógica de simulación.

Fuente: Creación propia (2017).

El estudiante no puede acceder al espacio de simulación si primero no hace el entrenamiento. El simulador asigna el equipo de forma aleatoria, cada uno estará conformado por cinco personas, una de ellas será el líder, quien será el único que podrá incluir los datos numéricos finales en la simulación grupal y enviará el informe final al tutor. 


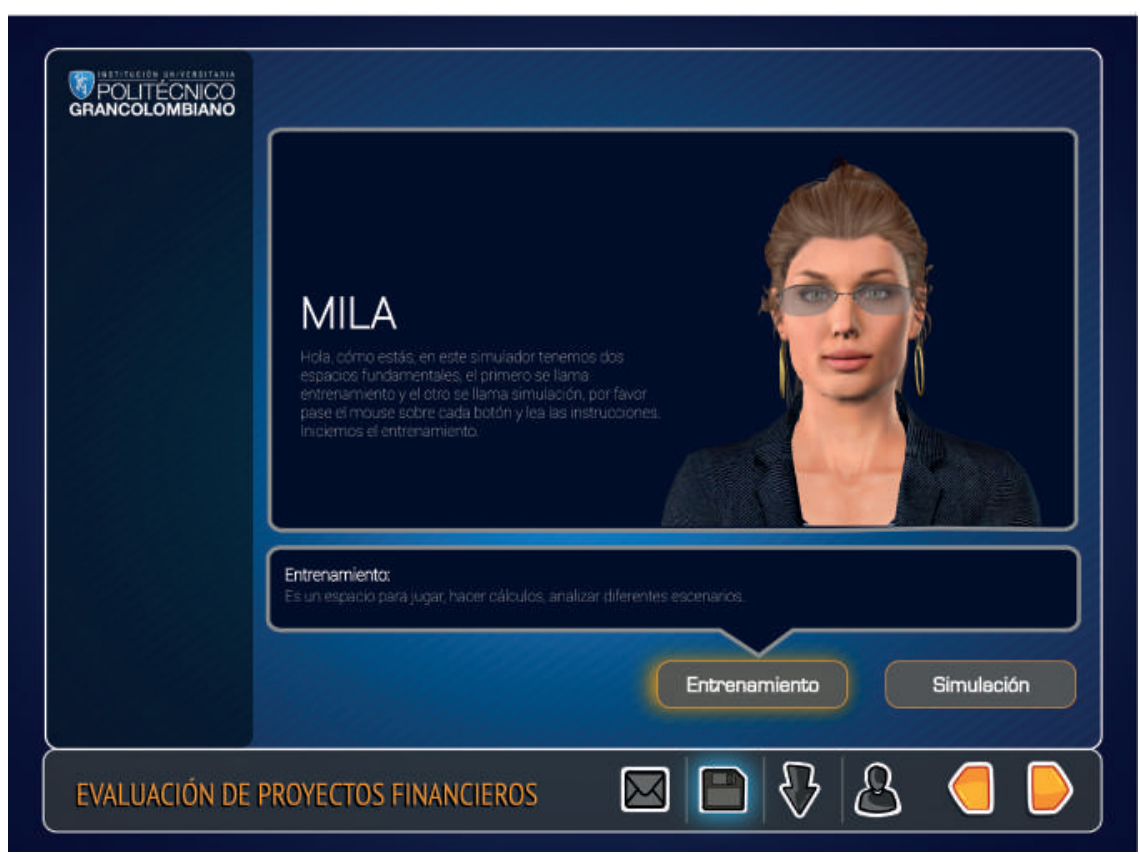

Figura 2. Espacios de trabajo del estudiante en el simulador.

Fuente: Politécnico Grancolombiano. Diseño: Carrero M. (2017)

Es importante tener en cuenta, que cada miembro del equipo (incluyendo al líder) debe participar en las justificaciones que solicita el simulador, la persona que no participe en las argumentaciones no será evaluada, por eso antes de hacer la simulación grupal el equipo debe reunirse de tal manera que la información consignada por el líder sea el consenso del equipo. Se espera que el trabajo colaborativo sea enriquecido gracias a la interdisciplinariedad de los estudiantes matriculados; en un aula hay alumnos de diferentes programas de la facultad, así que además del proceso de simulación y el desarrollo de habilidades técnicas en los conceptos concernientes al área financiera, también se pretende fortalecer habilidades gerenciales como el liderazgo, trabajo en equipo, capacidad de análisis y la toma de decisiones.

\section{Modelo para la simulación}

El fundamento para el desarrollo del simulador desde lo financiero, parte de las teorías de estructura financiera, así como de los métodos del cálculo del riesgo del proyecto y retorno esperado del mismo. En primer lugar, se acude 
al modelo CAPM, modelo de valoración de activos financieros, esta teoría fue publicada por (Sharpe, 1964), (Lintner, 1965) y (Mossin, 1966), de forma independiente en revistas especializadas. Los tres mencionan un modelo que determina el retorno de una inversión teniendo en cuenta el riesgo de la industria. En segundo lugar, se aplica el método de descuento de flujos de caja que permite valorar las compañías o los proyectos de inversión. De allí se parte para el cálculo de otros métodos de decisión para proyectos de inversión como el valor presente neto (VPN), la tasa interna de retorno (TIR) o la relación beneficio costo $(\mathrm{RBC})$.

Además de dichos modelos se utilizaron como textos de referencia: Evaluación Financiera de Proyectos Meza Orozco (2013) y Evaluación de proyectos de Gabriel Baca (2006).

El modelo de simulación en la evaluación financiera de proyectos es un desarrollo propio que toma como referencia algunos modelos de análisis financiero de entidades financieras, y de evaluación de proyectos de capital semilla resultado de la experiencia profesional. Como punto de partida para generar el modelo se toma como base los cambios fundamentales que se dan en las cifras teniendo en cuenta las Normas Internacionales de Información Financiera (NIIF), según La ley 1314 de 2009 que regula los principios y las normas de contabilidad e información financiera y de aseguramiento de la información, aceptadas en Colombia y reglamentada por el decreto 3022 de 2013 para los preparadores de información financiera que conforman el Grupo 2. Por lo tanto, en el desarrollo del modelo de evaluación financiera de proyectos, se integran los principios sobre la depreciación de los activos fijos y el tratamiento a los activos diferidos, así como al efectivo y los equivalentes del efectivo. (Decreto3022, 2013)

Por otra parte, algunos supuestos toman como referencia el modelo del fondo Emprender, pero adaptando las cifras al ejercicio académico y agregando de forma metodológica el paso a paso con la ayuda de herramientas tecnológicas; lo que tiene como objeto explicar y conducir a los estudiantes por la simulación, así mismo se crean espacios pertinentes para que el grupo de estudiantes realice el análisis e interpretación de resultados para alcanzar los objetivos de aprendizaje. El modelo también integra el cálculo de costo de capital y el análisis de sensibilidad. En ambos casos es necesario ingresar datos tomados de páginas financieras de actualidad, o datos derivados del análisis que realiza cada grupo de su caso de aplicación, con lo que se logra que se aprenda de 
manera significativa, entendiendo cada proceso, dado que el modelo simula a medida que el estudiante avanza con algunos datos clave.

El simulador utiliza algunas variables macroeconómicas, tales como el PIB, el IPC, y las tasas de interés de referencia para determinar el costo de capital. Estas variables son el punto de partida, para realizar los estados financieros previsionales. El estudiante por su parte con el conocimiento previo y el adquirido durante el módulo de evaluación de proyectos, podrá incluir todos los supuestos sobre la inversión, los costos fijos y costos variables, la capacidad instalada, los precios, entre otros, harán parte de estos supuestos.

Los supuestos iniciales son:

- Inversión Inicial: Descrita como inversión en activos fijos, en capital de trabajo y en activos intangibles. Así como definir del total de la inversión cual es la participación de los socios y cuál es la participación de recursos de terceros, es decir deuda.

- Descripción de la inversión en activos fijos: se deberá definir cada uno de los activos requeridos y los años de depreciación para cada uno de ellos. Con la información de activos fijos, podemos concluir cual será la capacidad de producción, es decir, el número de productos o servicios y las cantidades anuales de cada uno de ellos a fabricar o prestar.

- Descripción del capital de trabajo: el simulador solicita el monto de capital inicial para operar la empresa y las políticas de cartera, inventarios, y pago a proveedores.

- Descripción de la inversión en activos intangibles: se definirán los gastos en activos intangibles, describiendo cada uno de ellos, así como los años de amortización de cada uno.

- Costos variables por unidad: se debe definir la mano de obra directa, los materiales directos y los costos indirectos de fabricación variables por unidad.

- Costos y gastos fijos: el simulador solicita los costos fijos y los gastos de administración y ventas generados en el proyecto.

- Condiciones de la deuda: el simulador solicita el valor de la deuda, es decir la parte del proyecto que se financia con terceros y las condiciones tales como interés y plazo.

- Margen de rentabilidad: el simulador solicita el margen de rentabilidad por producto, para hallar el precio de cada uno de los productos contemplados en el proyecto. 
- Pago de dividendos: El simulador solicita el porcentaje de las utilidades que se repartirá a los socios como dividendos en cada periodo.

Para cada uno de los anteriores supuestos el simulador generará cuadros de texto que solicitarán una justificación sobre la decisión tomada para incluir cada dato.

Posteriormente, el simulador ayuda al estudiante a determinar el costo de capital, solicita el Beta de la industria y con ese dato toma el flujo de caja libre y el flujo de caja del accionista de los cinco años previsionales para generar los cálculos de los métodos de decisión (VPN, TIR Y RBC).

El simulador toma el flujo de caja libre y el flujo de caja del accionista de los cinco años previsionales y genera los cálculos de los métodos de decisión (VPN, TIR Y RBC). En el cuadro de texto correspondiente se deben interpretar estos resultados, teniendo en cuenta el papel del costo de capital obtenido.

La herramienta recopila la interpretación de los estados financieros y de los métodos de decisión generando el segundo informe.

El simulador muestra las cifras para los tres escenarios optimista, pesimista y probable, (estado de resultados, estado de situación financiera, flujo de caja, tabla de datos para determinar costos de capital y métodos de decisión. Se realiza en el cuadro de texto correspondiente la interpretación y comparación de los resultados.

Por último, recopila la justificación de los supuestos para el análisis de sensibilidad y la interpretación de los resultados para los tres escenarios y genera el tercer informe.

\section{Desarrollo de la experiencia de aprendizaje}

El simulador se concibe como una herramienta para fortalecer las competencias de los estudiantes con respecto a la evaluación financiera de proyectos, teniendo en cuenta que es un módulo o una asignatura transversal, que involucra el conocimiento de los cálculos de los métodos de decisión, así como la interpretación y el análisis de resultados. En este sentido la asignatura o módulo también concatena conocimientos contables, económicos y administrativos, para lograr la simulación. 
La construcción del simulador, sin duda nace como respuesta a las deficiencias evidenciadas en el estudio previo, y también con el ánimo de estructurar una herramienta innovadora, que dinamice el aprendizaje y genere significancia en el proceso de formación de los estudiantes. Durante el proceso de construcción de la estrategia metodológica, se identificaron cambios que permitieron desde el punto de vista pedagógico, fortalecer el proceso de enseñanza - aprendizaje, tal es el caso de la atribución de variables condicionantes, que permiten a cada grupo obtener un caso particular para desarrollar su simulación, así como la integración de la herramienta wiki, con el fin de evidenciar la participación de todos los integrantes en el proceso.

La secuencia metodológica, inicia con el sílabo que tiene como eje las competencias que el estudiante debe alcanzar durante el proceso de aprendizaje. Se plasmó cada uno de los ejes temáticos incluyendo la descripción de cada una las actividades de aprendizaje con el fin de alcanzar los objetivos. Así mismo, durante este proceso se planteó realizar la simulación en tres etapas con el fin de realimentar el proceso del estudiante y evaluarlo para continuar con la siguiente fase. En la planeación se atendió a la necesidad de involucrar el trabajo en equipo; fundamental para poner al estudiante en un contexto cercano a la realidad en el que se espera pueda liderar procesos o ser parte activa de un equipo generando valor.

Se realizó la elaboración de la ficha pedagógica que trabaja las competencias, la estrategia a emplear, los núcleos temáticos que se van abordar en el simulador y una descripción del mismo.

El proceso para el desarrollo del simulador se inició con el diseño funcional a través del modelo conceptual y de tareas que permite definir los ejes temáticos que serán abordados en cada fase, así como de cada una de las partes que intervienen y las acciones de cada uno de los elementos que intervienen (estudiante, tutor, simulador). Superado lo anterior, fue posible realizar el diagrama del proceso que generó, de forma visual, cada una de las tareas a realizar para llevar a cabo el simulador en su parte de programación.

A partir del informe anterior se definieron los escenarios para las interfaces que fueron consignados en la escaleta. Este documento describe los personajes que interactuarán en el simulador con los estudiantes, el objetivo de cada escenario (pantalla) y la información general que debe contener. De esta manera se plasman las pautas generales para que el área de diseño elabore el ambiente de simulación y los personajes. 
Con toda la estructura realizada previamente se procede a construir los guiones, que permiten detallar de manera minuciosa cómo se estructurará el simulador, en su parte técnica, de diseño y programación.

Este documento plantea con exactitud la información que se verá reflejada en cada etapa de la simulación, incluye los comentarios para diseñador y la formulación que se requiere para la programación. Además, se formula en un Excel simultáneamente el modelo financiero, de acuerdo con la estructura lograda en los pasos previos, así la descripción de la programación se realiza paso a paso.

Durante el proceso de elaboración de los guiones, se encontró significativo que el ejercicio de simulación permitiera dos espacios para los estudiantes, el primer espacio llamado Entrenamiento, en el que de forma individual los estudiantes pueden ingresar y realizar la simulación verificando una y otra vez los resultados financieros, este perfil se estimó para todos los integrantes del equipo. El segundo espacio se denomina Simulación, este perfil requiere de un líder dentro del equipo de trabajo que asignará el simulador, con el objeto que ingrese las cifras según el consenso del equipo, además este perfil contará con la herramienta wiki, que permitirá explicar cada una de las decisiones tomadas para los supuestos, y también dejará los espacios pertinentes para explicar los resultados obtenidos en el costo de capital, estados financieros, métodos de decisión y análisis de sensibilidad. El perfil de simulación entonces es donde se evidenciará el trabajo del equipo y permitirá recopilar cada uno de los comentarios del equipo, para así conformar los tres informes de acuerdo con las fases de simulación.

En el documento de los guiones queda descrita toda la parte técnica detalladamente, y las pautas para el diseño. Por su parte se describe al programador la formulación necesaria para el cálculo de las cifras que surgen a partir de los datos de supuestos y otros datos ingresados por el equipo asignado.

Como el simulador se desarrolla para la parte financiera, conserva una unidad de imagen para todos los proyectos de dicha área, junto con los colores, formas y personajes. Dentro de la construcción del simulador se seleccionaron dos personajes con funciones claramente definidas. En primer lugar, el estudiante encontrará un Avatar llamado Mila que está presente en otras estrategias de simulación realizadas en el Politécnico Grancolombiano; es una mujer que conduce de forma amigable por la simulación, explicando el objeto general del ejercicio académico y el propósito particular de cada escenario. Ver figura 3. 


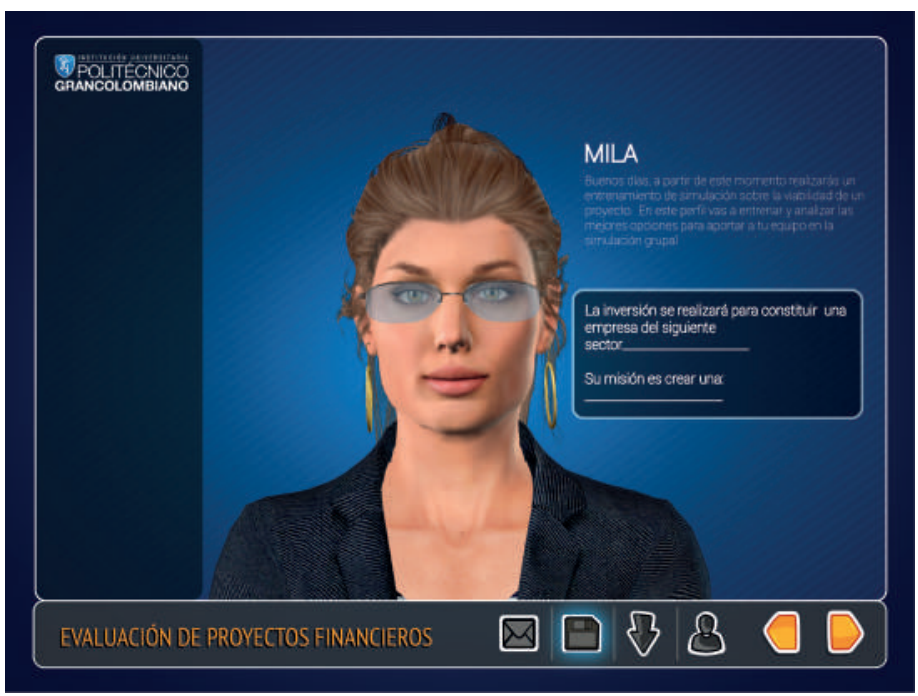

Figura 3. Personaje de ayuda al estudiante.

Fuente: Politécnico Grancolombiano.

Como ya se mencionó el modelo financiero está implícito en el simulador, de esta manera se evidencia en las interfaces y en el diseño navegacional, se muestra en la figura 4 los espacios para que el estudiante ingrese los datos y realizar los cálculos, internamente se encuentra la programación de las fórmulas.

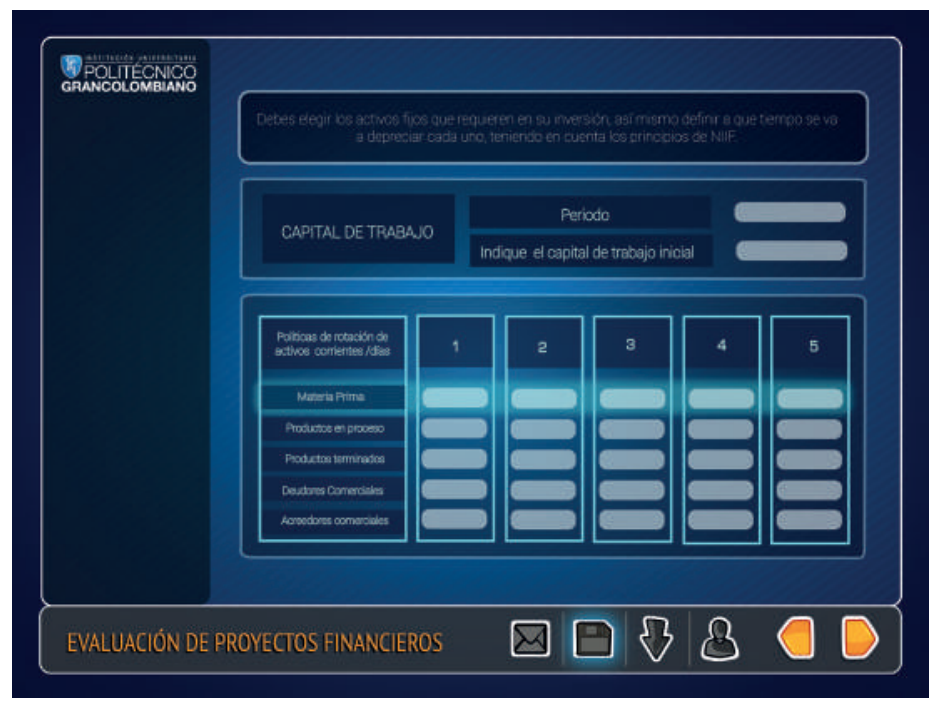

Figura 4. Espacios de trabajo del estudiante en el simulador.

Fuente: Politécnico Grancolombiano. 
El Inversionista, es el segundo personaje, que reta al equipo para que verifiquen la viabilidad del proyecto de inversión, de acuerdo con unas condiciones a manera de caso, que el simulador atribuye a cada equipo.

En la figura 5 se ve el escenario donde inicia la segunda etapa que corresponde a visualizar los estados financieros que el simulador genera a partir de los supuestos ingresados.

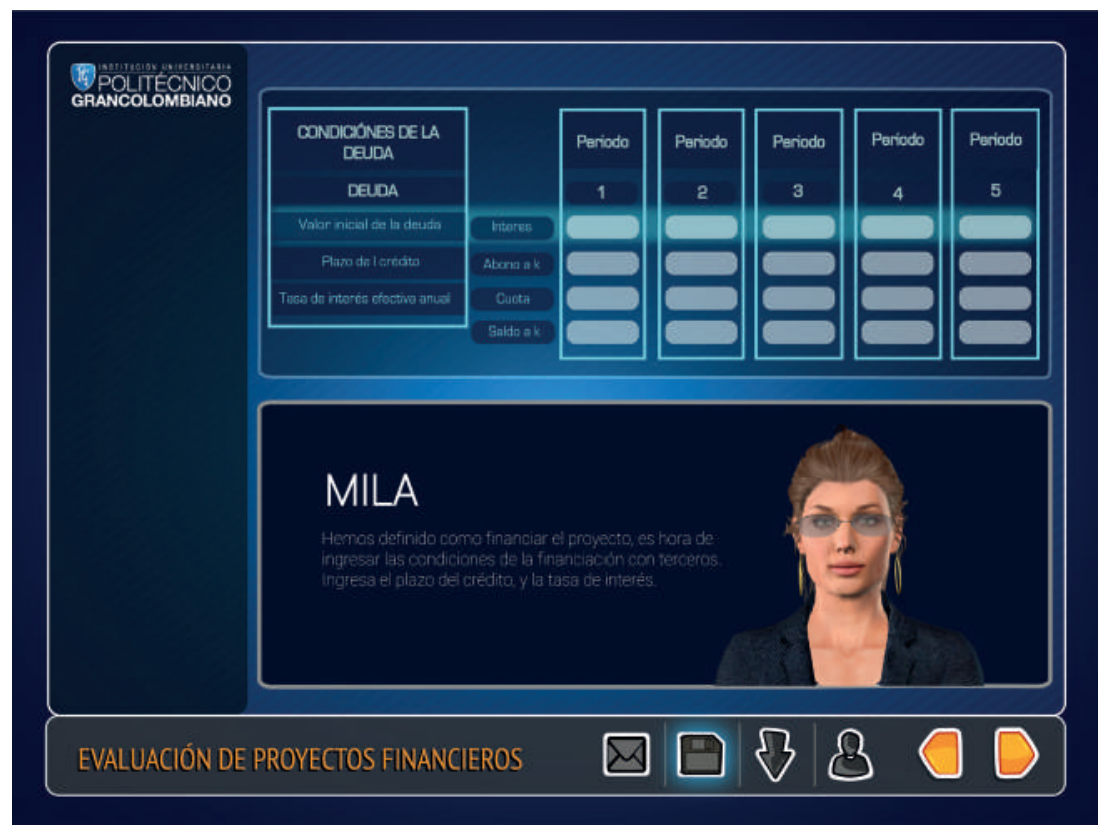

Figura 5. Inicio de la segunda fase en el simulador.

Fuente: Politécnico Grancolombiano.

\section{Resultados obtenidos}

En primer lugar, al evidenciar las falencias de los estudiantes dado los niveles de calificaciones encontrados en las modalidades virtual y presencial, así como de la percepción del equipo de docentes/tutores del área de finanzas, es óptimo pensar en una estrategia, que tenga como base la innovación y la tecnología, y que permita fortalecer las competencias en las deficiencias encontradas. Así es como se decide desarrollar un simulador financiero para evaluar proyectos de inversión, con un componente de diseño y otro de programación.

Durante el proceso de planeación y desarrollo de la parte técnica o financiera del simulador, y con el apoyo de los procesos pedagógicos por parte del área de innovación, se ejecutó un proceso que permitió trasformar la idea inicial 
del simulador, del que se tenía como base un modelo en Excel que ya había sido usado en clase en algunas oportunidades, sin embargo, el modelo solo tenía como objetivo evaluar la viabilidad de proyectos de inversión y por lo tanto, para el ejercicio académico no era pertinente. Así las cosas, al iniciarse con el planteamiento pedagógico y con la claridad de las competencias que deseamos fortalecer, se formuló el modelo desde su inicio, danto lugar a los espacios de justificación de las decisiones y argumentación de resultados por parte de los estudiantes. Asimismo, dio lugar a la creación de avatares con objetivos específicos, uno con el ánimo de conducir y permitir al estudiante construir su aprendizaje, y el otro que retara a desarrollar el caso sobre la evaluación del proyecto.

Desde el inicio se contempló el trabajo en equipo, no obstante, durante el desarrollo de la estrategia y el planteamiento de los guiones se pensó en la forma de motivar la participación de cada integrante, al igual que evidenciar el aporte de cada uno de ellos, así es como se integra la herramienta wiki en todos los escenarios, donde el estudiante debe justificar las decisiones o interpretaciones y recomendaciones.

\section{Conclusiones}

A través de herramientas tecnológicas y en el caso particular del simulador, se espera dinamizar el aprendizaje y motivar a los estudiantes con el fin de alcanzar las competencias de parametrizar datos de entrada en un proyecto de inversión, diagnosticar e interpretar los resultados generados en la simulación y tomar decisiones a partir de los resultados financieros que puedan ser sustentados de acuerdo con los conceptos financieros.

En el proceso, el docente o tutor, tendrá una importante herramienta de apoyo que le permita realizar de manera estandarizada la enseñanza de las temáticas en torno al módulo o asignatura. De igual forma, la herramienta insta al estudiante a tomar elementos de diversos módulos/asignaturas, para aplicarlos en el simulador, por tanto, permite vincular los conocimientos administrativos, contables, financieros y económicos. Tal integración de saberes presenta un valor agregado en el proceso de enseñanza-aprendizaje dado que se da un sentido de aplicación de los conocimientos en escenarios cercanos a la realidad.

El simulador como herramienta pedagógica permite innovar en el proceso de enseñanza-aprendizaje, motivando al estudiante no solamente en el desarrollo de competencias disciplinares, sino también en el manejo de un software. En 
el mundo globalizado, día a día se trabaja con diversas herramientas on line o corporativas con las que el profesional debe familiarizarse y tomar ventaja de ellas para ser más eficiente en su trabajo.

\section{Bibliografía o referencias}

Baca Urbina, G. (2006). Evaluación de Proyectos. México D.F.: McGraw-Hill Interamericana.

Cocco, L. C. (2017). Using an artificial financial market for studying a cryptocurrency market. Journal of Economic Interaction and Coordination, 12(2), pp. 345-365.

Decreto3022. (12 de 27 de 2013). Superintendencia Financiera. Obtenido de https://www. superfinanciera.gov.co/SFCant/Normativa/NIIF/dec3022_13.pdf

Fiering M. y Hufshmidt M (1966). Simulation Techniques for the Desig of Water Resources Systems. Massachussets: Harvard University Press, p. 205.

Lintner, J. (1965). The Valuation of Risk Assets and the Selection of Risky Investments in Stock Portfolios and Capital Budgets. The Review of Economics and Statistics, 1337.

Meza Orozco, J. d. (2013). Evaluación financiera de proyectos. Bogotá: Ecoe Ediciones.

Mossin, J. (1966). Equilibrium in a Capital Asset Market. Econometrica, 768-783.

Observatorio de Innovación Educativa del Tecnológico de Monterrey (2016). Aprendizaje Basado en Retos. Monterrey: Tecnológico de Monterrey. Recuperado en: https:// observatorio.itesm.mx/edutrendsabr [consultado 11/09/2017]

Otal, S. H. (2010). LEARNING BUSINESS ADMINISTRATION USING SIMULATION. Developments in Business Simulation and Experiential Learning, 210-220.

Sara J. Thompson, S. M. (2010). Estados Unidos Patente no US20100248192 A1.

Sharpe, W. F. (1964). Capital Asset Prices: A Theory of Market Equilibrium under conditions of Risk. Journal of Finance, 423-442. 


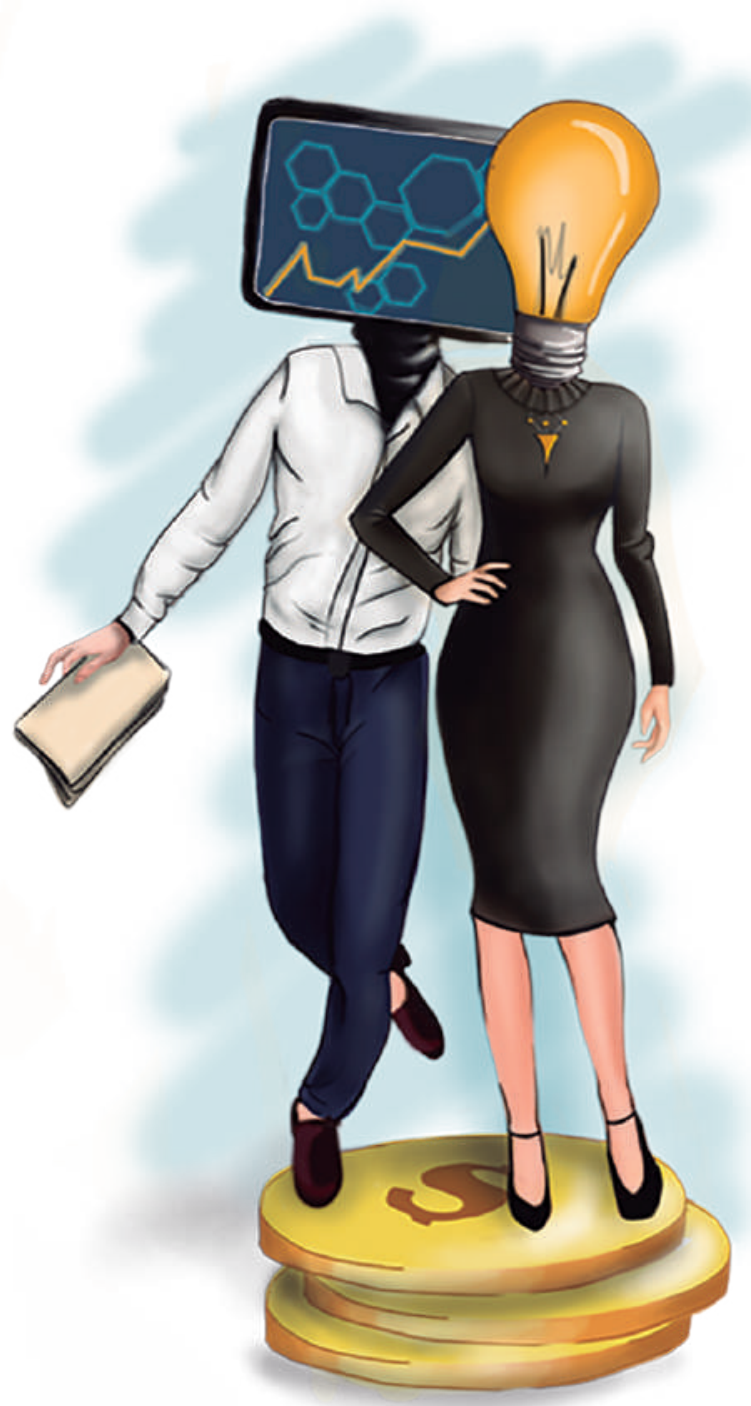




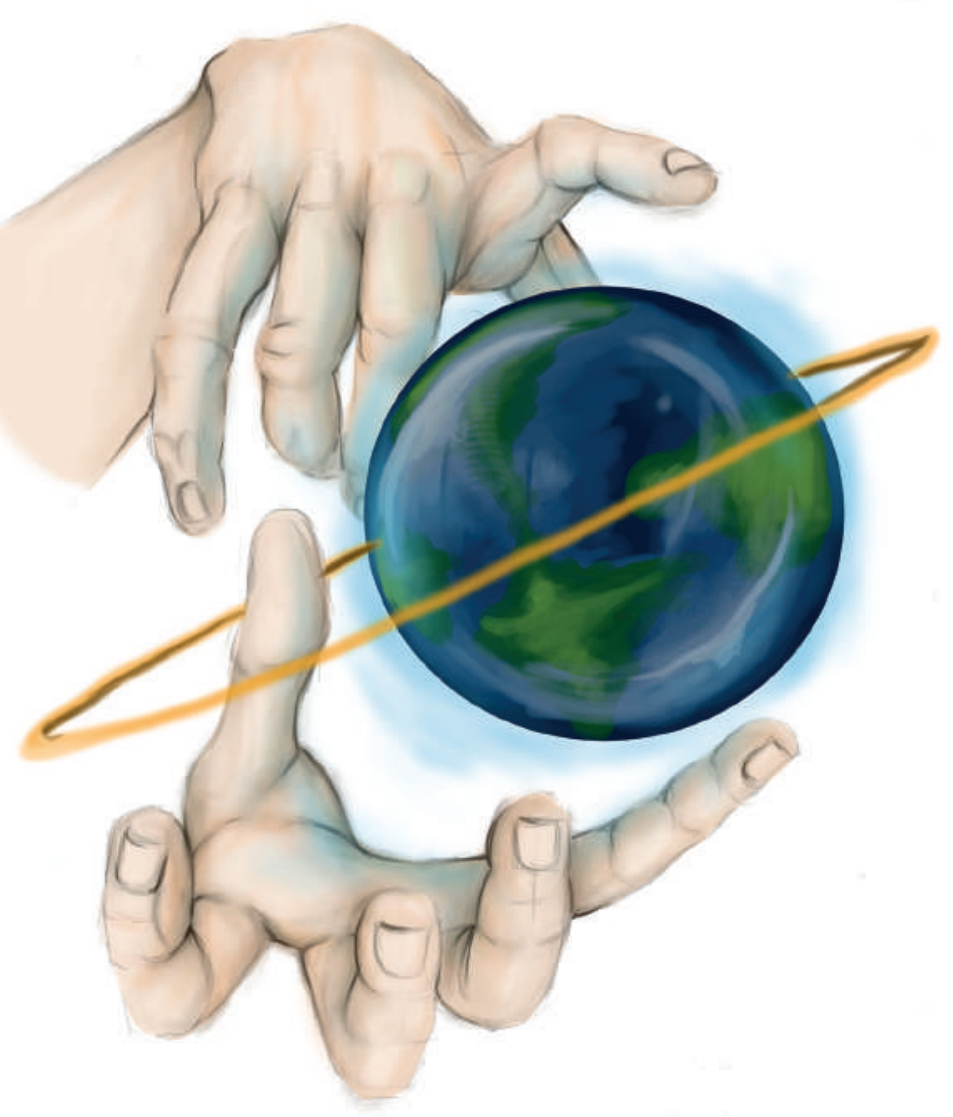

\section{- Capítulo 6 - \\ Juego Gerencial basado en Balanced Scorecard}

\section{Autores}

Germán Andrés Castro Cabal. Business Manager graduado de la Universidad de Queensland en Brisbane Australia. MBA de la Universidad de la Salle en Bogotá, con experiencia de más de diez años en el sector industrial, actualmente Docente tiempo completo del Politécnico Grancolombiano. 
Luis Martín Trujillo Flórez. Ingeniero Electricista Universidad Nacional de Colombia, Máster en Edición Literaria Universidad de Salamanca España. Master en Ambientes Virtuales de Aprendizaje Universidad de Panamá. Especialista en Ambientes Virtuales Centro de Altos Estudios Argentina. Coordinador del Laboratorio de innovación pedagógica Virtual del Politécnico Grancolombiano.

Correspondencia:mtrujilo@poligran.edu.co

\section{Diseñador de interfaces del simulador}

Leonardo Stiglich Campos. Diseñador gráfico de la universidad Los Libertadores, desarrollador de interfaces interactivas desde 2008. Se ha desempeñado en diferentes organizaciones como ilustrador, animador, maquetador. Actualmente se desempeña como diseñador del Laboratorio de innovación pedagógica del Politécnico Grancolombiano.

Correspondencia: Iscampos@poligran.edu.co

\section{Resumen}

Este proyecto consiste en la creación de un video juego interactivo que enfrentará al estudiante ante decisiones gerenciales basado en la metodología Balanced Scorecard. El juego es de participación individual y según las decisiones tomadas por cada jugador serán asignados puntajes acumulativos semana a semana, de acuerdo con su desempeño se afectarán los indicadores de la compañía. Gana el juego quien tome las decisiones más acertadas y con ellas genere el mayor crecimiento de la empresa. A partir de esta estrategia pedagógica se busca que los estudiantes se apropien de la metodología y a la vez adquieran la competencia de tomar decisiones acertadas para un proceso gerencial.

\section{Palabras claves}

Juego serio, juego de Balanced Scorecard, aprendizaje lúdico, innovación educativa por medio del juego. 


\section{Introducción}

El Juego Gerencial se desarrolla de manera paralela con el módulo Gerencia de Mercadeo y Comercial II. Cada semana el estudiante debe hacer una jugada acorde con la metodología del Balanced Scorcard y según las decisiones que tome el estudiante como Chief Executive Officer (CEO) de la compañía tendrá una variación en sus indicadores o Key Performance Indicator (KPIs), lo que genera un ranking de los mejores puntajes. Con la decisión tomada se reflejará un cambio equivalente al aumento o disminución en los indicadores.

Al final del juego se implementa un componente de gamificación correspondiente al ranking que ocupe el estudiante y se resaltan a los diez primeros puestos. El propósito es que rete al estudiante y lo confronte con sus competidores, en este caso, sus compañeros de aula.

Parte del diseño del juego está basado en el uso ordenado de la metodología gerencial del Balanced Scorecard, si el estudiante la aplica adecuadamente el juego le dará indicadores más altos, es decir, una mejor puntuación. Al aplicar la metodología en el juego, este se convierte en el componente práctico del módulo porque el estudiante ensaya en un escenario simulado los efectos de sus KPIs en la buena gestión de la organización.

El juego afronta al estudiante a las decisiones gerenciales y cómo estas afectan el crecimiento o decrecimiento de la compañía. El objetivo pedagógico del juego es enseñarle al estudiante la repercusión del uso eficiente de sus recursos en la consecución de las metas propuestas en su empresa, que serán medibles a través de los indicadores de gestión definidos para cada perspectiva del Balanced Scorecard.

\section{Marco teórico}

\section{Problemática que atiende}

Como parte de la experiencia docente se ha detectado que muchos jóvenes emprendedores deben enfrentar el fracaso de sus proyectos empresariales debido a cinco causas bien definidas, la más fuerte y la primera de ellas, es la inexperiencia en el sector empresarial. La segunda, un desconocimiento en la toma de decisiones acertadas a nivel gerencial. En tercer lugar, la falta de 
habilidades gerenciales, estrategias o capacidades empresariales. La cuarta razón es que incurren en gastos innecesarios o gastan más de lo que la empresa está generando por la falta de un uso ordenado y adecuado de los recursos disponibles. Por último, debido a, las dinámicas del mercado o la influencia del sector industrial. Es claro que el $90 \%$ de las empresas nuevas van a la quiebra antes del primer año.

Los estudios efectuados no corroboran que los resultados de las nuevas empresas estén ligadas a las características del empresario, pero si tienen influencia sus capacidades empresariales, por lo tanto, se está investigando si depende más de su estrategia y de la capacidad de establecer relaciones alrededor de la empresa o de la influencia del sector industrial. (García, Molina, Lajara y Quer, 2012)

Lo anterior significa que una de las problemáticas relevantes para la academia es preparar a sus futuros profesionales con competencias de direccionamiento y que posean diferentes capacidades empresariales. Por tal razón, buscando una apropiación en las competencias gerenciales la Institución Politécnico Grancolombiano en el programa de Mercadeo y Publicidad oferta dos módulos en su programa virtual y presencial denominados Gerencia de Mercadeo y Comercial I y II. El primero de ellos aborda la gerencia comercial con temas como manejo de portafolio de producto, medición de resultados de fuerza de ventas. El segundo se enfatiza en la logística y desde allí se trabaja la metodología Balanced Scorecard.

De los objetivos de formación descritos surge desde la dirección del programa la idea de crear un Ambiente Virtual de Aprendizaje (AVA) para preparar al aprendiz del área administrativa y en especial del mercadeo en la toma de decisiones. Esta idea se fue transformando en un juego por varias razones, la primera de ellas es que el estudiante pueda sortear las variables del mercado mediante una experiencia simulada que les sirva como modelo cuando enfrente un mercado real. La segunda, es por ser pedagógicamente más adecuado para la apropiación de la metodología Balanced Scorecard construir un ambiente lúdico susceptible de ser cuantificado en términos de indicadores de gestión que pueden describir la tendencia de una empresa, que hacer un AVA con diversos elementos informativos que no conduzcan a la apropiación, en otras palabras, la estrategia de aprendizaje pretende que el estudiante aplique, trabaje de forma activa y no que se limite a la consulta que es un trabajo pasivo. En tercer lugar porque desde el juego puede abordarse 
la metodología de una forma más holística donde pueda percibirse el cuadro de mando de manera integral, ya que cualquier decisión tomada afecta los indicadores de la compañía, esto le permite al futuro gerente ver la empresa como un todo con múltiples dimensiones por tal razón debe tener en cuenta las cuatro perspectivas de la metodología de manera integral para que las decisiones tomadas ayuden al crecimiento de su empresa.

Por lo tanto, aprovechando las virtudes del aprendizaje lúdico se crea la herramienta digital o video juego altamente motivacional para la comprensión y apropiación de la metodología Balanced Scorecard que desde lo teórico sería compleja para el estudiante.

\section{Antecedentes}

Como paso inicial del proceso se realizó una indagación de las posibles herramientas existentes en el mercado que trabajan con la metodología Balanced Scorecard que permitiera apropiarla mientras se aplica en un entorno que emula un proceso real. La búsqueda se propuso hallar una herramienta que permitiera la simulación desde una perspectiva gerencial y así fortalecer la parte práctica del módulo Gerencia de Mercadeo y Comercial. La indagación arrojó los siguientes resultados:

El primer modelo de simulación que se revisó está basado en el software Powersim, el cual lo implementó la empresa TQM Latinoamérica S.A. El proceso se estructura utilizando el mapping (mapas mentales) para generar diagramas de causas y consecuencias, dichos mapas se implementan en el modelo de simulación, se identifican los indicadores y las variables de decisión. Los usuarios simulan ser la gerencia que realiza la toma de decisiones y genera los reportes de gerencia basados en la metodología. Para el correcto desempeño de los usuarios estos deben proponer diversas estrategias gerenciales. (TQM Latinoamericana S.A., 2004)

El segundo modelo de simulación fue Vensim, donde hay diferentes empresas en pugna por el liderazgo en el mercado, cada una tiene sus productos que se designan como producto 1, 2, 3 y 4, respectivamente. Las empresas se dedican a distribuir los productos, por lo tanto, deben aprovisionarse previamente y deben almacenarlos. La capacidad de venta de cada empresa depende del mercado, de sus existencias en almacén y de la fuerza de venta. El simulador se puede utilizar con dos finalidades: Como herramienta para mostrar el 
funcionamiento en el procedimiento de la construcción de un Cuadro Integral de Mando Dinámico y para analizar los resultados mediante un Cuadro Integral de Mando Dinámico en un libro de Excel. (Micro Simuladores Empresariales, S.F.)

El tercer software que se analizó fue el Gestión Estratégica creado por Stratec desde el 2005. La herramienta permite realizar la planeación de las metas y planes de acción para una empresa, sistematiza los modelos de gestión: Balanced Scorecard (BSC), Value Based Management (VBM), Gestión por Directrices (GPD), Modelo de Excelencia en Gestión (MEG), Gestión en calidad y el Modelo Integrado de gestión (ISO), Corporate Performance Management (CPM). (Stratec, 2005)

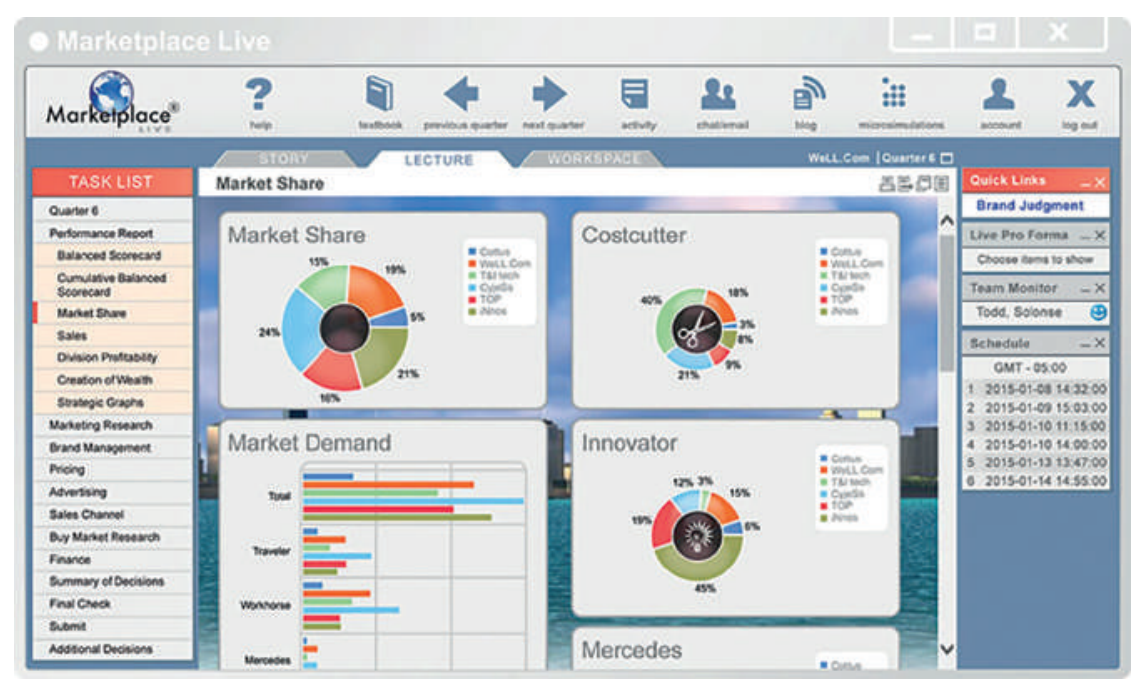

Figura 1. Pantalla del Simulador de Gerencia Estratégica Stratec.

Fuente: Portal Stratec

El cuarto software fue Balanced Scorecard Game (BSC), es un simulador interactivo desarrollado por Gamelab bajo un caso de estudio llamado NeXstore. Los jugadores asumen el rol de CEO y deben definir una estrategia gerencial que les permita cumplir con lo solicitado por el directorio y de esa manera resolver el caso. En su rol de CEO es estudiante decide cuáles objetivos va a posicionar en cada lineamiento y en cada perspectiva, cuáles son los KPI que representan de mejor manera el cumplimiento de cada uno de ellos, qué iniciativa llevarán a cabo. El juego consta de tres etapas: Definición del mapa 
estratégico, definición de los KPI y la selección de las iniciativas que se llevarán a cabo en cada semestre de operación, ya que la simulación se hace bajo el supuesto de un periodo de seis meses. (Gamelab, S.F.).

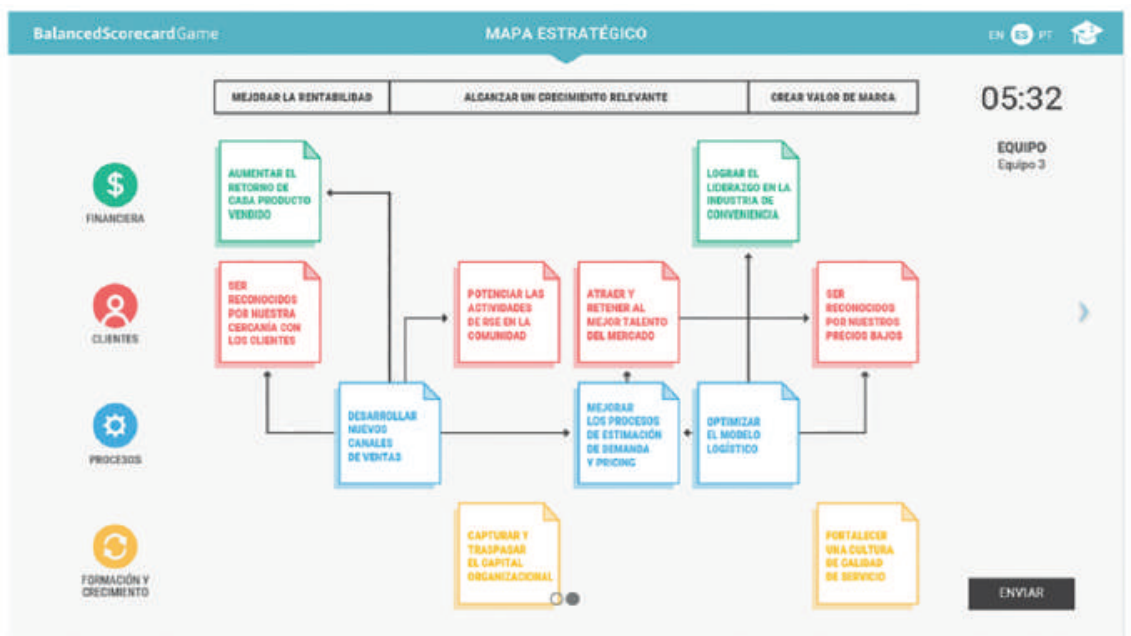

Figura 2. Pantallazo del simulador Balanced Scorecard Game de Gamelab.

Fuente: Portal de gamelab.

Cada una de las cuatro herramientas tiene aspectos interesantes para trabajar, sin embargo, no satisfacen las expectativas de aprendizaje que se pretende con la estrategia pedagógica. Las dos primeras herramientas visualmente son poco motivantes ya que su trabajo es más numérico. Las dos últimas son más completas porque emplean una metodología más activa y le permiten al usuario la toma de decisiones. La cuarta herramienta tiene aspectos en común con la estrategia propuesta en este documento, por ejemplo, en las dos el estudiante es el CEO de la compañía, sin embargo, la visión de la experiencia desarrollada tiene una visión más holística de la metodología, integra las cuatro perspectivas (financiera, interna, comercial, aprendizaje) y de acuerdo a la toma de decisiones realizadas por el estudiante se ven afectados sus indicadores, las jugadas hechas en alguna perspectiva afectan a las otras y tienen un orden implícito para que el estudiante lo descubra, quiere decir, si el estudiante juega con la secuencia apropiada aumenta sus indicadores. Las dos herramientas son valiosas, sin embargo, sus pretensiones académicas son diferentes. 


\section{Estrategia de aprendizaje}

La estrategia de aprendizaje se ideó para ser la parte práctica del módulo Gerencia de Mercadeo y Comercial desde una perspectiva teórico- práctica, donde la teoría se trabaja con la tutoría, los materiales didácticos del aula virtual, y la práctica se trabaja a través de un juego serio. Implementar en el aula un serious game no es novedoso porque diversas universidades y empresas aplican la misma estrategia en sus capacitaciones. La innovación es el juego mismo y la forma cómo se estructuró con el módulo y la metodología Balanced Scorecard.

En la parte teórica el estudiante aprende la teoría del uso de los recursos y del uso de un mapa estratégico de gestión del estilo de Balanced Scorecard, entendiendo su funcionalidad y aplicabilidad para así hacer las jugadas de forma acertada. Como parte del juego el estudiante deberá usar recursos que se le dan inicialmente o aquellos que gane derivado de sus actividades de venta de productos, por lo tanto, se verá obligado a hacer un uso eficiente de sus recursos, es decir, obtener mejores resultados en sus indicadores con la utilización de menos recursos.

La elección de un juego como estrategia pedagógica se debe a que este genera un ambiente innato de aprendizaje, el cual puede ser aprovechado como estrategia didáctica, una forma de comunicar, compartir y conceptualizar conocimiento y finalmente de potenciar el desarrollo social, emocional y cognitivo en el individuo (Posada, 2014). Los anteriores puntos se aplican todos en la estrategia, el estudiante debe comunicar cada una de sus jugadas y argumentarlas, dicha argumentación le exige un manejo de los conceptos vistos en la teoría, asimismo, la experiencia lúdica lo implica en sus emociones y lo reta a un buen desempeño en su rol dentro del juego.

Este juego serio se enmarca en la categoría de Negocios, los cuales simulan estrategias de liderazgo o de control de las empresas, por tal razón, se centran en cómo fueron tomadas las decisiones para la organización. Este tipo de juegos permite emular situaciones, superar niveles de dificultad, enfrentar escenarios de presión, sin contar qué, mejoran el pensamiento estratégico, la atención, la velocidad para la toma de decisiones y la capacidad para la multitarea.

Por otro lado, el juego serio se presenta como un modo de actividad basada en la imaginación, que integra dimensiones cognitivas, sociales y emocionales de la experiencia e intencionalmente incluye los beneficios emergentes de jugar 
para influir en los desafíos organizacionales (Ross, Victor \& Statler, 2004). Por tal razón, cada vez que el estudiante toma una decisión no se trata únicamente de aplicar la metodología, sino que debe aplicar el sentido común, la lógica para una realidad de lo que implica sus decisiones. Por ejemplo, un estudiante en el juego puede comprar un vehículo de alta capacidad de carga, esto en una instancia inicial aumentaría sus indicadores porque tiene la posibilidad de transportar una mayor cantidad de productos, sin embargo, puede ser que los baje, porque si compra un vehículo tan costoso es porque ya adquirió una maquinaria que aumenta su producción, una bodega para guardar sus productos y ahora para transportar esa sobre producción compra un vehículo, si realizó las jugadas con esa lógica sus indicadores aumentarán de manera significativa, entonces, cada decisión va enlazada a las demás y se mantienen para las otras jugadas.

Algunas herramientas analizadas casi no tienen en cuenta las operaciones anteriores y no traen un histórico de las jugadas, cada una de ellas está separada de las demás, entonces la simulación se vuelve más de resultados que de análisis. En este caso el simulador le da una continuidad de la primera a la última jugada que le permite al estudiante proponer decisiones conformes a las que ya tomó.

Tal vez, el componente pedagógico más importante es que cada jugada cuando el estudiante la realiza tiene un espacio de argumentación y debe enviar a su tutor las razones por las cuales tomó la decisión, lo que lleva al proceso más allá de los resultados, porque evidencia la apropiación de la metodología. Dichas argumentaciones son enviadas al tutor quien retroalimenta al estudiante y le orienta para que fortalezca sus deficiencias en la metodología o en la lógica de funcionamiento de la misma.

A su vez el tutor realiza un papel fundamental revisando dónde ocurrieron las fallas dentro del juego, cuáles fueron los errores más comunes entre los estudiantes para detectar posibles falencias en el proceso de aprendizaje de la metodología o en la estructuración del currículo, ya que las fallas pueden depender de aprendizajes previos de los estudiantes que ya deberían manejarse al llegar al módulo.

Para propiciar la toma de decisiones se crearon casos o escenarios donde el estudiante debía decidir: ¿Qué necesita la empresa para ser más eficiente?, necesita un staff o equipo directivo que genere nuevas estrategias, personal operario para aumentar la producción en cada uno de los departamentos, más 
maquinaria, bodegas más grandes y/o un mejor transporte. Necesita procesos de capacitación para sus empleados o procesos de innovación. Según el criterio del estudiante cada decisión lo enfrenta a diversas circunstancias, el proceso evaluativo se da de acuerdo con las decisiones tomadas. A partir de allí se puede hacer un análisis comportamental tanto del alumno (el CEO de la empresa) como de la organización de acuerdo con las decisiones tomadas.

\section{Modelo para la simulación}

La herramienta de software es un juego gerencial que se basa en la metodología Balanced Scorecard, por tal razón pertenece a lo que se conoce como juegos serios que tienen un uso amplio en las organizaciones. Dentro del modelo propuesto cada estudiante será el CEO de la empresa y tendrá a su cargo la toma de decisiones de compra de diferentes bienes, la contratación de personal, la venta de productos producidos por la empresa, y la posibilidad de innovar o capacitar a su equipo de trabajo, por lo tanto, contará con varias jugadas en las que podrá hacer cualquiera de las actividades ya descritas mientras cuente en con el presupuesto disponible para hacerlo. Cada actividad o movimiento realizado ocasionará un cambio en los indicadores de desempeño en la empresa y en sus recursos disponibles, el jugador que en sus jugadas logre elevar más los niveles de dichos indicadores será el ganador del juego.

El estudiante tendrá la oportunidad de hacer ocho jugadas, una por semana, y decidirá si las hace seguidas en una sola perspectiva (dos jugadas seguidas en la misma perspectiva) o las reparte entre las diferentes perspectivas que tiene la metodología (financiera, interna, comercial, de innovación). El orden de las jugadas en cada perspectiva las decide el estudiante, dicho orden y los recursos usados si se realizan en una secuencia específica van a determinar la puntuación obtenida por cada jugador, en general, el simulador es autónomo, le va a otorgar al estudiante una puntuación dependiendo de la forma en que juegue.

Cada una de las perspectivas donde el estudiante juega se extraen de la metodología del Balanced Scorecard propuesta por los profesores David P. Norton, DBA de la Universidad de Harvard nacido en 1941 y Robert Samuel Kaplan profesor emérito de la Universidad de Harvard nacido en 1940. La metodología es un mapa estratégico propuesto por estos dos autores por 
primera vez en 1992 en un artículo académico y posteriormente en 1996 en su libro Balanced Scorecard. La metodología brinda la posibilidad de analizar cualquier organización productora o generadora de bienes o soluciones para un mercado, desde el análisis de cuatro perspectivas principales: la Financiera, la Comercial, la Interna y la de Innovación o aprendizaje (para esta experiencia será denominada de innovación), mismas que pueden ser medidas a través de múltiples indicadores claves de gestión KPIs que estarán presentes para poder medir el rendimiento de una organización que después de ser analizados nos permiten describir tendencias de mejoramiento o deterioro en el desempeño de la empresa (Norton y Kaplan, 1996).

La Perspectiva Financiera: permite al gerente medir el desempeño de la empresa basado en el eficiente y eficaz uso de los recursos económicos. Dentro de ella se deben tener en cuenta todos los factores y las variables que afectan el desempeño de la empresa en el área financiera, así como las decisiones de inversión y sus consecuencias futuras en términos de retorno. en este sentido, sin embargo, entre los más importantes y que pueden dar una amplia relación de control para una acertada toma de decisiones están: la rentabilidad, el retorno de la inversión y el retorno sobre activos. Para el juego los indicadores financieros son rentabilidad, retorno de inversión (Return on Investment ROI y Resturn on Assets ROA) y reducción de costos.

La Perspectiva Comercial: permite establecer un sistema de control sobre las actividades de la empresa cuando se está desarrollando la estrategia de mercado objetivo y la conexión con el mismo a través de un portafolio de productos ya establecido y dinámicamente modificable. Es la perspectiva que mide la correcta o incorrecta interacción de una organización con el mercado utilizando las alternativas muy variadas de promoción y concreción de relaciones, experiencias y transacciones. Los KPIs de control usados son muchos, entre los más relevantes se cuenta: la cuota de mercado compartido y las tasas de conversión de la fuerza de ventas. Para el juego los indicadores comerciales son cuota de mercado, reincidencia en las compras, porcentaje de clientes nuevos y porcentaje de entregas a tiempo.

La Perspectiva Interna: cuantifica las efectivas interacciones entre los diferentes procesos al interior de las organizaciones que de forma inequívoca crean el valor y la competitividad que hace posible tener participación en el mercado. Indicadores como la productividad y la capacidad de asociación serán 
determinantes para medir el desempeño interno de una organización. Para el juego los indicadores internos son productividad, porcentaje de productos no defectuosos, porcentaje de producción de residuos y porcentaje de utilización de personal.

La Perspectiva de Innovación: mide la capacidad de una organización de aprender del mercado y cambiar, reinventar procesos y productos para adaptarse a las realidades cada vez más volátiles y cambiantes del mercado, indicadores de desarrollo de nuevos productos y practicas más amigables con el medio ambiente serán los que se deben cuantificar para esta perspectiva. Para el juego los indicadores internos son porcentaje de nuevos productos, habilidades de los empleados, impacto ambiental y eficiencia en uso de recursos.

Explicación de una Jugada: cada jugada es la actividad que realiza el estudiante durante una semana, es decir, el plazo para la realización de una jugada será una semana calendario de su módulo, si el estudiante en esa semana no juega pierde la posibilidad de jugar esa semana, por ejemplo, un estudiante no jugó en la segunda semana, en la tercera semana no hace dos jugadas porque pierde la jugada solo realiza la jugada de la tercera semana. Esto tiene una finalidad pedagógica de continuidad y de investigación, pues parte del propósito es que con los resultados obtenidos el estudiante indague cómo realizar una jugada mejor la siguiente semana.

Cada jugada consta de cinco movimientos. El movimiento es la unidad de interacción mínima con el juego, consiste en utilizar recursos para comprar bienes, contratar personas, adquirir mejoras en innovación o vender productos. Para la ejecución de un movimiento el jugador decide en qué perspectiva va a jugar (financiera, interna, de innovación, comercial) y de acuerdo con esta elección tendrá acceso a diferentes tiendas. Para las cuatro perspectivas tendrá acceso a la tienda de personal, la tienda de vehículos, la tienda de bodegas, la tienda de oficinas, tienda de maquinaria. En la perspectiva de innovación tendrá acceso a una tienda exclusiva que no encuentra en las otras perspectivas denominada tienda de la innovación. Algo similar sucede en la perspectiva comercial donde tendrá acceso a la tienda de venta de productos, allí tiene los clientes según su decisión de a quien le vende sus ganancias podrán ser mayores. 


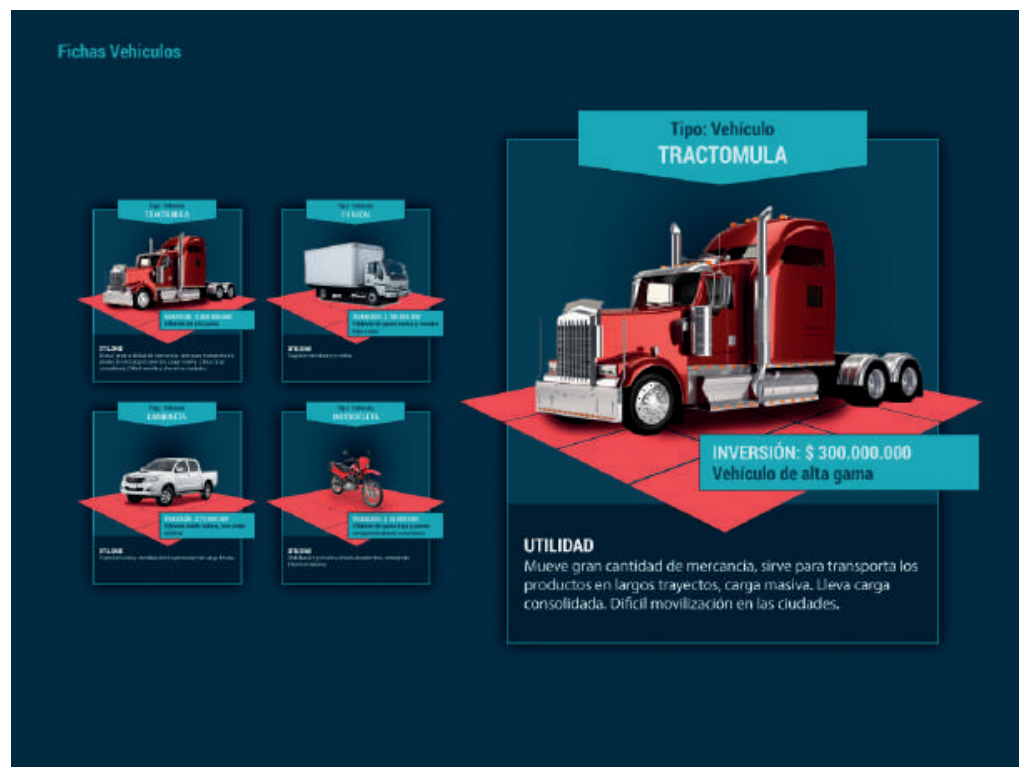

Figura 3. Tienda de vehículos.

Fuente: Politécnico Grancolombiano (2017).

El movimiento consiste en contratar una persona de la tienda de personal, o comprar una bodega, maquinaria, vehículo u oficina. Una compra de cualquiera en cualquiera de las tiendas es un movimiento, puede hacer todos los movimientos contratando cinco personas o comprando cinco vehículos. El objetivo es que las buenas combinaciones de sus compras mejoren su perspectiva, por consiguiente, los indicadores de la empresa. Una vez el jugador complete cinco movimientos habrá terminado una jugada. Esto lo podrá hacer cada semana mientras esté vigente en el juego.

Cada movimiento implica el uso de recursos y genera cambios en los indicadores de la empresa, todo bien, persona o mejora que sea adquirida dejará de estar disponible en la tienda respectiva y pasará a ser parte de los activos de la empresa. El cúmulo de los resultados de cada una de las jugadas mostrarán al terminar el juego la evolución final de los indicadores, y los estudiantes que obtengan mayor progreso en sus indicadores lograrán un lugar destacado en el ranking final de los jugadores.

Internamente cada movimiento afecta a ciertos indicadores y conforme a la secuencia o momento de adquisición por parte del alumno afectará sus resultados. No hay una secuencia ideal para un mayor puntaje, sin embargo, 
si el estudiante sigue la lógica de la metodología Balanced Scorecard obtendrá mejores resultados.

\section{Desarrollo de la experiencia de aprendizaje}

El juego nace a partir de la experiencia docente en los módulos de Gerencia de Mercadeo en el cual los estudiantes tienen que enfrentarse a la difícil tarea de aprender a tomar decisiones. La alternativa más utilizada para una experiencia pedagógica de esta índole por la mayoría de los docentes es emplear la metodología de estudios de caso donde los estudiantes analizan la forma en que transcurren los hechos en una determinada compañía y a partir de ello argumentan que hubieran hecho ellos si fueran el CEO de la compañía.

Esta práctica es útil y ayuda a conocer las características de diferentes entornos en los que se ubican los diferentes estudios de caso. También permite sugerir algunas soluciones desde la perspectiva de un consultor externo. Sin embargo, para el equipo de académicos, hacía falta una experiencia más vivencial que llevara al estudiante al conflicto cognitivo de asumir la responsabilidad de tomar una decisión. Se pensó entonces en una empresa nueva que emprende el estudiante, sin embargo, las decisiones son diferentes en una empresa nueva a una ya constituida, por tal razón, se decidió una empresa constituida bajo el parámetro: Si fuera mi empresa ¿Qué haría? Esa es la motivación fundamental para crear el juego.

Este pensamiento inicial llevó al equipo de académicos a brindarle al estudiante la oportunidad de sentarse en la silla del gerente general de una empresa y tomar decisiones de muchas índoles que llevaran a su empresa al éxito o al fracaso. Dependiendo de las buenas o malas elecciones que sean hechas en termino de uso de recursos y el incremento o deceso de los indicadores que será consecuencia directa precisamente de lo que decida.

La decisión de basar el juego en la metodología Balanced Scorecard fue pensada desde el inicio, uno por la experiencia en la metodología de uno de los académicos del proyecto y por el sílabo del módulo. La metodología, además, sintetiza los diferentes frentes de decisión que debe contemplar cada gerente para la construcción de una estrategia organizacional conjunta que le permita modificar los indicadores clave al alza llevando el rendimiento de la empresa a los niveles de desempeño deseados. 
El proceso de diseño del juego fue uno de los aspectos más difíciles porque resulta complejo enseñar a una persona a priorizar lo que realmente requiere o qué es lo más importante para una organización, independientemente del oficio o profesión de esta. Se pensó en una ruta inicial para jugar, sin embargo, una ruta sesgaba el propósito de que el estudiante tomara sus decisiones con total autonomía. De la metodología de Balanced Scorecard se tomaron las cuatro perspectivas. A partir de esto, se pensó en una empresa de productos y se diseñaron las respectivas tiendas (la de maquinaria para aumentar la producción), las bodegas para guardar dicha producción, los vehículos la posibilidad de transportar dichos productos, las oficinas para que la empresa tenga la capacidad de relacionarse con el entorno.

Se tuvo en cuenta algo fundamental para el éxito de una organización y es su talento humano, por eso se crearon en tres tipos de personal indispensable para cualquier compañía que son las personas estratégicas, las personas tácticas y las personas operativas. El estudiante debe saber qué tipo de personal contratar para fortalecer sus equipos, en algunos casos el mayor puntaje se lo dará el personal estratégico, en otros el personal táctico, y en otros el personal operativo. Incluso hay personajes, como pasa en muchas compañías, que le cuestan mucho a la organización y no tienen ningún papel trascendental para la misma.

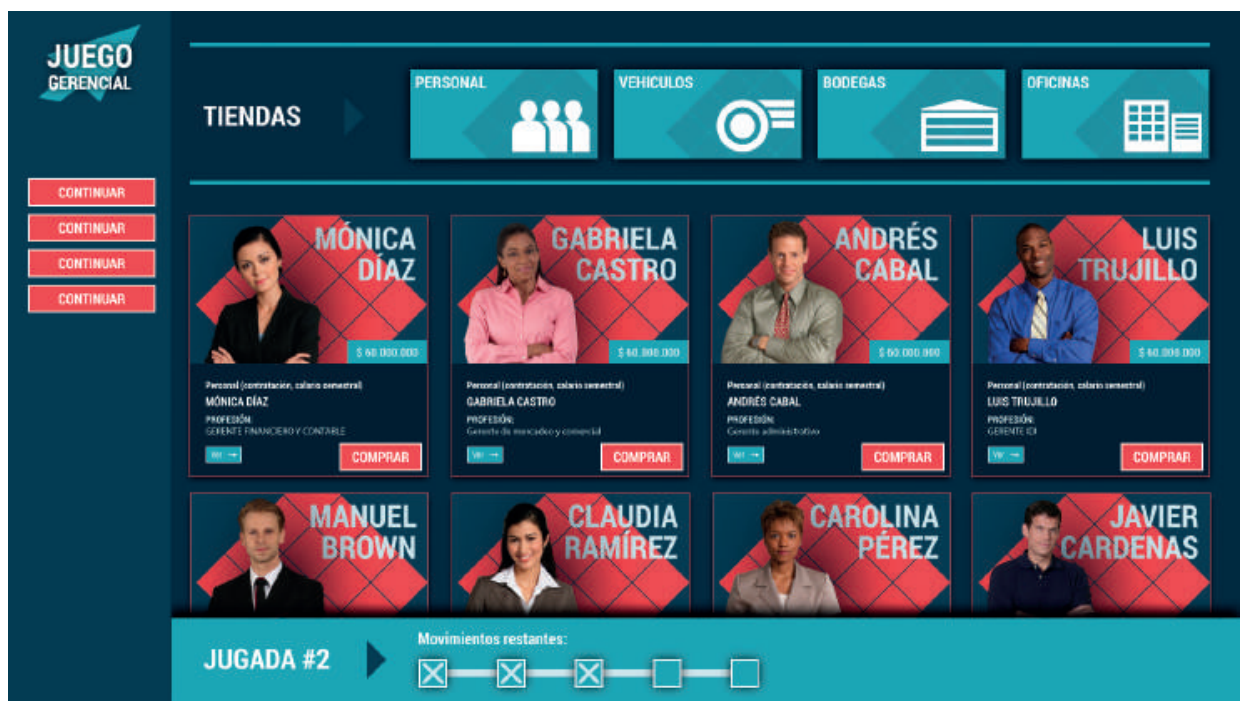

Figura 4. Tienda de personajes.

Fuente: Politécnico Grancolombiano (2017). 


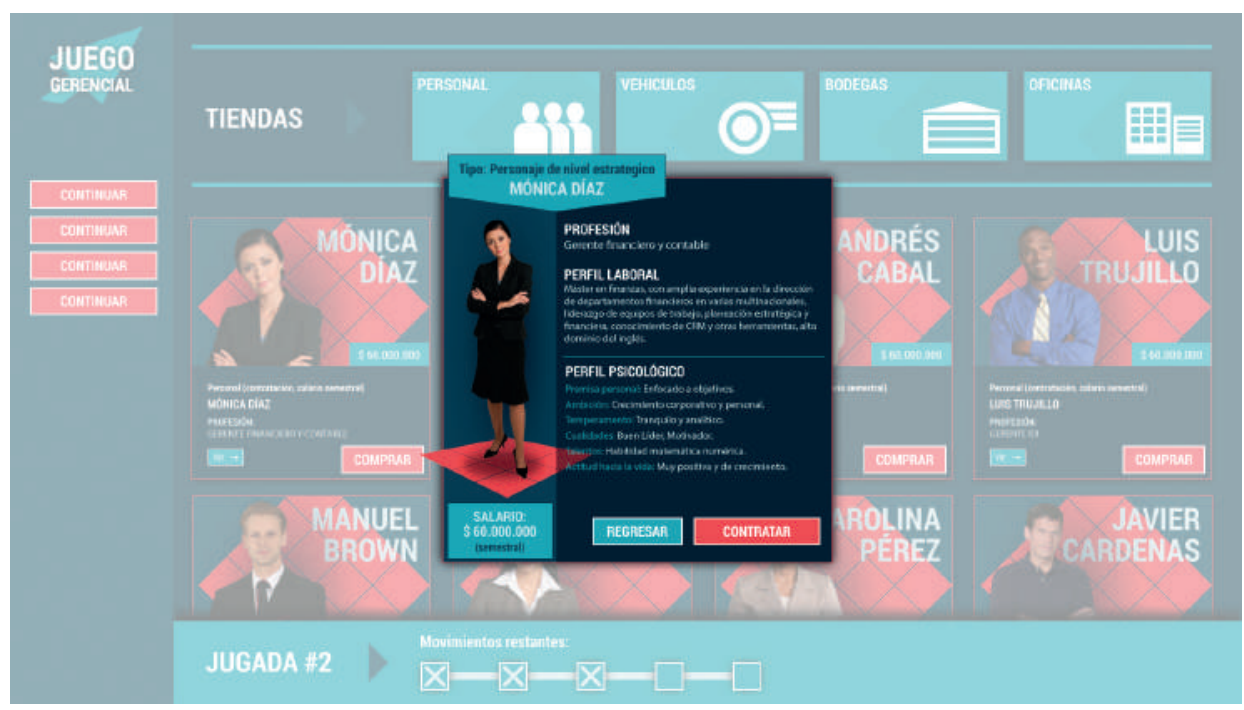

Figura 5. Movimiento contratación de un colaborador.

Fuente: Politécnico Grancolombiano (2017).

Los indicadores se verán afectados de acuerdo con las personas que contrate el estudiante, cada persona que elija es un movimiento dentro de una jugada, después de que seleccione una persona y la contrate no podrá elegirla nuevamente.

De la misma manera como se estructuró la tienda de personal se hizo cada una de ellas, la de vehículos, de bodegas, de oficina, de maquinaria. También se estructuraron las tiendas de innovación y comercial, la primera se estructuró a partir del arco iris de la innovación. Según Morales M y León A. (2013) El arcoíris de la innovación, considera doce colores o tipos de innovación que se clasifican en categorías. De igual manera, la tienda de ventas es la única que permite vender productos y recibir ingresos que se puedan reinvertir en la compañía y generen mejores indicadores, sin embargo, es recomendable antes de iniciar la venta fortalecer la compañía para tener más productos y más capacidad de producción. Vale la pena aclarar que la venta también es un movimiento, es decir, la cantidad de lo que se puede vender es limitado.

Por lo pronto, deben diseñarse los escenarios de planteamiento del problema y de las diferentes opciones de decisión que tome el estudiante, para ello es muy útil trabajar los árboles de decisión para el planteamiento del proyecto. 

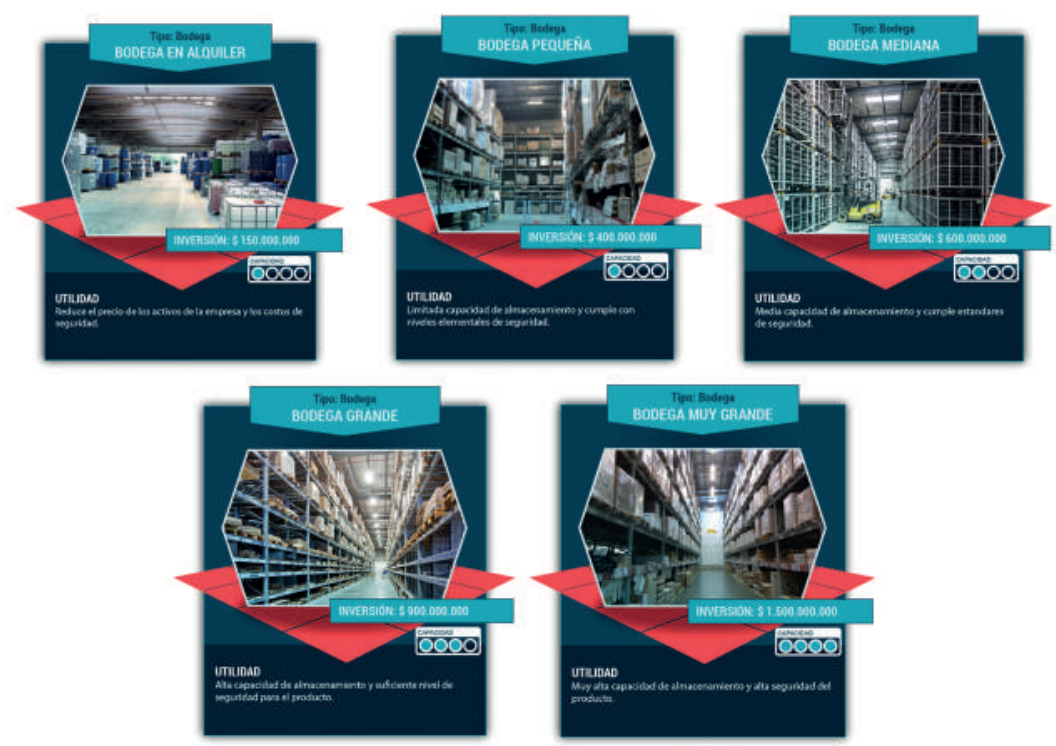

Figura 7. Fichas de la tienda de bodegas.

Fuente: Politécnico Grancolombiano (2017).

Con las perspectivas creadas y las tiendas se creó el sistema de calificación, es decir qué pasaba si el estudiante compraba o contrataba, de igual manera, si vendía el producto.

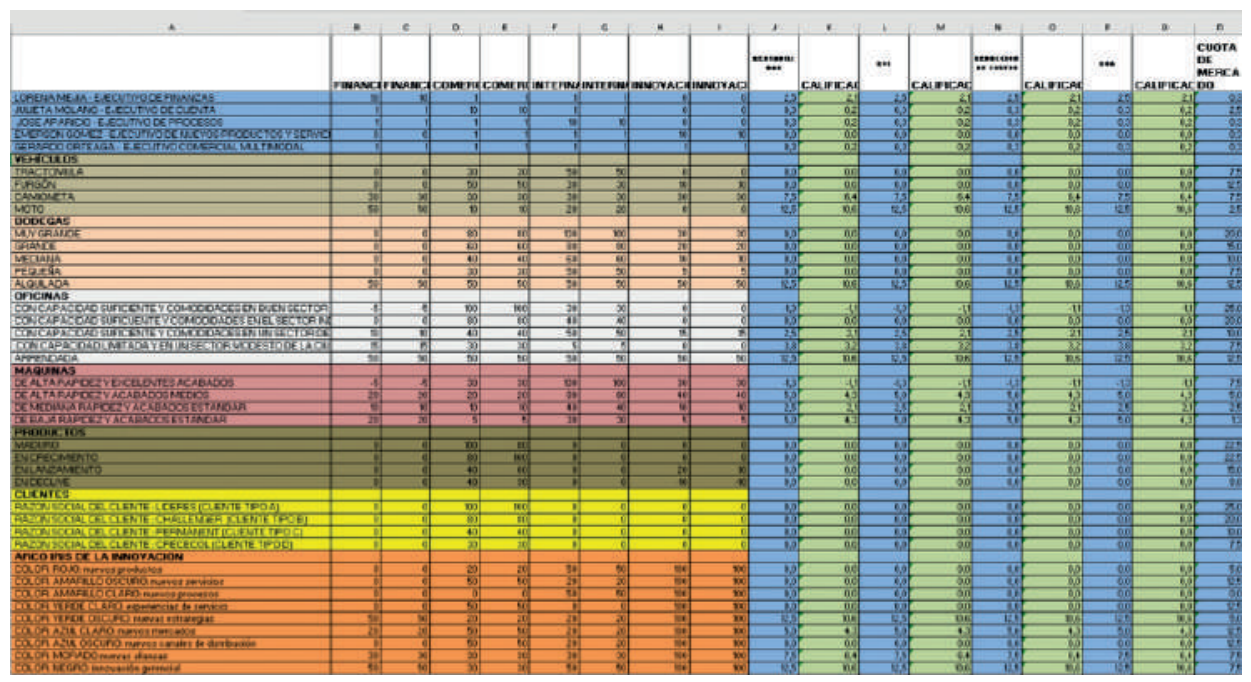

Figura 8. Sistema de calificación del juego.

Fuente: Creación Propia. 
Después se construyeron los guiones, con estos se procedió al diseño gráfico y el desarrollo de software. Dentro del guion se incluyó un personaje que se desempeñará como un avatar de guía del juego, su nombre se desprende de la metodología y se llama BSC. Ver figura 8.

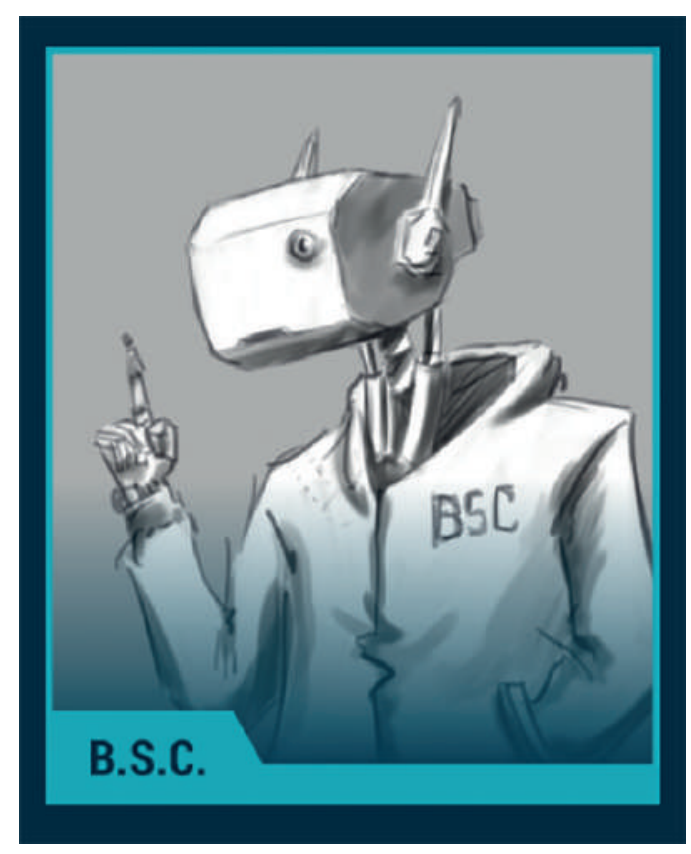

Figura 9. Bosquejo de BSC.

Fuente: Politécnico Grancolombiano (2017).

Para finalizar la experiencia se construyó la guía metodológica para los estudiantes cuando vayan a realizar la simulación o jugar. Esta guía no es un tutorial del juego, es una orientación con las instrucciones y el paso a paso de lo que los estudiantes deben hacer y entregar a su tutor, además de las orientaciones y recomendaciones metodológicas para que el proceso sea toda una experiencia gratificante de aprendizaje.

\section{Resultados obtenidos}

Se diseñó un simulador gerencial que enfrenta al estudiante con un mercado desde la gerencia general de una empresa de manufactura que cuenta con unos recursos iniciales y con la posibilidad de comprar bienes o de contratar personal o soluciones. De las decisiones tomadas por el jugador dependerá 
la mejora de los indicadores de desempeño de la empresa, una vez finalizado el juego se dará un ranking de jugadores los gerentes serán ordenados de acuerdo a su desempeño, de mejor a peor, y a las mejoras que causaron a la empresa derivadas de sus decisiones.

El proceso ha sido el resultado de un trabajo interdisciplinario conformado por un experto académico en la metodología Balanced Scorecard docente y tutor del módulo de Gerencia Comercial y Laboral, un experto pedagógico Coordinador del Laboratorio de innovación pedagógica, diseñadores gráficos, programadores. El trabajo ha sido colaborativo. Con el área de diseño se trabajó de manera mancomunada en la elaboración de los gráficos necesarios en las diferentes tiendas, diseñando la apariencia de los bienes y personas, llegando a común acuerdo entre los requerimientos académicos y el diseño. También con el área de programación se trabajó en la creación del juego, basados en los conceptos que desde la parte académica se entregaron, conservando las secuencias y lógicas que descritas en los guiones. Asimismo, el acompañamiento metodológico brindado por el Laboratorio de Innovación de Educación Virtual para el paso a paso de la creación del simulador, nutriendo cada etapa. Todo con el fin de volver realidad el juego gerencial que se va empezar a ofertar a los estudiantes. Todo el equipo para el proyecto pertenece a la institución Politécnico Grancolombiano, lo que permite pensar en futuros desarrollos para el juego o para otros proyectos.

\section{Conclusiones}

En conclusión, se detectó una oportunidad de confrontar a los estudiantes con una simulación que les exigiera medir la repercusión del uso de recursos y la toma de decisiones en un orden u otro para llevar a una organización al éxito dentro de un mercado. Se utilizó como base la metodología del Balanced Scorecard porque es un modelo que se ajusta a la perfección pues permite evaluar el progreso de una empresa en los cuatro frentes fundamentales que se deben medir para saber si están logrando crear tendencias positivas en el desempeño de esta.

Finalmente, para lograr adaptar esta idea a un programa de software por computador se ha contado con el soporte de áreas de apoyo que contribuyeron con su experticia a constituir la experiencia de simulación pensada para los estudiantes. 
Una de las ventajas más importantes que tiene el juego es que se puede trabajar en cualquier módulo o proceso de formación que trabaje el Balanced Scorecard porque se centra en la apropiación de la metodología por parte del estudiante a través del juego. Urquidi y Calabor (2014) en su investigaron sobre la percepción de los juegos serios con los siguientes resultados: "Los alumnos los aceptan y los consideran como una herramienta altamente motivadora ya que les permite un aprendizaje constructivo y creativo, basado en la resolución de problemas y en la toma de decisiones". Esperamos lograr ese impacto en los estudiantes con la apertura del juego y el inicio de la estrategia de aprendizaje en las aulas.

\section{Bibliografía o referencias}

Abell, D. F. (1980). Defining the business: The starting point of strategic planning (pp. 87115). Englewood Cliffs, NJ: Prentice-Hall.

Gamelab (S.F.). Balanced Scorecard Game (BSC). Disponible en: http://www. gamelabeducation.com/es/games/balance-scorecard-game/

García F., Molina J. F., Lajara B. y Quer D. (2012). Factores de éxito y fracaso en las nuevas empresas. Universidad de Alicante, Dialnet. Disponible en: https://dialnet.unirioja. es/descarga/articulo/565260.pdf

Kaplan, R. S., \& Norton, D. P. (1995). Putting the balanced scorecard to work. Performance measurement, management, and appraisal sourcebook, 66, 17511.

Kaplan, R. S., \& Norton, D. P. (1996). The balanced scorecard: translating strategy into action. Harvard Business Press.

Kaplan, R. S., Norton, D. P., Robert, S. K., \& David, P. N. (2004). Mapas estratégicos: cómo convertir los activos intangibles en resultados tangibles. Gestión 2000.

Morales M. y León A. (2013) Adiós a los mitos de la innovación, una guía práctica para innovar en América Latina. P.19. Ed Innovare: México D.F.

Posada R. (2014) La lúdica como estrategia didáctica. Universidad Nacional de Colombia. Tesis de maestría, p. 26. Bogotá. Disponible en: http://www.bdigital.unal.edu. co/41019/1/04868267.2014.pdf

TQM Latinoamericana SA (2004). Programa de simulación basado en el Balanced Scorecard. Miami. Disponible en: http://www.cacitgroup.com/pdf/programabsc.pdf 
Micro Simuladores Empresariales Basado en un modelo de simulación con Vensim (S.F.). Disponible en: http://dinamica-de-sistemas.com/revista/1203d.htm

Ross, J, Victor, B. \& Statler, M. (2004). Playing Seriously with Strategy. Long-Range Planning, 37(6), 549- 568. Elsevier

Stratec, (2005). Software Gestión Estratégica. Disponible en: http://www.stratecsoluciones. com/productos/gestion-estrategica

Urquidi, A. \& Calabor, M. (2014). Aprendizaje a través de juegos de simulación: un estudio de los factores que determinan su eficacia pedagógica. EDUTEC. Revista Electrónica de Tecnología Educativa. 47, 1-15.

\section{Referencias de figuras}

Stratec (2016). Pantallazo del Simulador de Gerencia Estratégica Stratec. Disponible en: https://www.marketplace-simulation.com/es/strategic-management-simulations

Gamelab (2016). Pantallazo del simulador Balanced Scorecard Game de Gamelab. Disponible en: http://www.gamelabeducation.com/en/games/balanced-scorecard-game/

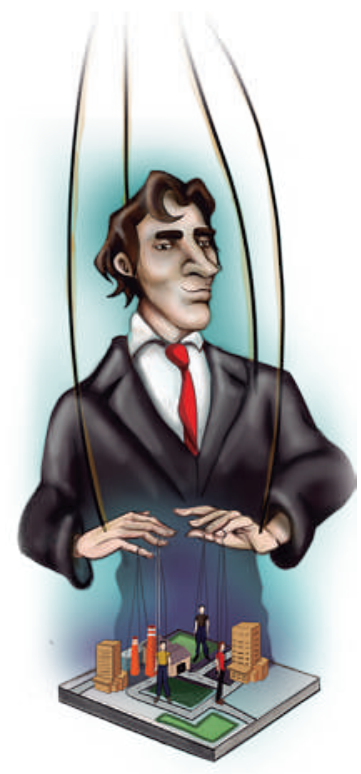




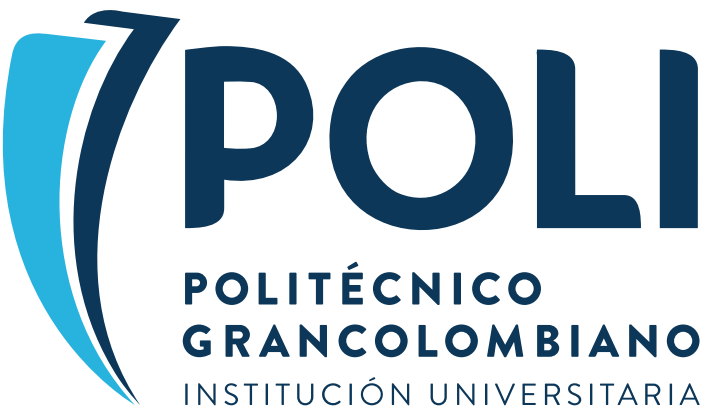

